\title{
Porous Organic Polymers Containing Active Metal Centers as Catalysts for Synthetic Organic Chemistry
}

\author{
Kramer, Søren; Bennedsen, Niklas Rosendal; Kegnæs, Søren
}

Published in:

A C S Catalysis

Link to article, DOI:

10.1021/acscatal.8b01167

Publication date:

2018

Document Version

Peer reviewed version

Link back to DTU Orbit

Citation (APA):

Kramer, S., Bennedsen, N. R., \& Kegnæs, S. (2018). Porous Organic Polymers Containing Active Metal Centers as Catalysts for Synthetic Organic Chemistry. A C S Catalysis, 8, 6961-6982.

https://doi.org/10.1021/acscatal.8b01167

\section{General rights}

Copyright and moral rights for the publications made accessible in the public portal are retained by the authors and/or other copyright owners and it is a condition of accessing publications that users recognise and abide by the legal requirements associated with these rights.

- Users may download and print one copy of any publication from the public portal for the purpose of private study or research.

- You may not further distribute the material or use it for any profit-making activity or commercial gain

- You may freely distribute the URL identifying the publication in the public portal 


\section{Review}

Subscriber access provided by DTU Library

\section{Porous Organic Polymers Containing Active Metal Centers as Catalysts for Synthetic Organic Chemistry}

Søren Kramer, Niklas R Bennedsen, and Søren Kegnæs

ACS Catal., Just Accepted Manuscript • DOI: 10.1021/acscatal.8b01167 • Publication Date (Web): 14 Jun 2018

Downloaded from http://pubs.acs.org on June 15, 2018

\section{Just Accepted}

"Just Accepted" manuscripts have been peer-reviewed and accepted for publication. They are posted online prior to technical editing, formatting for publication and author proofing. The American Chemical Society provides "Just Accepted" as a service to the research community to expedite the dissemination of scientific material as soon as possible after acceptance. "Just Accepted" manuscripts appear in full in PDF format accompanied by an HTML abstract. "Just Accepted" manuscripts have been fully peer reviewed, but should not be considered the official version of record. They are citable by the Digital Object Identifier (DOI®). "Just Accepted" is an optional service offered to authors. Therefore, the "Just Accepted" Web site may not include all articles that will be published in the journal. After a manuscript is technically edited and formatted, it will be removed from the "Just Accepted" Web site and published as an ASAP article. Note that technical editing may introduce minor changes to the manuscript text and/or graphics which could affect content, and all legal disclaimers and ethical guidelines that apply to the journal pertain. ACS cannot be held responsible for errors or consequences arising from the use of information contained in these "Just Accepted" manuscripts. 


\title{
Porous Organic Polymers Containing Active Metal
}

\section{Centers as Catalysts for Synthetic Organic}

\section{Chemistry}

\author{
Søren Kramer*, Niklas R. Bennedsen, Søren Kegnces* \\ Department of Chemistry, Technical University of Denmark, 2800 Kgs. Lyngby, Denmark
}

\begin{abstract}
Porous organic polymers (POPs) containing catalytically active mononuclear metal centers can bridge the gap between homogeneous and heterogeneous catalysis. These materials offer catalysts with straightforward control over the active site analogously to homogeneous organometallic catalysts; however, just like classical heterogeneous catalysts, they are easy to separate from reaction mixtures and recycle. The main objective of this review is to provide an overview of the different types of reactions for synthetic organic chemistry where metal-POP catalysts have been utilized. In addition, a brief description of different synthesis strategies for accessing metal-POPs is included. We also propose a uniform naming system for metal-POP catalysts. Finally, current challenges, which could advance the field and facilitate industrial application, are discussed.
\end{abstract}

KEYWORDS: Heterogeneous catalysis, single-site catalysts, porous organic polymers, organic synthesis, metal catalysis, organometallic chemistry. 


\section{INTRODUCTION}

In the view of the continuous environmental and economic challenges in the world there is a pressing need to develop a more sustainable and efficient chemical industry by creating and implementing more efficient chemical transformations. This can be done by developing new highly selective catalysts with increased product yield and therefore lowered process costs. Ideally, catalysts are developed by catalyst-design where the active sites are introduced so that the catalyst selectively drive the reaction to form only the desired products. The uniform active sites accessible in homogeneous catalysis often streamlines this task and allows for rationalization based on computational simulations. ${ }^{1}$ In contrast, heterogeneous catalysts may contain multiple active sites which, historically, have led to a greater requirement for trial-and-error experiments in the production of numerous catalysts. Nonetheless, heterogeneous catalysts often displays significant advantages over homogeneous catalysts in terms of sustainability, recyclability, robustness, and ease of catalyst separation..$^{2,3,4}$ One of the reasons for the trial-and-error approach in synthesis of heterogeneous catalysts, may be due to the difficulty in design and synthesis of well-defined uniform active sites in many types of heterogeneous catalysts. This is for instance illustrated in "classic" heterogeneous catalysts consisting of metal nanoparticles on a high surface area support, where several different types of active sites often exist on the metal particles. ${ }^{5}$ Catalyst-design of heterogeneous catalysts has therefore often focused on reducing the size of the active metal particles in order to enhance catalytic performance and efficiency of the heterogeneous nanoparticle catalysts. A reduction of the size of the metal particles in general leads to a more efficient use of metal as the relative surface area of the particles is increased. The ultimate sizereduction of nanoparticles is when each metal "particle" only consist of a single metal atom and 
each single metal atom acts as active site. Ideally, this will give a highly efficient use of the metal but would also lead to more well-defined and uniform active sites as known from homogeneous catalysis. However, the reduction of particle size enhances the tendency for particle sintering leading to a decrease in the catalytic activity. Thus, the development of sintering-stable heterogeneous nanoparticle catalysts has therefore attracted attention over the years and many strategies have been developed to address the problem of sintering of nanoparticle catalysts. ${ }^{6,7,8,9,10}$ Many synthesis strategies have also been developed in order to combine the advantages of molecular homogeneous catalysts and heterogeneous processes, in the aim to obtain the high reactivity and selectivity of the molecular catalysts, while facilitating product recovery and catalyst recycling. $3,4,11,12,13$

Herein, we will focus on the use of porous organic polymers (POPs) containing active mononuclear metal centers and how they are applied as single-site catalysts for synthetic organic chemistry (Figure 1). The solid nature of POPs and their high porosity makes them attractive in heterogeneous catalysis. ${ }^{14,15}$ In addition, the possibility to incorporate ligands in the structures of POPs makes it possible to design single-atom metal active sites. The active metal sites in POPs are well-defined and tunable similar to homogeneous catalysts. In this way, POPs containing active mononuclear metal centers are bridging the gap between homogeneous and heterogeneous catalysis. 


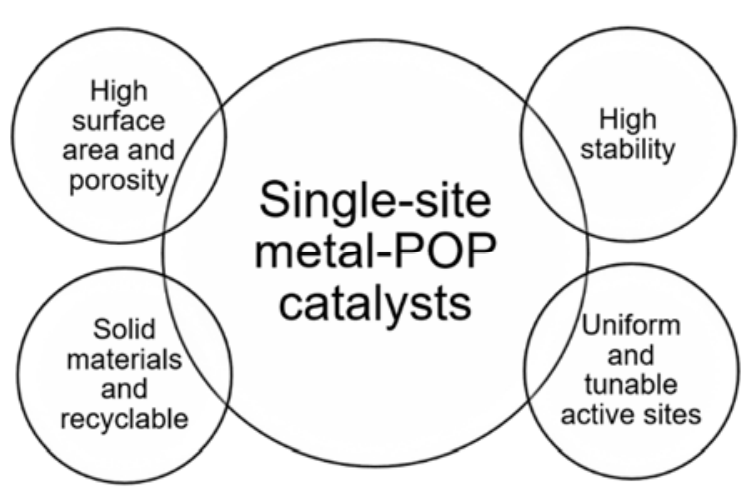

Figure 1. Important properties of porous organic polymers (POPs) containing active mononuclear metal centers for catalysis.

A number of excellent reviews, which focus predominantly on the synthesis and properties of metal-POPs for use in gas storage and catalysis, have been published. ${ }^{14,15,16,17,18,19,20,21,22,23}$ In this review, we will only provide a short overview of the different ways to synthesize POP-catalysts; instead, the main focus will be on the different reaction types - from the perspective of synthetic organic chemistry - where POPs containing an active mononuclear metal center have found use as catalysts. We have included as many representative examples as possible in order to demonstrate the variation in reactivity accessible at the current state of research in porous organic polymers containing an active mononuclear metal center. This overview focuses on the development during the last five years with the inclusion of a few illustrative earlier examples. Most of the selected examples utilize amorphous POPs containing robust, non-hydrolyzable carbon backbones. Although characterization of the metal-POP catalysts are an integral part of the research field, this 
review focuses on applications of metal-POPs in synthetic organic chemistry, and we refer to specialized reviews for in-depth discussion of different characterization techniques. ${ }^{24}$

\begin{abstract}
Synthesis of POPs are done by polymerization of selected building blocks. In section 2 of this review, six different polymerization categories are briefly described: Radical polymerization, alkyne trimerization, nitrile trimerization, Sonogashira coupling, Friedel-Crafts reactions, and miscellaneous reactions (Figure 2). The end of section 2 will also shorty cover examples of metalation, where metal atoms are incorporated into the synthesized polymers, and the effect of polymer swelling. The following section 3 describes the different reaction types where POPs containing an active metal center have found use as catalysts. The reaction types have been categorized into seven main classes: Lewis acid catalysis, oxidations, reductions, coupling reactions, oxidative coupling reactions, photocatalysis, and miscellaneous (Figure 2). The final section discusses current challenges and future possibilities in the field. We hope the broad overview provided here can help identify current trends in the types of organic reactions that have been catalyzed by single-site metal-POPs and thus facilitate future advances in the field.
\end{abstract}




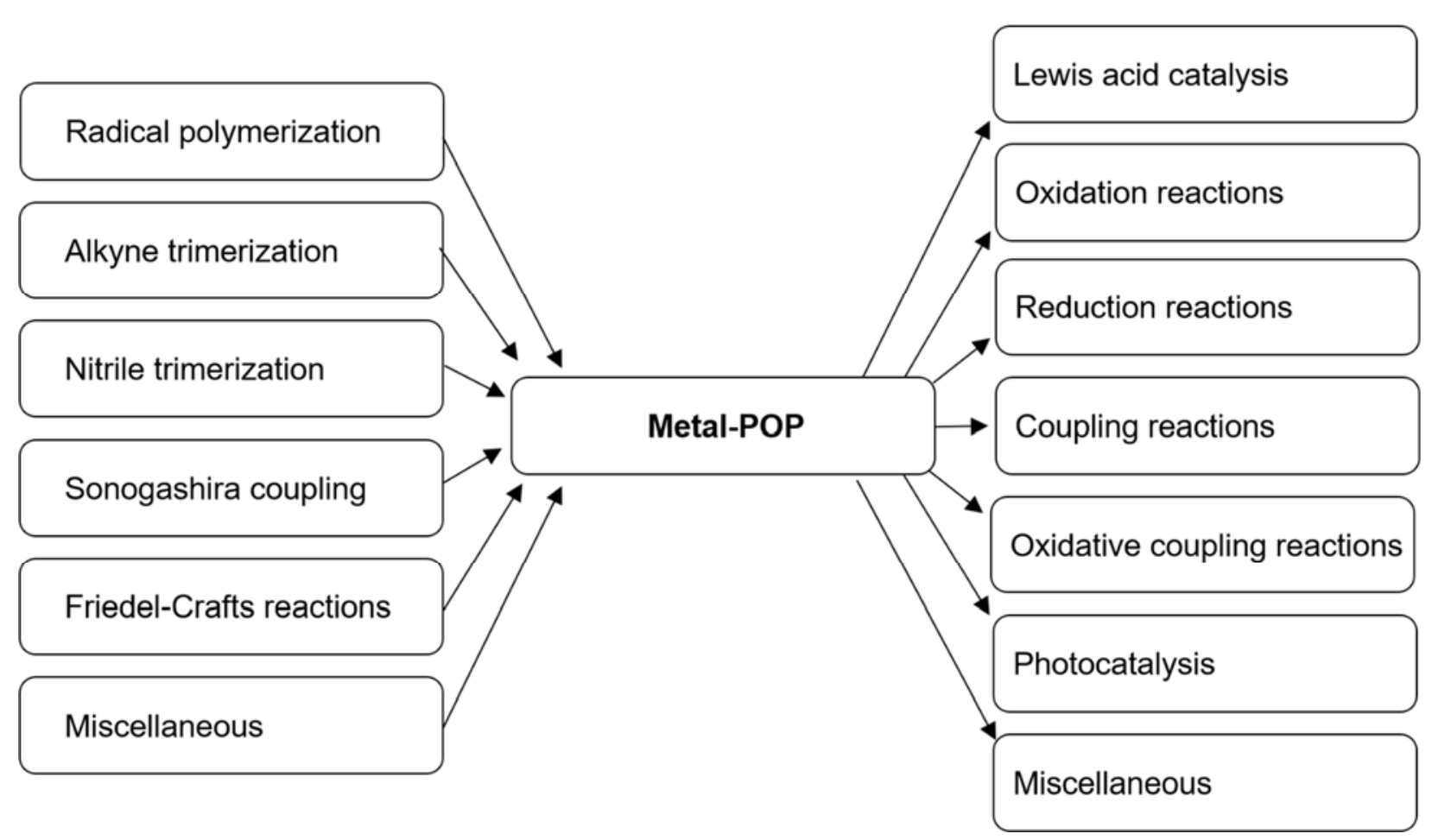

Figure 2. Overview of synthesis of metal-containing porous organic polymers (POPs) and their application in catalysis.

In order to label the different catalysts, we have used the systematic naming: metal-ligand-POP. The mentioned ligand is defined as the ligand which coordinates the metal to the polymer. Other ligands around the metal center are not mentioned in this nomenclature. Although the naming system does not take into account linkers and polymerization methods, we believe it is a good indicator for a first prediction of reactivity trends in a similar manner to homogeneous catalytic systems. For inclusion of more information, it is possible to add this in a parenthesis after the systematic name. In contrast to the diversity of catalyst labelling used in the field covered by this review, the application of such a nomenclature provides a concise and accessible overview when browsing through the research literature. 


\section{SYNTHESIS OF POP-CATALYSTS}

For the past decades, surface area and porosity have been crucial properties for heterogeneous catalysis and controlling these parameters have been the target for many researchers. ${ }^{25,26,27,28}$ It is the same case for single-site catalysts incorporated into polymers, where the porosity makes the active sites more accessible and may lead to catalytic selectivity based on which substrates can reach and react with the catalytic sites. The porosity for POPs is most often achieved by having rigid monomers with specific binding sites for polymerization, which form a systematic and rigid porous polymer network. Therefore, the choice of building block(s) when synthesizing POPs has crucial impact on the porosity of the final polymer. This was for instance illustrated in the research by Li et al. where a BINAP (2,2'-bis(diphenylphosphino)-1,1'-binaphthalene) monomer together with different rigid co-building blocks was used. ${ }^{29}$ These co-building blocks influenced the porosity of the material which in turn affected the catalytic performance of the final catalysts. The porosity of the catalyst is also affected by the ligand-containing building block. ${ }^{14,30,31}$

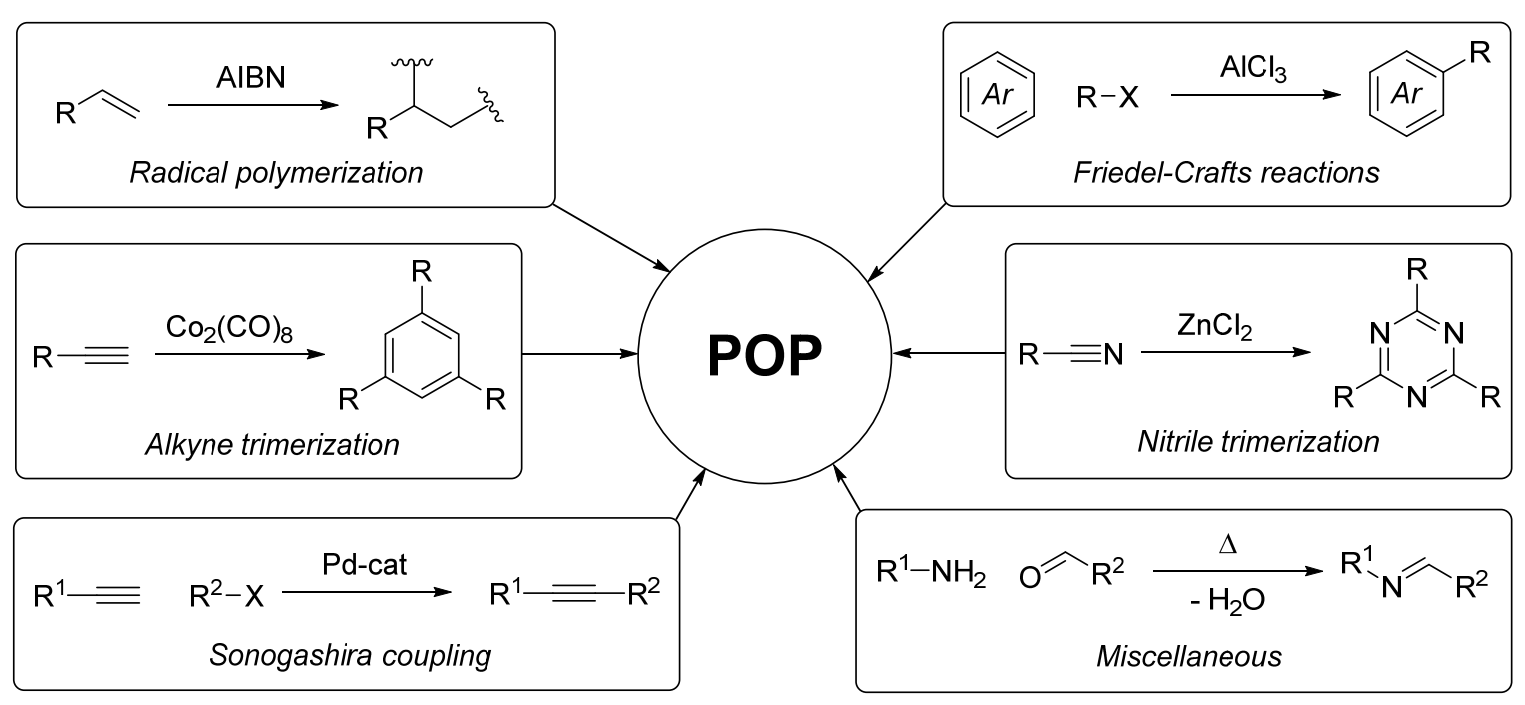


Figure 3. The different types of polymerization techniques presented in this review. Each technique is represented by a general example.

The chosen building block(s) has to be polymerized in order to obtain the POP, which may be used for single-site catalysis. Polymerization of the building blocks can be achieved in different ways (Figure 3). The polymerization methods have been categorized into six groups: Radical polymerization, alkyne trimerization, nitrile trimerization, Sonogashira coupling, Friedel-Crafts reactions, and miscellaneous reactions. Common for all categories is the possibility to vary the composition of the polymer backbone by modifying the individual ligands/building blocks and/or the ratio in between the used building blocks. Furthermore, it is also possible to change the solvent and the size, type, and denticity of the linkers. All these different possibilities for modifications make it possible to fine-tune the properties of the final catalyst including active site, metal loading, and porosity.

\subsection{RADICAL POLYMERIZATION}

A common strategy in the synthesis of single-site catalysts is the polymerization of alkene groups through a radical mechanism. Therefore, ligands, which display the desired selectivity and activity in homogeneous catalysis, are often the first choice for alkene functionalization followed by polymerization to make new heterogeneous catalysts. The mechanism for the polymerization is a free radical chain growth polymerization, which is initiated by a radical initiator. A commonly used radical initiator is azobisisobutyronitrile (AIBN). The polymerization step is often conducted by stirring the monomers and radical initiator together at room temperature before the mixture is 
transferred to an autoclave for solvothermal synthesis. ${ }^{30,32,33,34,35,36}$ The solvent is often $N, N$ dimethylformamide (DMF), tetrahydrofuran (THF), or chlorobenzene, but solvents like ethyl acetate $^{33}, 1-$ methyl-2-pyrrolidinone ${ }^{37,38}$, and mixtures such as benzotrifluoride/water ${ }^{39}$ have also been used. The monomers used for this kind of polymerization are usually inspired by phosphineor nitrogen-based ligands such as $\mathrm{PPh}_{3}^{30,40}, \mathrm{BINAP}^{34}$ or bipyridine ${ }^{41}$ (Figure 4).
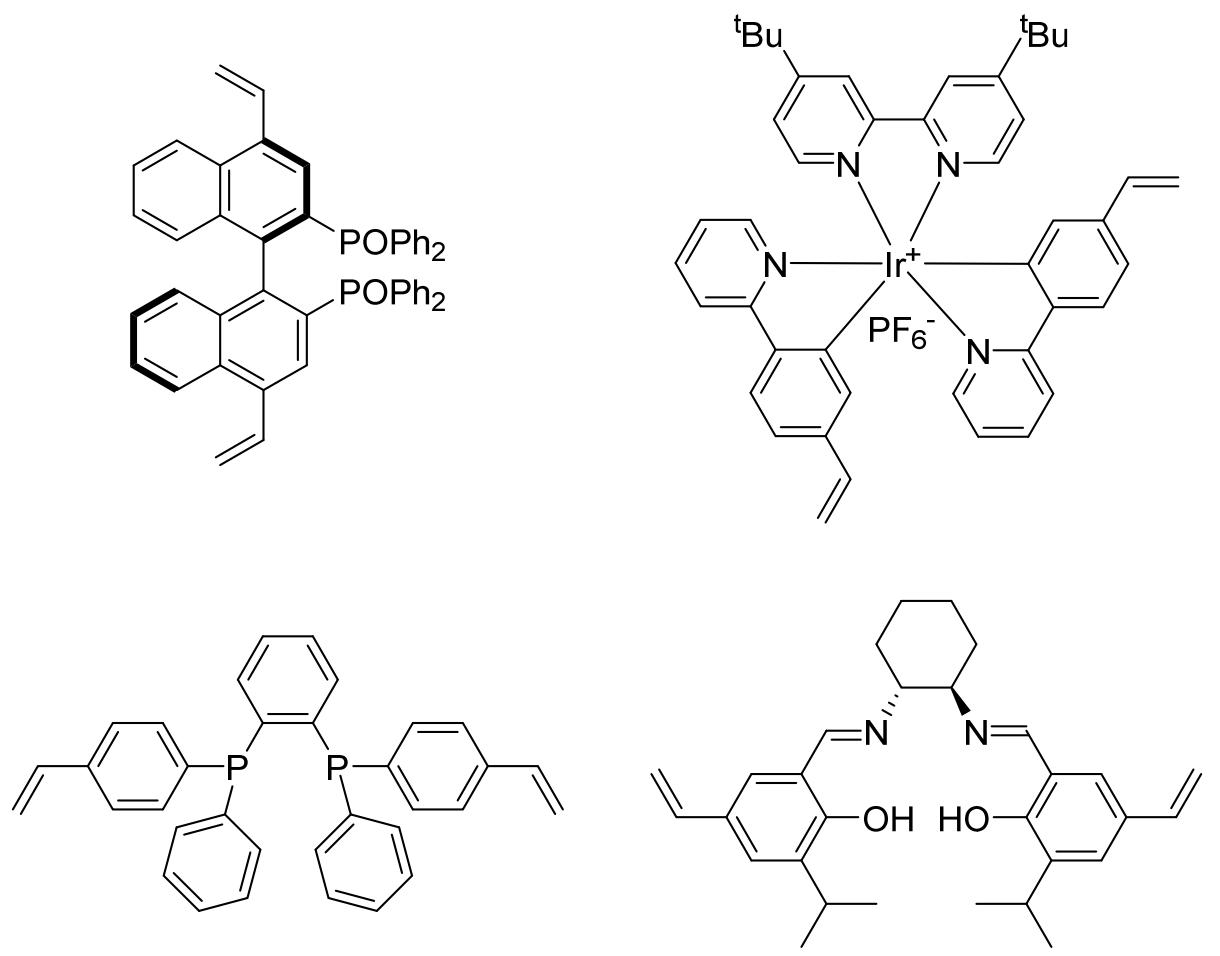

Figure 4. Examples of building blocks used for radical polymerization.

Divinylbenzene, styrene, and derivatives of styrene are common co-building blocks for radical polymerizations. An example of radical polymerization using a mixture of vinyl-functionalized ligand building blocks and co-building blocks was reported by Sawamura and coworkers. ${ }^{42}$ By 
mixing divinylbenzene and vinyl-functionalized bis(diphenylphosphino)benzene, a polymer was obtained where the bisphosphine was incorporated as every $60^{\text {th }}$ unit, on average.

One of the advantages of radical polymerization in comparison to most other commonly used polymerization methods is that the polymerization takes place in the absence of metal catalysts. Accordingly, this approach removes the risk of metal-contamination in the final metal-POP catalyst and no precautions in this regard are required. Polymers made by radical polymerization are often highly flexible, leading to almost quasi-homogeneous environments. Although these polymers are robust, the high frequency of benzylic $\mathrm{C}-\mathrm{H}$ groups in the polymer backbone might make it prone to oxidation or functionalization under reaction conditions which generate radicals, e.g. certain oxidations and cross-coupling reactions.

\subsection{ALKYNE TRIMERIZATION}

Similar to radical polymerization, polymerization through alkyne trimerization, which forms connecting benzene moieties, is another widespread technique for synthesizing POPs. The catechol-POP synthesized by Nguyen and coworkers is a representative example of the utilization of alkyne trimerization (Scheme 1) ${ }^{43}$ The $\mathrm{Co}_{2}(\mathrm{CO})_{8}$-mediated polymerization reaction of 2,3(ethoxymethylenedioxy)-1,4-diethynylbenzene (A) and tetrakis(4-ethynylphenyl)methane (B) is the foundation of various catalysts reported in literature. ${ }^{44,45,46,47,48,49,50,51}$ The catechol-POP is capable of coordinating to a large variety of different metals, including $\mathrm{Ta}^{44}, \mathrm{La}^{45}$, and $\mathrm{Al}^{49}$. Furthermore, the composition of the polymer backbone can be modified as the ratio between the two building blocks, $\mathbf{A}$ and $\mathbf{B}$, can be changed as seen with the $\mathbf{A}_{\mathbf{2}} \mathbf{B}_{\mathbf{1}}$ and $\mathbf{A}_{\mathbf{1 0}} \mathbf{B}_{\mathbf{1}}$ polymers. ${ }^{43}$ 
Altering the ratio between building block $\mathbf{A}$ and $\mathbf{B}$ gave control over the metal loading. For manganese, a weight percentage of $10.9 \%$ was observed for the $\mathbf{A}_{2} \mathbf{B}_{1}$ polymer and $21.8 \%$ for the $\mathbf{A}_{10} \mathbf{B}_{1}$ polymer. Similar to the metal loading, the surface area and pore volume changed as well with changing the composition of the polymer. The $\mathbf{A}_{\mathbf{2}} \mathbf{B}_{\mathbf{1}}$ polymer had a Brunauer-Emmett-Teller (BET) surface area of $1050 \mathrm{~m}^{2} / \mathrm{g}$ and a pore volume of $0.41 \mathrm{~cm}^{3} / \mathrm{g}$ whereas the $\mathbf{A}_{\mathbf{1 0}} \mathbf{B}_{\mathbf{1}}$ polymer had $617 \mathrm{~m}^{2} / \mathrm{g}$ and $0.25 \mathrm{~cm}^{3} / \mathrm{g}$ in comparison.
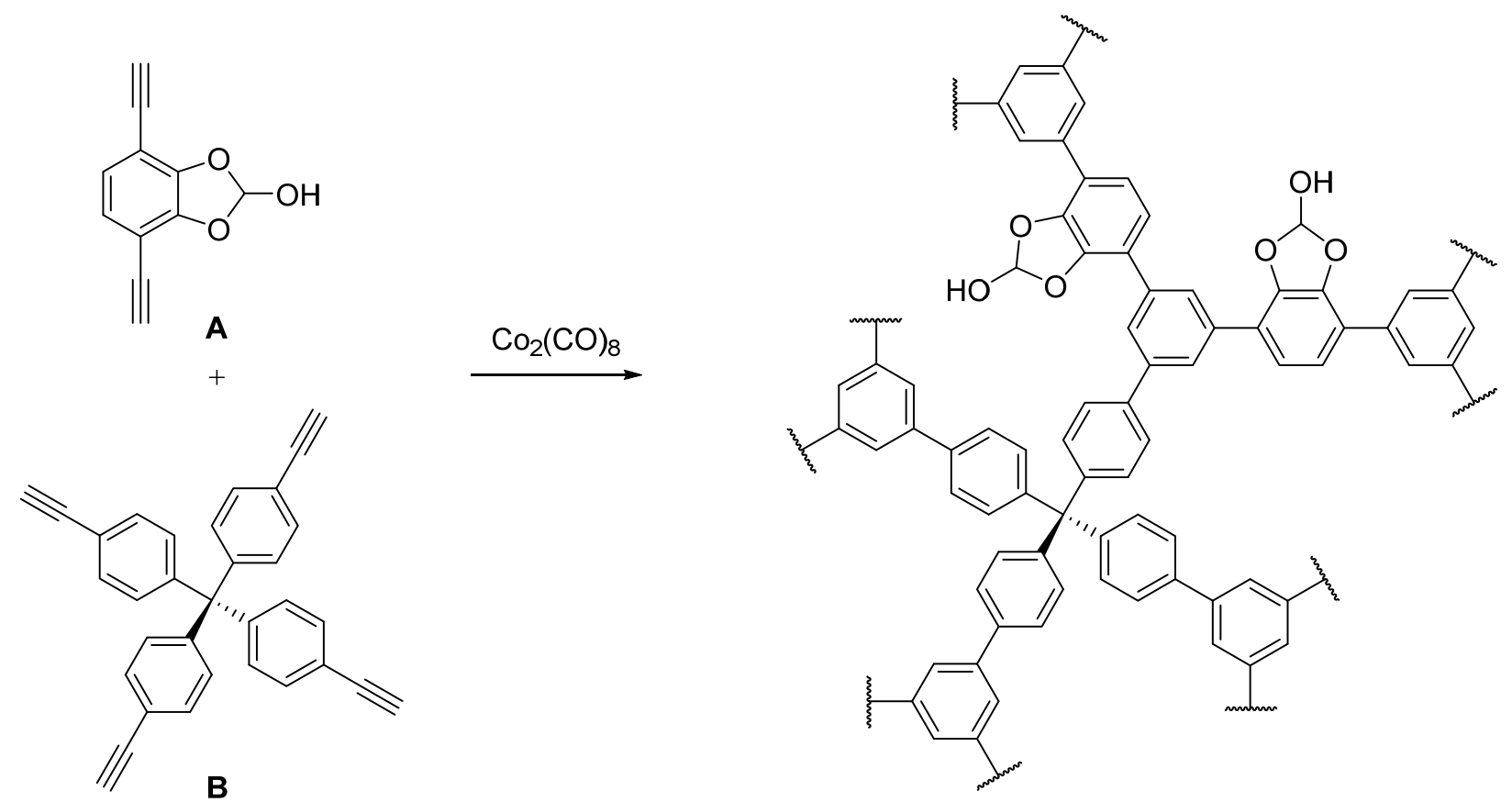

\section{Scheme 1. Synthesis of a Catechol-POP through Alkyne Trimerization by Nguyen and Coworkers. ${ }^{43}$}

In contrast to radical polymerization, the alkyne trimerization is metal-catalyzed. Accordingly, an additional step, often acid wash, is necessary to ensure complete removal of this metal catalyst 
from the polymer. The absence of functional groups and weak $\mathrm{C}-\mathrm{H}$ bonds in the final polymer makes it robust to oxidation and radical intermediates.

While the nature and flexibility of the linker in the final polymer is markedly different for radical polymerization and alkyne trimerization (alkyl vs. phenyl), there are similarities in the building block syntheses. This can be illustrated by comparing the syntheses of the BINAP-containing building block for either radical ${ }^{34}$ or alkyne ${ }^{50}$ polymerization (Scheme 2). The introduction of the handle for polymerization, vinyl or alkyne group, goes through the bromide-derivative in both cases. Since the steps from the bromide-derivative are equally simple, both polymers are easy to access with the common intermediate in hand.
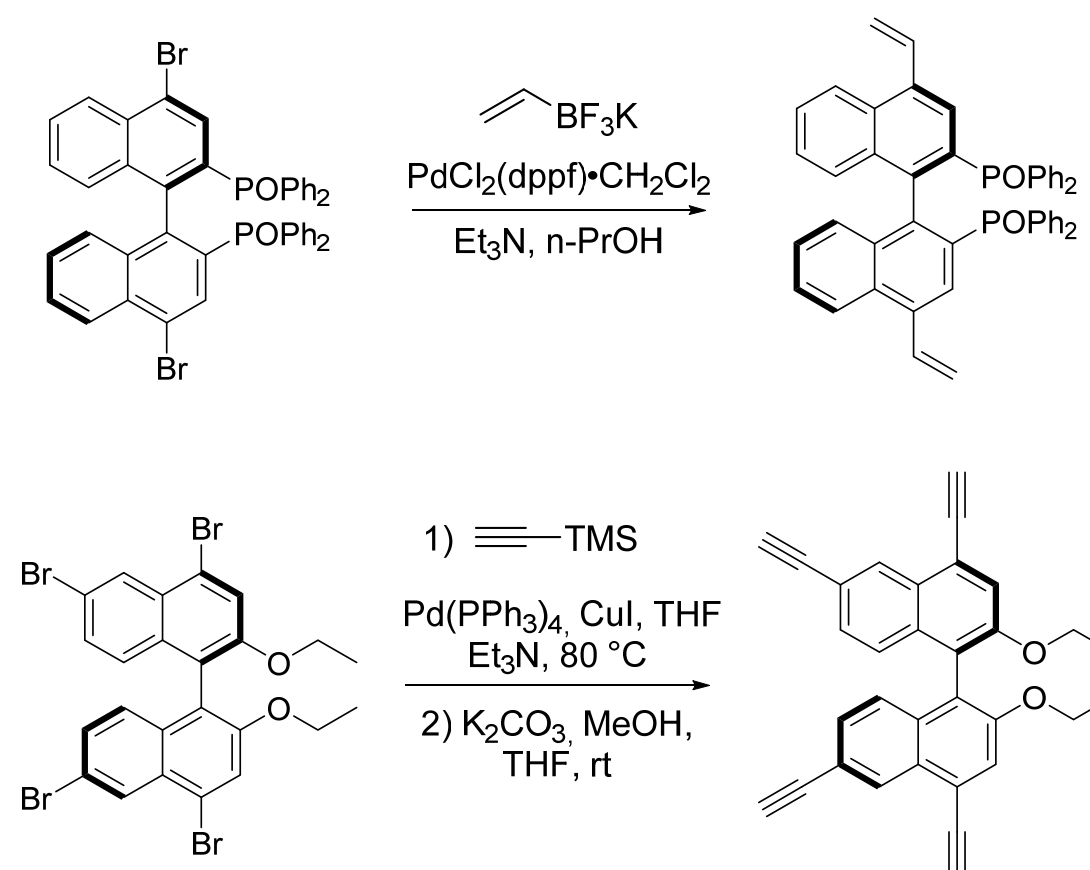

1) $\equiv$ TMS

$\mathrm{Pd}\left(\mathrm{PPh}_{3}\right)_{4} \mathrm{Cul}, \mathrm{THF}$ $\mathrm{Et}_{3} \mathrm{~N}, 80^{\circ} \mathrm{C}$<smiles>C#Cc1ccc2c(-c3c(OCC)cc(C#C)c4cc(C#C)ccc34)c(OCC)cc(C#C)c2c1</smiles>

\section{Scheme 2. Comparison of Monomer Synthesis for Radical Polymerization and Alkyne Trimerization for two BINAP-derivatives (dppf=1,1'-bisphenylphosphino)ferrocene).}




\subsection{NITRILE TRIMERIZATION}

Trimerization of nitrile groups, forming triazine linkers, is another option for constructing porous polymers. The trimerization is similar to the alkyne trimerization described earlier but the reaction involves nitrile functionalities instead of alkynes (Scheme 3) ${ }^{52}$ The nitrile trimerization can be facilitated by different reagents and catalysts including $\mathrm{ZnCl}_{2}{ }^{53}$, trifluoromethanesulfonic acid ${ }^{54,55}$, and nonylphenol. ${ }^{56}$ Triazine-based polymers can also be synthesized directly from moieties of 1,3,5-triazine building blocks through various polymerization techniques such as aromatic electrophilic substitution, ${ }^{57}$ radical polymerization, ${ }^{58}$ condensation,${ }^{59}$ Sonogashira coupling,${ }^{60}$ and Friedel-Crafts reactions. ${ }^{61,62}$
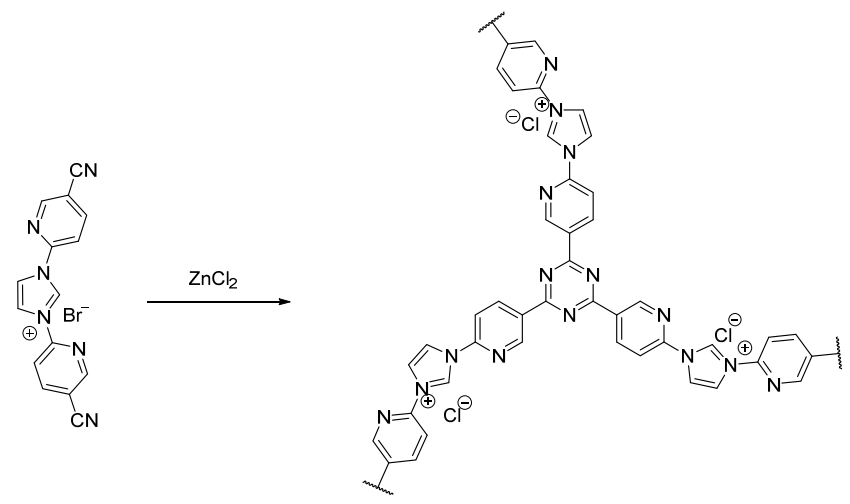

\section{Scheme 3. Polymerization by Trimerization of Nitrile Groups Promoted by $\mathrm{ZnCl}_{2} .{ }^{52}$}

Triazine-based polymers often have a very high nitrogen content giving them properties that can differ quite significantly from less nitrogen-dense polymers. ${ }^{63,64}$ In terms of metal-POP catalysts containing defined metal-ligand centers, the high nitrogen content provides many alternative binding sites for the metal. In fact, polymers with high triazine content, without any other ligands, may serve as support for metal ions. ${ }^{65}$ Accordingly, caution must be exercised to determine the 
actual metalation site in these polymers. In addition, polymers based on triazine often form crystalline, highly-ordered materials and, hence, they are outside the scope of this review. A review on triazine polymers and their application have recently been published by Ahn et al. ${ }^{63}$

\subsection{SONOGASHIRA COUPLING}

The Sonogashira coupling between a terminal alkyne and an arylhalide is another polymerization reaction used to synthesize POPs for single-site catalysis. ${ }^{29,66,67,68,69,70,71,72,73,74}$ The reaction is catalyzed by a palladium/copper catalyst system, typically in THF or DMF and in the presence of $\mathrm{PPh}_{3}$ and $\mathrm{NEt}_{3}$. The coupling between two different functionalities is a useful feature in the synthesis of POPs as it provides full control over the polymerization process where only polymers with the $\mathrm{ABAB}$ composition can be formed. This is in contrast to the polymerization techniques described above where the building blocks are randomly incorporated into the polymer backbone. On the downside, the polymerization requires a precious metal catalyst. The presence of two transition-metals in the polymerization step using the Sonogashira coupling also necessitates a reliable method for their removal, in order to circumvent trace metal impurities, which could be catalytically active, in the final metal-POP.

In the work of Li et al., a single-site catalyst was synthesized by the Sonogashira coupling of 1,3bis-(3-iodo-2,6-diisopropylphenyl)-imidazol-2-ylidene (I-IPr) with different rigid alkyne linkers (Scheme 4). ${ }^{67}$ They studied the effect of altering the amount of solvent used to synthesize their polymers. The study shows that the pore size, surface area, and catalytic activity can be changed by using different amounts of solvent in the formation of the POP. Additionally, the effect of 
changing size and denticity ( 3 or 4 ) of the linker on the resulting catalytic activity and porosity was also investigated. It was concluded that the largest linker with a denticity of 4 yielded the best catalyst. In another study, BINAP was used instead of IPr and either ruthenium or iridium coordinated to the polymer. ${ }^{29}$ For the polymer with iridium, the authors concluded that iridium did not form any inactive dimers or trimers which are often observed for homogeneous iridium catalysts. ${ }^{29}$ This made the Ir-BINAP-POP more active than the homogenous Ir-BINAP catalyst when assessed on the asymmetric hydrogenation of quinaldine. ${ }^{75}$
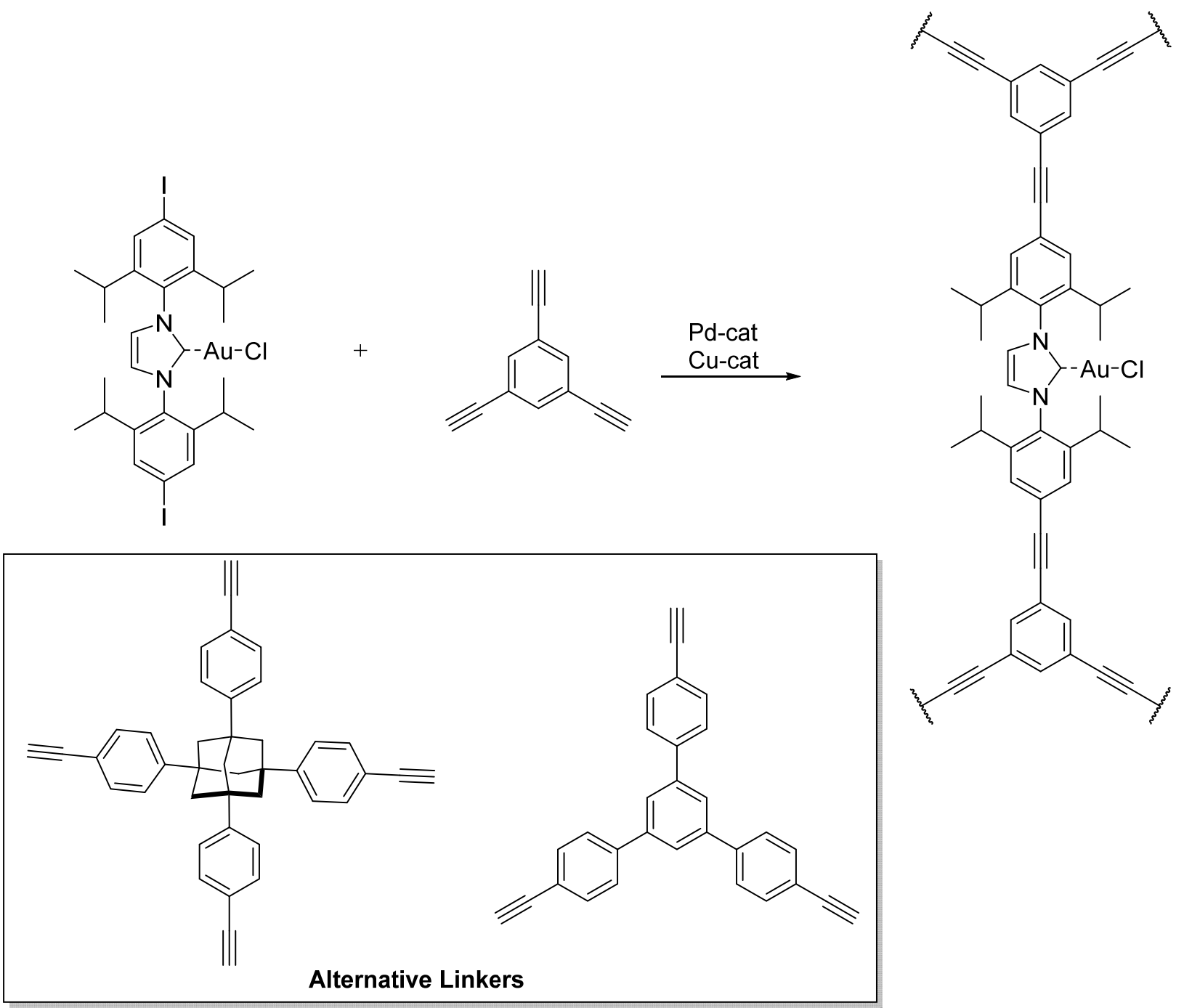


\section{Scheme 4. Synthesis of Au-IPr-POPs through Sonogashira Coupling by Li et al. ${ }^{67}$}

\subsection{FRIEDEL-CRAFTS REACTIONS}

Polymerization by Friedel-Crafts alkylation/acylation is another important method for synthesizing single-site catalysts with polymer supports. The polymerizations are conducted by using stoichiometric or excess amount of either $\mathrm{FeCl}_{3}$ or $\mathrm{AlCl}_{3}$ in combination with a linker precursor such as dichloromethane or formaldehyde dimethylacetal. ${ }^{76,77,78,79}$ An advantage of using Friedel-Crafts alkylation/acylation for the formation of POPs is that it does not require the same kind of synthetic modification on the building blocks as the other techniques presented; the Friedel-Crafts reaction can take place directly on aryl moieties without any pre-functionalization. However, this also means that the cross-linking can be unselective and potentially even modify the ligand sites, if they contain nucleophilic aryl groups. Although the metals used for polymerization are cheap, the need for stoichiometric amounts during the polymerization again emphasizes the importance of effective methods for metal removal from the POP. As a representative example of polymerization by Friedel-Crafts reaction, Li, Tan, and coworkers carried out the synthesis of a porphyrin-POP which displayed an excellent BET surface area (1360 $\left.\mathrm{m}^{2} / \mathrm{g}\right)$ and a pore volume of $1.13 \mathrm{~cm}^{3} / \mathrm{g}$ (Scheme 5$) .^{76}$ 

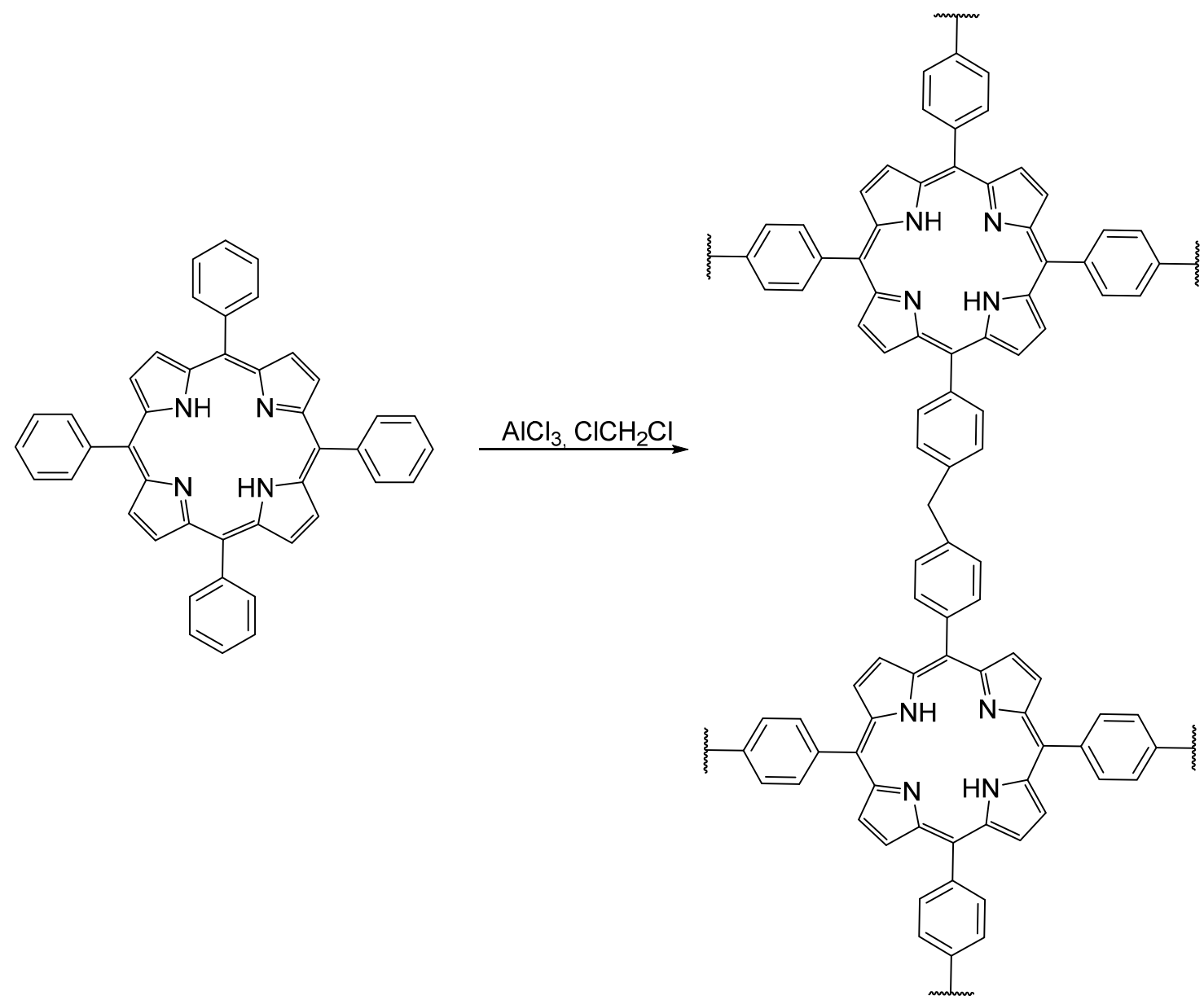

Scheme 5. Synthesis of a Porphyrin-POP by Friedel-Crafts Alkylation Reported by Li, Tan, and Coworkers. ${ }^{76}$

\subsection{MISCELLANEOUS}

Polymerization by condensation, where the driving force is release of water, has also been demonstrated. ${ }^{80,81}$ In the work of Gu et al., an approach for the polymerization by a ketoenamine condensation of amino-functionalized porphyrin and 1,3,5-triformyl-phloroglucinol was conducted (Scheme 6). ${ }^{80}$ This type of polymerization technique does not require additives in the form of radical initiators, metal catalysts, or stoichiometric amounts of metal in contrast to the 
other methods presented above. However, the condensations are, at least theoretically, reversible, and the resulting polymer may not be as robust as those linked by carbon-carbon bonds. Condensations forming carbon-carbon bonds have also been demonstrated. ${ }^{82}$

Polymerization through oxidative coupling has also been reported. ${ }^{83,84}$ In the work by Han et al., two different iridium-based photocatalysts was synthesized by polymerization of polycarbazolebearing tris(2-phenylpyridine)iridium(III)-complexes. ${ }^{84}$ The corresponding polymer contained a high loading of iridium and proved to be very suitable for photocatalysis. This kind of polymerization technique does not require a linker in contrast to many of the other examples presented here. However, even in the absence of a rigid linker, the BET surface areas for the two iridium-based polymers are still between $460-480 \mathrm{~m}^{2} / \mathrm{g}$ and the polymers have a defined microporous structure.

\begin{abstract}
Among other methods used for the formation of metal-POPs are nucleophilic aromatic substitution between fluoride-functionalized porphyrins and linkers bearing hydroxy-groups ${ }^{85,86}$, nickelcatalyzed Ullmann coupling for polymerizing porphyrin moieties ${ }^{87}$, Suzuki cross-coupling between bromide-functionalized porphyrins and aryl boronic esters ${ }^{88}$, and oxidative Eglinton coupling for synthesizing Ru-bpy-POPs ${ }^{31}$.
\end{abstract}



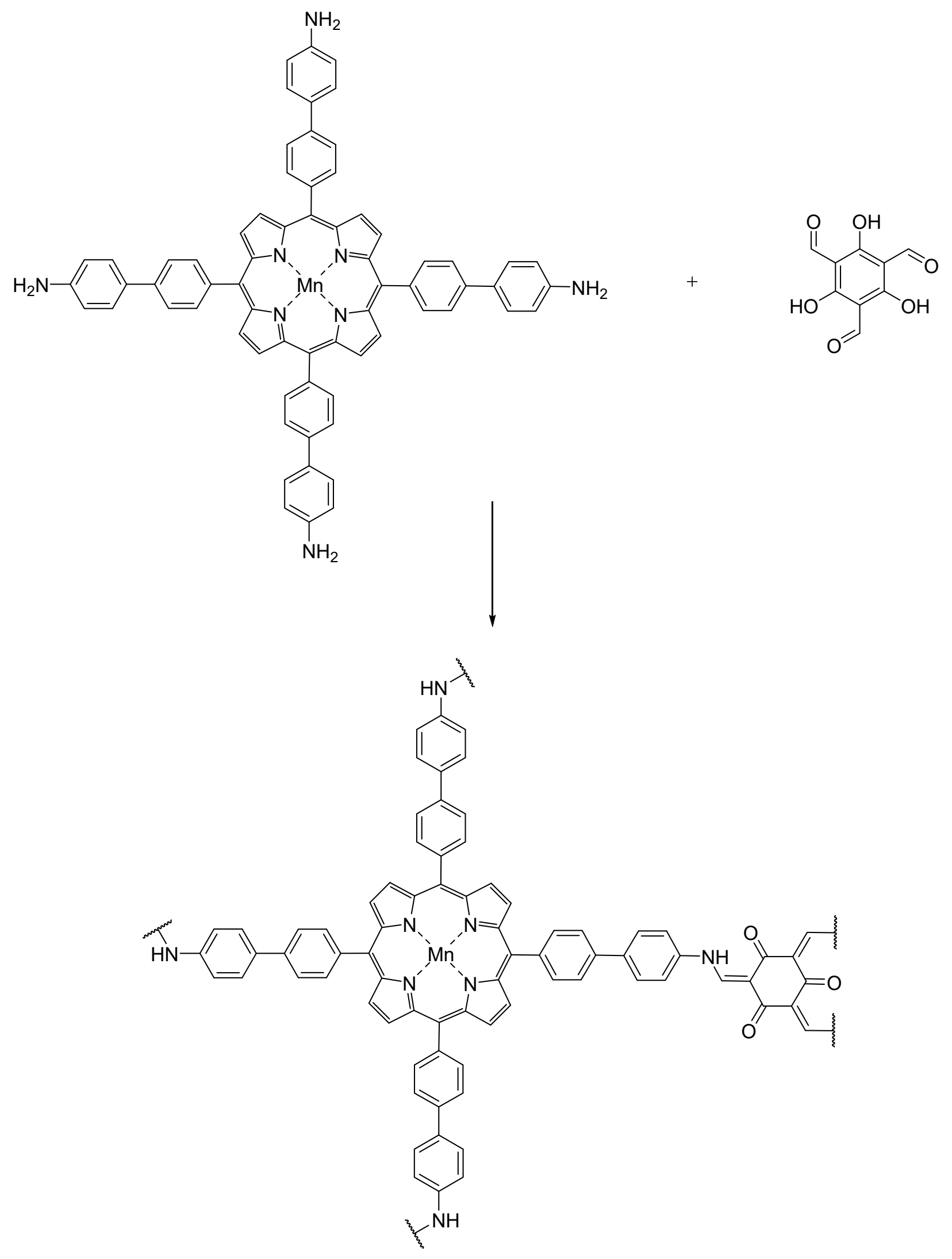

ACS Paragon Plus Environment 


\section{Scheme 6. Synthesis of a Mn-Porphyrin-POP by Ketoenamine Condensation. ${ }^{80}$}

In the synthesis of polymeric single-site catalysts, many different approaches have been reported in recent years. In this review, the trends have been categorized into five groups with a few additional polymerization techniques mentioned in miscellaneous. The availability of various techniques for the synthesis of metal-POPs provides numerous possibilities for catalyst-design.

\subsection{METALATION}

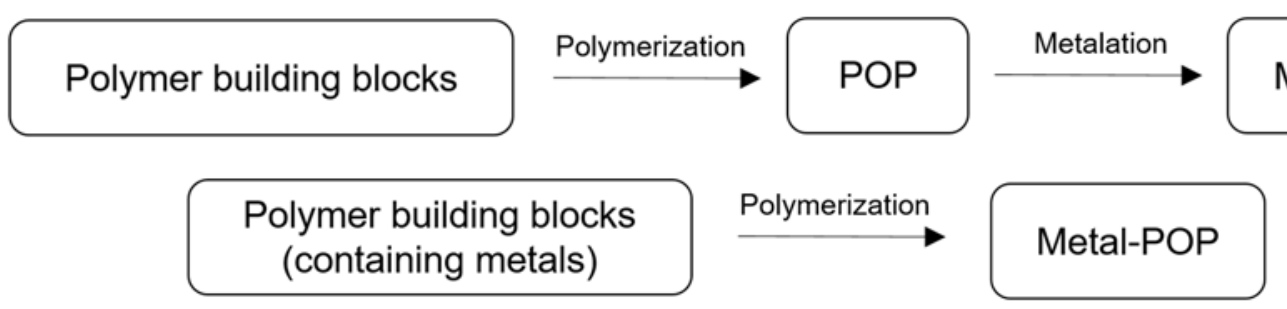

Figure 5. Two different metalation strategies utilized for the syntheses of metal-POPs.

An introduction to different polymerization techniques for synthesizing different POPs has been presented in the previous sections. However, in order to obtain a single-site metal catalyst, a metal has to be incorporated into the structure of the POP. There are essentially two different approaches for metalation: Either metalation is performed after the polymerization step or the desired metal is already ligated to the ligand building block during the polymerization (Figure 5). For the first approach, the metalation is typically conducted by stirring a mixture of the POP and the desired metal precursor. ${ }^{37,38,45,76,81,84,89}$ The second approach is often used for synthesis of metal-containing porphyrin-POPs. ${ }^{87,88}$ A benefit of introducing the metal into the monomers before polymerization 
is that the metalation can be almost quantitative whereas complete metalation after the formation of the POP may be difficult in some cases. ${ }^{87}$ A disadvantage of this approach can be encountered if the chosen polymerization technique requires a metal catalyst. In such a case, it can be difficult to ensure complete removal of the metal polymerization catalyst without removal of the desired metal-centers in the metal-POP. For some POPs made from Ru-bpy or Ir-ppy complexes, the metal is crucial during the polymerization as it functions as a template for accessing the desired porous polymer. A different type of metal templating was exploited in a study by Gagné et al., where the metal-coordination helps to induce a chiral cavity (Scheme 7). ${ }^{90}$

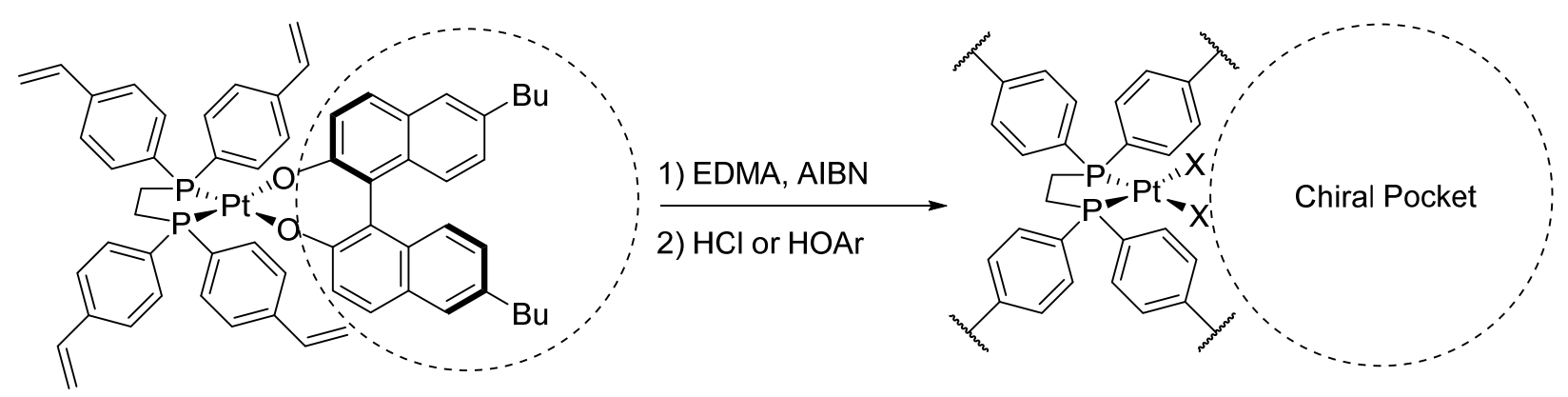

Scheme 7. Synthesis of Chiral Pocket by Metal Templating Reported by Gagné et al. (EDMA $=$ ethylenedimethacrylate $^{90}$

Undesired metalation can take place if a transition metal is required during the polymerization step and a coordination site is available. This was indicated in the work by Nguyen and coworkers, where the presence of nickel was required for the polymerization step. ${ }^{87}$ After the polymerization and workup, the POP still retain some nickel and an additional acid treatment was required to completely demetalate the POP. In some cases, complete metalation during the polymerization step is desired. In 2013, Bhaumik and coworkers reported the one-step synthesis of an Feporphyrin-POP by mixing $\mathrm{FeCl}_{3}$, pyrrole, and terephthaldehyde. ${ }^{82}$ 


\subsection{SWELLING}

Swelling is a common phenomenon when working with polymers and has often been addressed as a drawback of using polymer supports over inorganic supports like oxides, zeolites etc. ${ }^{16,91}$ However, recent studies demonstrate how good swelling properties allows for more accessible catalytic sites and the high degree of flexibility affords catalytic systems which can mimic homogeneous behavior. ${ }^{92,93,94,95,96}$ An example reported by Xiao and coworkers clearly demonstrates this point. When comparing ${ }^{31} \mathrm{P}$ static solid-state NMR of a dried dppe-based polymer with a swollen one (dppe $=1,2$-bis(diphenylphosphino)ethane), they observed a broad peak for the dried POP (Figure 6a) while the swollen POP gave a sharp signal at almost the same chemical shift as dppe in solution (Figure 6b).${ }^{95}$ Polymer swelling is also a profound feature in physisorption experiments which may explain unusually behavior in comparison to other porous materials (hysteresis loops, microporosity etc.). ${ }^{97}$ 


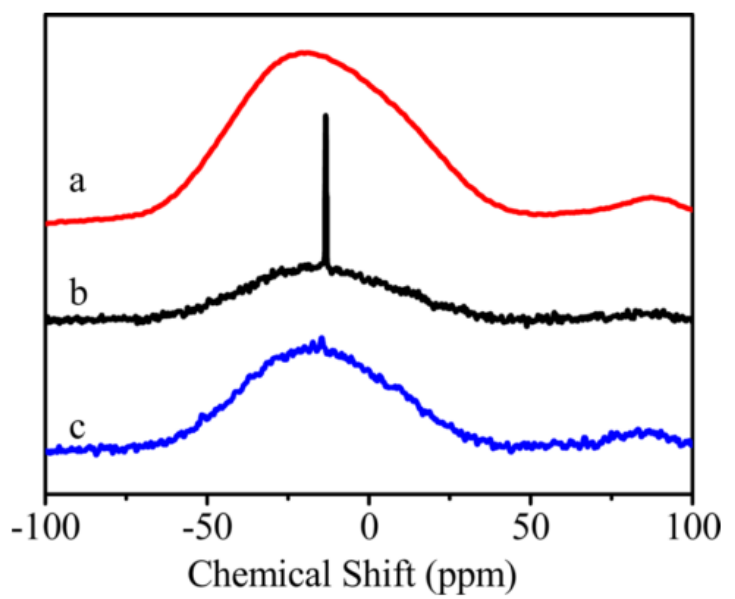

Figure 6. Static solid-state ${ }^{31} \mathrm{P}$ NMR of (a) the dried dppe-based polymer, (b) the dppe-based polymer in the presence of toluene, and (c) an non-porous dppe-based polymer in the presence of toluene. The sharp signal for the swollen polymer indicates homogeneous environment for the ligand in the swollen polymer. Adapted from Xiao and coworkers. ${ }^{95}$

\section{CATALYTIC REACTIONS USING METAL-POP-CATALYSTS}

The following sections are intended to provide an overview of the different reaction types where porous organic polymers containing an active mononuclear metal center have found use as catalysts. For reaction types with multiple reports, rather than an extensive listing of all the individual reports, representative examples have been selected. However, in many cases, only a single report on a reaction type exists and occasionally even only a single example. The transformations have been categorized into six main classes: Lewis acid catalysis, oxidations, reductions, coupling reactions, oxidative coupling reactions, and photocatalysis. A seventh section for reactions which do not fit well into these categories is also included (Miscellaneous). 
Some of the synthesized single-site metal-POPs can catalyze reactions in more than one of the main reaction classes and may accordingly be mentioned more than once.

\subsection{LEWIS ACID CATALYSIS}

The reactions included in this section are redox-neutral reactions where the catalyst can be considered to remain in the same formal oxidation state throughout the catalytic cycle. In general, these reactions involve addition of a nucleophile to a Lewis acid-activated electrophile. Catalytic activation of both hard and soft electrophiles has been examined. An overview of the reactions discussed in this section is presented in Table 1.

\section{Table 1. Overview of Lewis Acid Catalysis with Metal-POPs}




\begin{tabular}{|c|c|c|c|}
\hline Entry & Reaction & Catalyst & Reference \\
\hline \multirow[t]{8}{*}{1} & Cyclic Carbonate formation & $\mathrm{Zn}-\mathrm{PPh}_{3}-\mathrm{POP}$ & $93,94,98$ \\
\hline & from $\mathrm{CO}_{2}$ and epoxides & Al-porphyrin-POP & 38,77 \\
\hline & - & Co-porphyrin-POP & $38,76,77$ \\
\hline & - & Fe-porphyrin-POP & 77 \\
\hline & - & Mg-porphyrin-POP & 38 \\
\hline & - & Mn-porphyrin-POP & $38,78,99$ \\
\hline & - & Co-bpy-POP & 41 \\
\hline & - & Cu-bpy-POP & 41 \\
\hline 2 & Nucleophilic addition to epoxides & Fe-porphyrin-POP & 85 \\
\hline \multirow[t]{2}{*}{3} & Asymmetric addition of $\mathrm{ZnEt}_{2}$ to & Ti-BINOL-POP & 50 \\
\hline & aldehydes & Ti-TADDOL-POP & 71 \\
\hline 4 & Hetero-Diels-Alder reaction & Fe-porphyrin-POP & 78 \\
\hline 5 & 1,3-Dipolar cycloaddition & Cu-Phen-POP & 35 \\
\hline 6 & Methanolysis of organophosphate & La-catechol-POP & 45 \\
\hline \multirow[t]{2}{*}{7} & Alkyne hydration & Au-NHC-POP & 67 \\
\hline & - & $\mathrm{Au}-\mathrm{PPh}_{3}-\mathrm{POP}$ & 108 \\
\hline 8 & Hydroamination & $\mathrm{Au}-\mathrm{PPh}_{3}-\mathrm{POP}$ & 108 \\
\hline 9 & Enyne rearrangement & $\mathrm{Au}-\mathrm{PPh}_{3}-\mathrm{POP}$ & 108 \\
\hline 10 & Meyer-Schuster rearrangement & $\mathrm{Au}-\mathrm{PPh}_{3}-\mathrm{POP}$ & 108 \\
\hline 11 & 3,3-Rearrangement & $\mathrm{Au}-\mathrm{PPh}_{3}-\mathrm{POP}$ & 108 \\
\hline
\end{tabular}

One of the most studied transformations with porous organic polymers containing an active mononuclear metal center is the reactions between epoxides and $\mathrm{CO}_{2}$ leading to cyclic carbonates (Scheme 8). ${ }^{38,41,76,77,93,94,98}$ POPs with a range of different metals have successfully been used as catalysts for this transformation. The most commonly encountered metal in the active site is zinc, however, many other metals such as cobalt, aluminum, copper, and magnesium can also be used. Concurrent with the variation in metal, several binding sites for the metal have been reported including porphyrins, bipyridine, and phosphines. The two main strategies for assembling the metal-POPs, used for the $\mathrm{CO}_{2}$-trapping, are radical polymerization 
of vinyl-functionalized ligand monomers and Friedel-Crafts alkylation between aryl-containing ligand monomers and simple one- or two-carbon linkers.

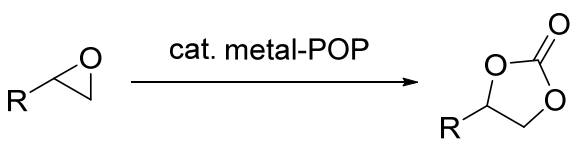

metal center: $\mathrm{Zn}, \mathrm{Al}, \mathrm{Cu}, \mathrm{Co}, \mathrm{Mg}$

\section{Scheme 8. Formation of Cyclic Carbonates from $\mathrm{CO}_{2}$ and Epoxides}

Interestingly, even though not a requirement, some of the examples of carbonate formation from epoxides and $\mathrm{CO}_{2}$ suggest a beneficial effect from having a bifunctional active site in the POP. A representative example of this was reported in 2015 by Zhang et al. who copolymerized triphenylphosphine with methyltriphenylphosphonium bromide using a Friedel-Crafts reaction with dimethoxymethane. ${ }^{98}$ The final catalyst was obtained after metalation with $\mathrm{ZnBr} 2$. Similar bifunctional catalysts have been reported by Ding and coworkers, however, using a radical polymerization. ${ }^{93,94}$ The superior activity of catalysts containing both phosphine-coordinated zinc bromide and phosphonium species was explained with a cooperative mechanism involving both moieties (Scheme 9). In 2017, Yan, Ding, and coworkers reported that a bifunctional Mnporphyrin-POP afforded an impressive TOF of $15,600 \mathrm{~h}^{-1}$ for the carbonate formation from $\mathrm{CO}_{2}$ and epoxides. They also demonstrated that the catalyst could be recycled at least four times with minimal loss of yield, and essentially no leaching was observed by ICP. ${ }^{99}$ 

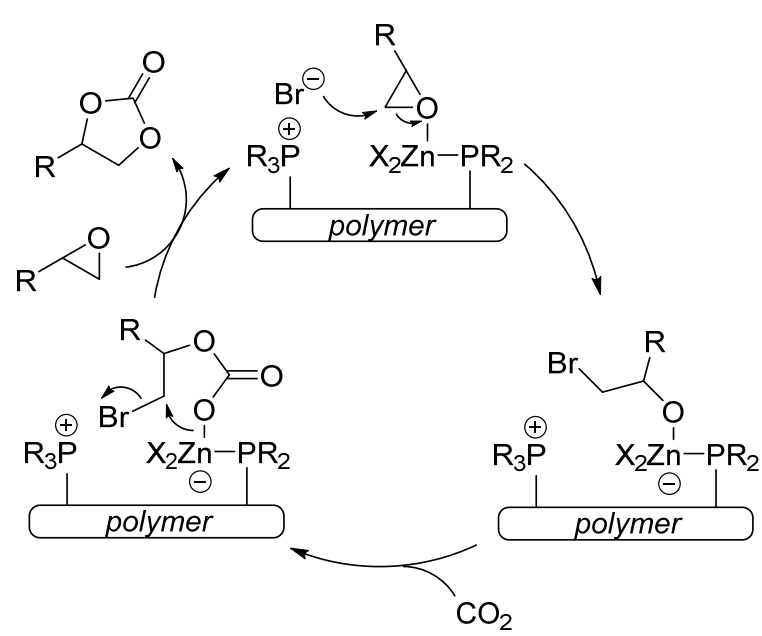

Scheme 9. Proposed Cooperative Mechanism for Cyclic Carbonate Formation using POPs Containing Bifunctional Sites

In addition to reactions with $\mathrm{CO}_{2}$, epoxide opening with an alcohol nucleophile using an iron porphyrin-based POP catalyst has also been reported (Scheme 10). ${ }^{85}$ The polymer catalyst was assembled through an $\mathrm{S}_{\mathrm{N}} \mathrm{Ar}$ reaction between hexahydroxytriphenylene and pentafluorophenyl moieties on the porphyrin monomers followed by metalation with $\mathrm{FeCl}_{2}$. No leaching was detected by ICP of the reaction mixture and recyclability of the catalyst was also demonstrated.

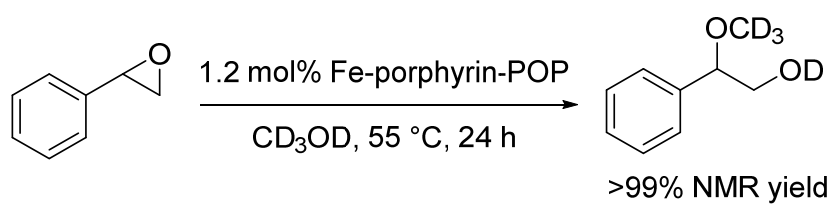

Scheme 10. Nucleophilic Addition to Epoxide Catalyzed by an Iron-Porphyrin-POP 
The activation of carbonyl moieties using single-site metal POPs have also been studied. In 2011, Lin and coworkers reported titanium-catalyzed asymmetric addition of diethylzinc to aryl aldehydes (Scheme 11a). ${ }^{50}$ The active metal center is titanium(IV) ligated to the heterogeneous polymer, which was made by cobalt-catalyzed alkyne trimerization of alkyne-bearing BINOL monomers $\left(\mathrm{BINOL}=(R)-(+)-1,1^{\prime}\right.$-binaphthalene-2,2'-diol). Even though a significant excess of $\mathrm{Ti}(\mathrm{Oi}-\mathrm{Pr}) 4$ is used, the activation of the metal catalyst by coordination to the BINOL-polymer is evidenced by the obtained enantioselectivities (55-81\% ee). It was demonstrated that when increasing the catalyst loading to $65 \mathrm{~mol} \%$, the BINOL-polymer could be reused nine times without loss of enantioselectivity and consistently providing high yields. Later, Wang and coworkers reported that the use of a TADDOL-based chiral porous polymer $(\mathrm{TADDOL}=$ (4R,5R)-4,5-bis(diphenylhydroxymethyl)-2,2-dimethyldioxolane) could improve the enantioselectivity of the transformation (Scheme 11b) ${ }^{71}$ This polymer catalyst was made by Sonogashira coupling between alkyne-derivatized TADDOL and a $\mathrm{C}\left(\mathrm{sp}^{3}\right)$-containing aryl bromide linker. The catalyst could be reused 10 times with no loss of yield; however, the enantiomeric excess of the product decreased from $91 \%$ ee in the first run to $76 \%$ ee in the 11 th run. The loss of enantioselectivity was believed to be due to build-up of metal oxides and organic residual in the pores of the polymer.

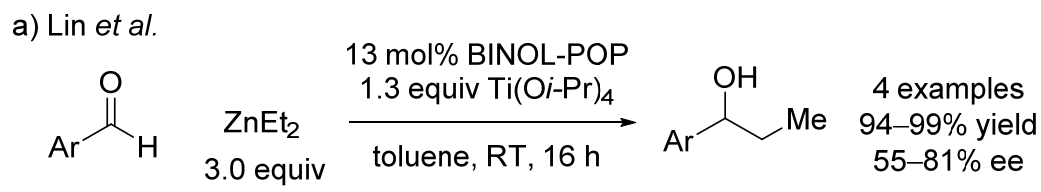

b) Wang et al.

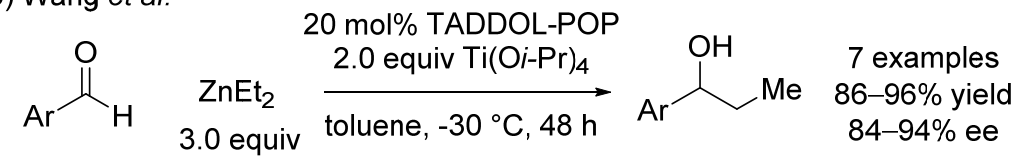




\section{Scheme 11. Titanium-Catalyzed Asymmetric Addition of $\mathbf{Z n E t}_{2}$ to Aldehydes using (a) a BINOL-POP Ligand and (b) a TADDOL-POP Ligand}

In 2016, Dou and Liu et al. reported that aldehydes can be activated for hetero-Diels-Alder reactions with simple, unfunctionalized dienes by a combination of a heterogenized iron chloride porphyrin (Fe-porphyrin-POP) and $\mathrm{AgBF}_{4}(\mathrm{Scheme} 12) .{ }^{78}$ The heterogeneous catalysts were made by hypercrosslinking iron porphyrins using Friedel-Crafts acylation which led to materials with a high density of catalytic sites. A hot filtration experiment indicated that the catalysis was heterogeneous in nature and it was also established that the catalyst can be reused four times. Finally, it was demonstrated that the reaction between benzaldehyde and 2,3-dimethylbuta-1,3diene can be performed on gram-scale with as little as $0.02 \mathrm{~mol} \% \mathrm{Fe}$-porphyrin-POP, however, the amount of added $\mathrm{AgBF}_{4}$ was not specified.

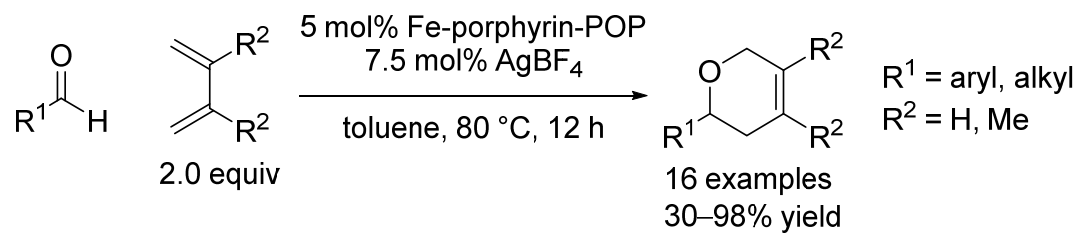

\section{Scheme 12. Hetero-Diels-Alder Reaction Catalyzed by Heterogeneous Iron-Porphyrin-POP and $\mathrm{AgBF}_{4}$}

The powerful "click reaction" between a terminal alkyne and an organic azide can be also be catalyzed by a POP-bound metal. ${ }^{100,101}$ In 2013, Meng, Chen, Xiao, and coworkers published a copper-Phen-POP-catalyzed version of this formal 1,3-dipolar cycloaddition (Scheme 13). ${ }^{35}$ The 
applied catalyst contains $\mathrm{Cu}(\mathrm{OAc})_{2}$ which is bound to 1,10 -phenanthroline in a polydivinylbenzene-polymer. Turnover frequencies were in the range of $1116-2970 \mathrm{~h}^{-1}$.

$$
\underset{1.05 \text { equiv }}{=} \mathrm{N}_{3} \widehat{\mathrm{Ph}} \frac{0.05 \mathrm{~mol} \% \text { Cu-Phen-POP}}{\mathrm{H}_{2} \mathrm{O}, \mathrm{RT}, 40 \mathrm{~min}} \overbrace{99 \% \text { yield }}^{\mathrm{Ph}}
$$

\section{Scheme 13. Formal 1,3-Dipolar Cycloaddition Catalyzed by a Cu-Phen-POP}

The hydrolysis and methanolysis of the phosphate ester motif in a nerve agent simulant has been demonstrated using a catechol-containing POP with an active lanthanum center (Scheme 14). ${ }^{45}$ The polymer catalyst was made through cobalt-catalyzed alkyne cyclotrimerization between alkyne-functionalized catechol fragments and alkyne-containing linkers followed by postsynthesis metallation. Despite very limited leaching of metal from the best catalyst, significant deactivation was observed for the methanolysis reaction. The deactivation was accompanied by a significant decrease in surface area possibly by clogging of the pores by trapped, degraded lanthanum species. The hydrolysis reaction was much less prone to catalyst deactivation than the methanolysis reaction.

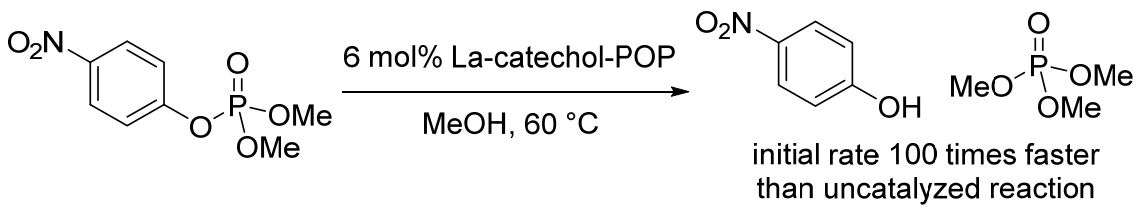

\section{Scheme 14. Methanolysis of an Organophosphate Catalyzed by a Lanthanum-Catechol-POP}


In recent years the field of homogeneous gold catalysis has witnessed tremendous activity. ${ }^{102,103,104,105,106,107}$ Considering the numerous reaction types reported with gold catalysis and the high price of gold, it is not surprising that strategies for recycling these precious metal catalysts have also been investigated. In 2014, Li and coworkers reported that a porous organic polymer containing gold-coordinated NHC ligand sites can efficiently catalyze hydration of alkynes (Scheme 15a) ${ }^{67}$ The polymer is made through a Sonogashira coupling between an iodide-functionalized NHC, $\operatorname{IPr}(\operatorname{IPr}=1,3$-bis-(diisopropylphenyl)-imidazole-2-ylidene), and various alkyne-bearing linkers. Interestingly, a significant influence of the solvent volume used during polymer synthesis on pore-size and catalytic activity was observed. The catalyst was recycled five times with essentially constant yield (83-85\%). After recycling, it was found that no hydration of the alkyne-containing linker in the polymer had occurred. While Li et al. only reported alkyne hydration, last year, Shi and coworkers demonstrated that, along with alkyne hydration, a range of other typical reactions in homogeneous gold catalysis are also accessible (Scheme 15b). ${ }^{108}$ These reactions included hydroamination, enyne rearrangement, MeyerSchuster rearrangement, 3,3-rearrangement, and an example of oxidative alkyne coupling (see Section 3.5). Instead of using NHC ligand sites in the polymers, Shi et al. used a phosphinebased polymer made through radical polymerization of vinyl-functionalized triphenylphosphine. For the majority of the reactions, no loss of yield was observed when recycled catalyst was utilized. 
a) Li et al.

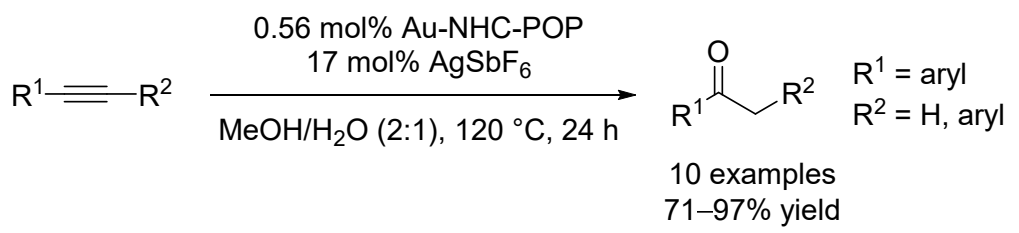

b) Shi et al.

$71-97 \%$ yield
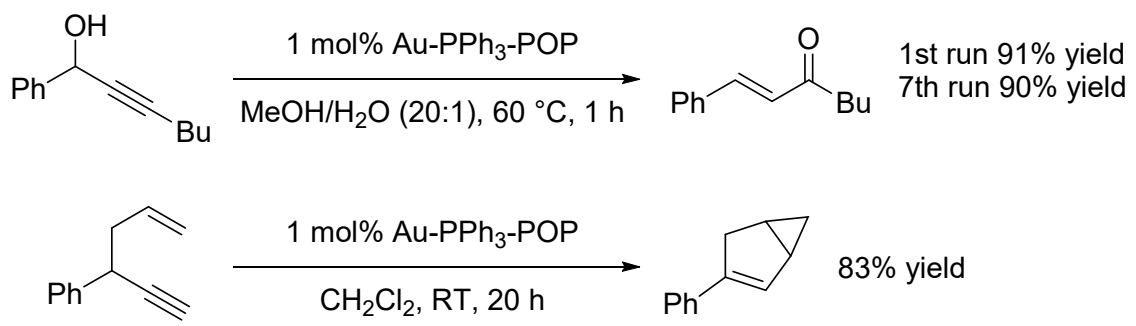

Scheme 15. Selected Reactions Catalyzed by Gold-Containing Porous Organic Polymers: (a) Alkyne Hydration by $\mathrm{Li}$ et al. and (b) Meyer-Schuster Rearrangement and Enyne Rearrangement by Shi et al.

\subsection{OXIDATION REACTIONS}

In this section, reactions where the substrate undergoes an overall oxidation are presented. The focus will be on oxidations in a more classical sense i.e. either addition of oxygen or removal of hydrogen (Table 2). Oxidative coupling reactions will be covered in a separate section (Section $3.5)$.

Table 2. Overview of Oxidation Reactions with Metal-POP Catalysts. 


\begin{tabular}{|c|c|c|c|}
\hline Entry & Reaction & Catalyst & Reference \\
\hline \multirow[t]{2}{*}{1} & Epoxidation of styrene & Fe-porphyrin-POP & 81 \\
\hline & - & Mn-porphyrin-POP & $80,81,87$ \\
\hline \multirow[t]{2}{*}{2} & Epoxidation of aliphatic alkenes & Mn-salen-POP & 70 \\
\hline & - & Mn-porphyrin-POP & 80 \\
\hline 3 & $\begin{array}{l}\text { Oxidation of styrene to phenyl- } \\
\text { acetaldehyde }\end{array}$ & Mn-porphyrin-POP & 88 \\
\hline 4 & $\begin{array}{l}\text { Oxidation of primary and } \\
\text { secondary alcohols }\end{array}$ & Fe-porphyrin-POP & 82 \\
\hline 5 & $\begin{array}{l}\text { Benzylic oxidation of ethylben- } \\
\text { zene }\end{array}$ & Mn-porphyrin-POP & 80 \\
\hline \multirow[t]{2}{*}{6} & Imine formation from benzylic & Ru-NHC-POP & 73 \\
\hline & alcohols and anilines & Ir-NHC-POP & 73 \\
\hline 7 & Oxidation of benzylic alcohols & Cu-bpy-POP & 79 \\
\hline
\end{tabular}

Oxidations of alkenes is among the most studied reactions with porous organic polymers containing an active mononuclear metal center. In 2011, Hupp, Nguyen, and coworkers demonstrated epoxidation of styrene by using a catalyst comprised of a manganese porphyrin complex embedded in a porous organic polymer. ${ }^{81}$ The analogous iron catalyst was also investigated but displayed inferior activity. In 2015, the same research group published a more comprehensive study of epoxidation of styrene and divinylbenzene catalyzed by a related manganese-porphyrin-POP ${ }^{87}$ The catalyst material was made by an Ullmann coupling between bromide-functionalized porphyrins and a tetrabromo-spirobifluorene. Manganese was incorporated into the polymer in a separate step. When styrene was used as the substrate, $80 \%$ yield of the corresponding epoxide was obtained. In addition, $7 \%$ phenylacetaldehyde and $6 \%$ benzaldehyde was observed (Scheme 16). A time-study revealed that benzaldehyde is formed from phenylacetaldehyde under the reaction conditions. Unfortunately, recycling was not possible due to difficulties with removing oxidant degradation products from the polymer. In 2017, Gu and coworkers also reported epoxidation of styrene with a manganese-porphyrin- 
POP ${ }^{80}$ However, the polymer backbone was very different and PhIO was used as oxidant. These changes meant that the catalyst could be recycled as demonstrated by five consecutive runs where only a minor decrease in yield was detected.

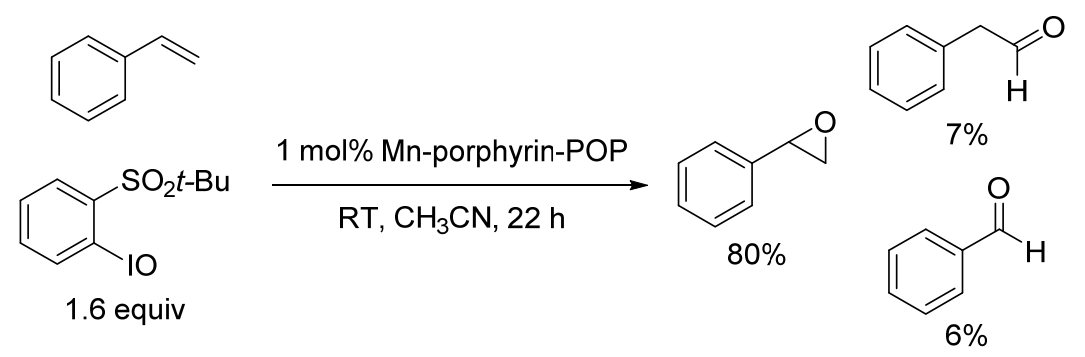

\section{Scheme 16. Epoxidation of Styrene Catalyzed by a Mn-porphyrin-POP}

In 2015, epoxidation of aliphatic alkenes, both terminal and internal (cyclic) was reported by Cao and coworkers. ${ }^{70}$ A palladium-catalyzed Sonogashira coupling of a manganese-salen complex bearing arylbromides and 1,3,5-triethynylbenzene afforded the heterogeneous catalyst. In general, high selectivity for the epoxide products were obtained, but the rate was highly substrate dependent (Scheme 17). For cyclohexene, four recycling experiments were performed providing consistently high yield and selectivity. Although the salen complex used for catalyst synthesis was chiral and enantiopure, no enantioselectivity was observed in the epoxidations. Later, Gu and coworkers also reported epoxidation of aliphatic alkenes. ${ }^{80}$

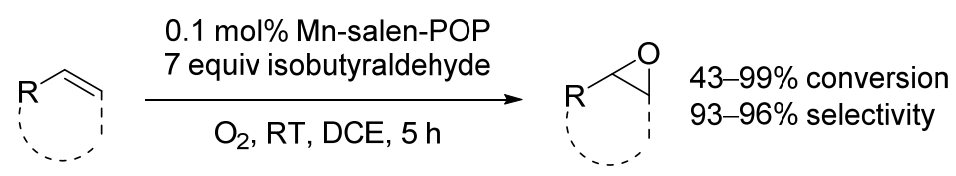




\section{Scheme 17. Aliphatic Alkene Epoxidation Catalyzed by a Mn-Salen-POP}

Selective oxidation of styrene to phenylacetaldehyde was published by Zou, Liu, and coworkers (Scheme 18). ${ }^{88}$ The catalyst was similar to the one used by Hupp, Nguyen et al. for styrene epoxidation in the sense that it consisted of manganese porphyrins linked by an organic backbone. However, the porous organic polymer was assembled using a Suzuki-Miyaura crosscoupling instead of a Sonogashira cross-coupling. A higher reaction rate was observed for the manganese-metalated POP; however, significant background activity was found when using the manganese-free porphyrin-POP ( $>99 \%$ selectivity for phenylacetaldehyde). It was speculated that traces of residual palladium from the catalyst synthesis could be responsible for the background activity. Finally, it was demonstrated that the catalyst could be recycled four times without any decrease in turnover frequency.

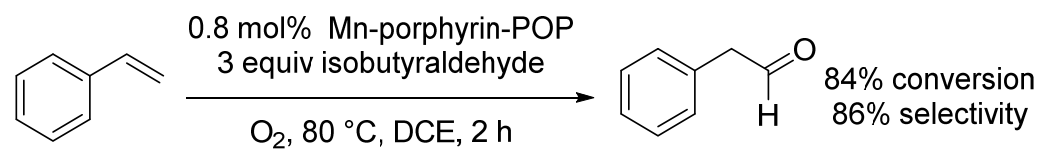

\section{Scheme 18. Catalytic Oxidation of Styrene to Phenylacetaldehyde}

In 2013, Bhaumik and coworkers reported oxidation of primary and secondary alcohols to aldehydes and ketones using an iron-porphyrin-POP catalyst and tert-butyl hydroperoxide (TBHP) as the terminal oxidant (Scheme 19). ${ }^{82}$ The reaction conditions could successfully be applied to a range of substrates. In addition, only a small decrease in yield was observed after 
two recycles (from $85 \%$ yield to $80 \%$ yield) and no metal leaching was detected in the filtrate of a completed reaction.

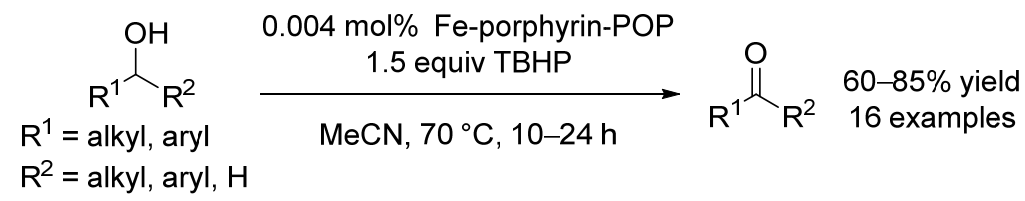

Scheme 19. Oxidation of Primary and Secondary Alcohols Catalyzed by an Iron-PorphyrinPOP

In 2017, Gu and coworkers demonstrated that the manganese-porphyrin-POP they used for olefin epoxidation could also catalyze benzylic oxidation of ethylbenzene and related unfunctionalized substrates. ${ }^{80}$ In the presence of TBHP, ketones were obtained in mostly high yields and selectivity (Scheme 20). For ethylbenzene, over the course of five consecutive runs with the same catalyst, the yield of acetophenone only decreased from $94 \%$ to $86 \%$.

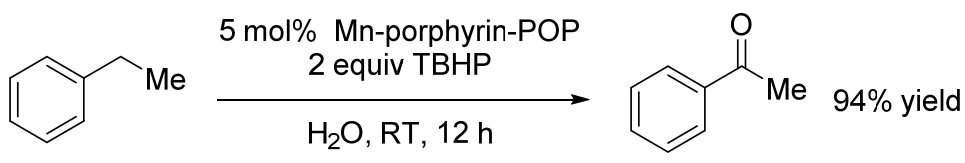

Scheme 20. Acetophenone Synthesis from Ethylbenzene Catalyzed by a ManganesePorphyrin-POP 
Another oxidation by removal of benzylic hydrogen has been reported by Iglesias, Sanchez, and coworkers. ${ }^{73}$ Using a porous organic polymer containing NHC ligands bound to either ruthenium or iridium, it was demonstrated that imines could be formed directly from benzyl alcohols and anilines, likely through arylaldehyde intermediates (Scheme 21). By modification of the catalyst and reaction conditions, the selectivity could be altered favoring amine instead of imine products. This is an example of a hydrogen-borrowing reaction and it will be discussed in more detail in Section 3.6. Huang and coworkers have also reported oxidation of three benzylic alcohols to arylaldehydes using a porous organic polymer containing copper-2,2'-bipyridine active sites. $^{79}$

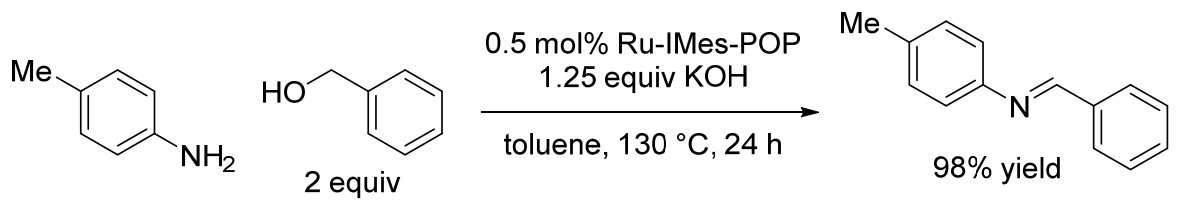

\section{Scheme 21. Oxidation/Condensation Sequence Catalyzed by a Ruthenium-IMes-POP (IMes = 1,3-bis-(2,4,6-trimethylphenyl)imidazol-2-ylidene)}

\subsection{REDUCTION REACTIONS}

Porous organic polymers containing an active mononuclear metal center have also catalyzed a number of reactions where the substrate undergoes an overall reduction. These reactions include alkene and alkyne reduction by $\mathrm{H}_{2}$; carbonyl reduction by $\mathrm{H}_{2}$, transfer hydrogenation, or hydrosilylation; asymmetric carbonyl reduction; reductive amination; and hydrogenation of nitro groups (Table 3). 
Table 3. Overview of Reduction Reactions with Metal-POP Catalysts.

\begin{tabular}{llll}
\hline Entry & Reaction & Catalyst & Reference \\
\hline 1 & Alkene and alkyne hydrogen- & Ta-catechol-POP & 44,48 \\
& ation & Ru-catechol-POP & 109 \\
& - & Al-catechol-POP & 48,49 \\
& - & Co-catechol-POP & 46,48 \\
& - & Cr-catechol-POP & 48 \\
& - & Fe-catechol-POP & 48 \\
& - & Mn-catechol-POP & 48 \\
& - & Ni-catechol-POP & 48 \\
& - & V-catechol-POP & 48 \\
2 & Reductive amination & Ir-ppy-POP & 110 \\
3 & Hydrogenation of $\beta$-keto esters & Ru-BINAP-POP & $29,34,111$ \\
4 & Hydrogenation of quinoline & & 29 \\
5 & Transfer hydrogenation & Ru-NHC-POP & 73 \\
6 & Carbonyl hydrosilylation & Fe-catechol-POP & 47 \\
\end{tabular}

Most hydrogenations of carbon-carbon multiple bonds use simple alkenes or alkynes and rarely is functional group tolerance investigated. These reactions frequently use catalysts where the metal is bound to a catechol ligand in the porous organic polymer. The catechol-POP is typically made first by a cobalt-catalyzed cyclotrimerization between a (tetrakis)alkyne-bearing linker and protected catechol units also containing alkynes. After deprotection of the catechol moiety, the catechol-POP is finally metalated.

In an early report, Mader, Johnson, Nguyen, and coworkers demonstrated hydrogenation of cyclohexene to cyclohexane using a tantalum-catechol-POP catalyst and later Hock and coworkers used a rhodium-catechol-POP for propylene hydrogenation. ${ }^{44,109}$ In 2017 , Stair and coworkers reported an aluminum-catechol-POP for use in hydrogenation of eight different alkenes and alkynes (Scheme 22a). ${ }^{49}$ While monosubstituted alkenes led to high conversions, 
1,1-disubstituted as well as tri- and tetrasubstituted alkenes reacted very sluggishly. In contrast, both terminal and internal alkynes were highly reactive, however, only moderate selectivity was observed leading to a mixture of cis/trans-alkenes and alkane from overreduction. It was shown that a ketone and an imine did not react under the reaction conditions.

a)

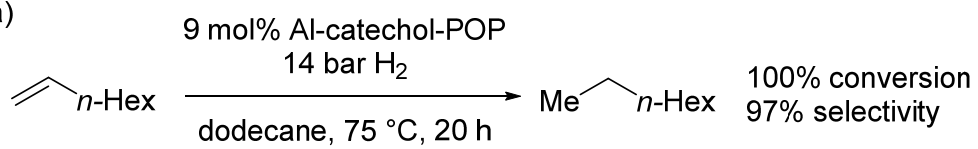

b)

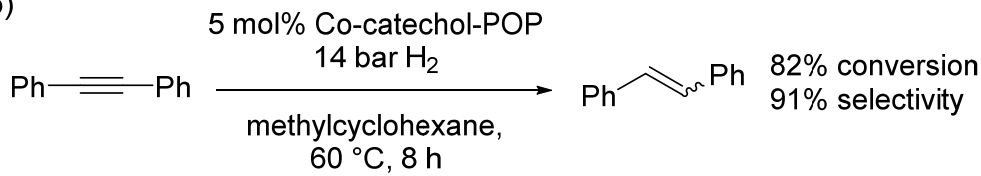

c)

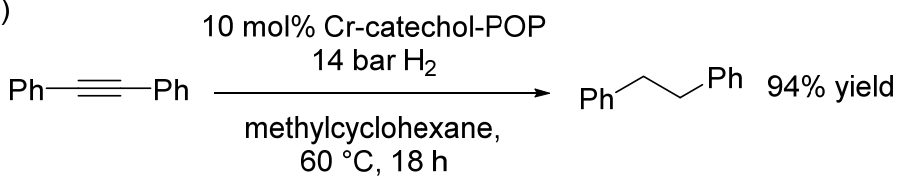

Scheme 22. Alkene and Alkyne Hydrogenation Catalyzed by Metal-Catechol-POPs. (a) Aluminum Catalyst, (b) Cobalt Catalyst, and (c) Chromium Catalyst.

Miller, Hock, Nguyen, and coworkers have also studied hydrogenation of diphenylacetylene using different first-row metal-catechol-POPs. First, semihydrogenation of diphenylacetylene was investigated using six different metal-catechol-POP catalysts. ${ }^{48}$ For cobalt-catechol-POP, $91 \%$ selectivity for stilbenes was obtained at $82 \%$ conversion (Scheme $22 b$ ). In a different study, Hock and coworkers demonstrated that while a mixture of semi- and fully hydrogenated products were obtained with $5 \mathrm{~mol} \%$ of chromium-catechol-POP catalyst, an increase in catalyst loading afforded $94 \%$ yield of the fully hydrogenated product (Scheme $22 \mathrm{c}){ }^{46}$ 
Reductive elimination, i.e. hydrogenation of imines formed in situ, catalyzed by an iridiumcontaining POP was reported by Cooper and coworkers. ${ }^{110}$ A palladium-catalyzed Sonogashira coupling between 1,3,5-triethynylbenzene and $\mathrm{Cp} * \mathrm{IrCl}$ cyclometalated onto a bisbromophenylpyridine afforded the Ir-ppy-POP. The application of $1 \mathrm{~mol} \%$ of this catalyst in the presence of formic acid led to high yields of the amine products (Scheme 23). The reaction worked well with a primary and secondary amine and an aniline.

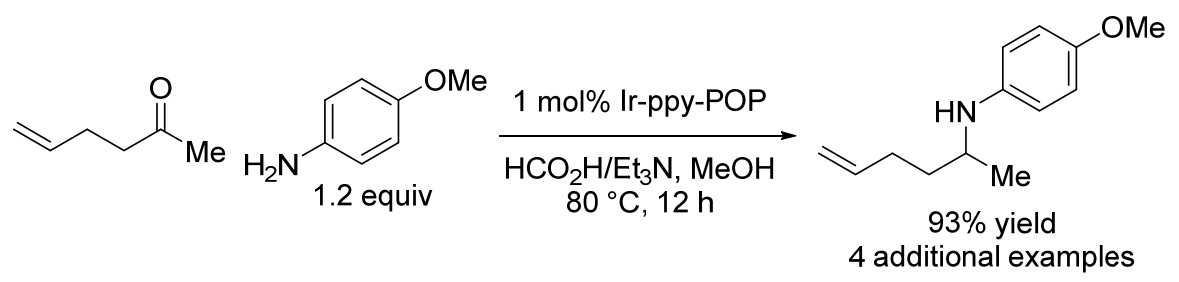

\section{Scheme 23. Reductive Amination Catalyzed by an Iridium-ppy-POP}

A few reports on direct reduction of carbonyl groups to alcohols have also appeared. Asymmetric hydrogenation of $\beta$-keto esters using ruthenium-BINAP-POPs has been studied by several groups. In 2012, Meng, Yang, Xiao, and coworkers synthesized a porous organic polymer by radical copolymerization of 1,4-divinylbenzene and acrylamide-functionalized BINAP (as the bis-phosphine oxide). ${ }^{111}$ After reduction of the phosphine oxides, the polymer was metalated with $\left[\mathrm{RuCl}_{2} \text { (benzene) }\right]_{2}$. Application of this material as catalyst for asymmetric hydrogenation of eight different $\beta$-keto esters afforded the corresponding $\beta$-hydroxy esters in high yields and with high enantioselectivity (Scheme 24). For one substrate, it was demonstrated that the catalyst could be reused six times without any decrease in yield or enantioselectivity. Furthermore, an experiment with $0.02 \mathrm{~mol} \% \mathrm{Ru}-\mathrm{BINAP}-\mathrm{POP}$ also provided quantitative yield 
with only a small decrease in enantioselectivity (from 95\% ee to 90\% ee). In 2017, Ding et al. reported a related catalyst which was made by radical dimerization of 1,4-divinylbenzene and vinyl-functionalized BINAP followed by metalation with $\left[\mathrm{RuCl}_{2}\right.$ (benzene) $] 2 .{ }^{34}$ This catalyst also displayed good activity and enantioselectivity for hydrogenation of different $\beta$-keto esters. A hot filtration experiment showed that no catalytic activity was present in the liquid phase after the hot filtration, thus indicating the heterogenous nature of the catalyst.

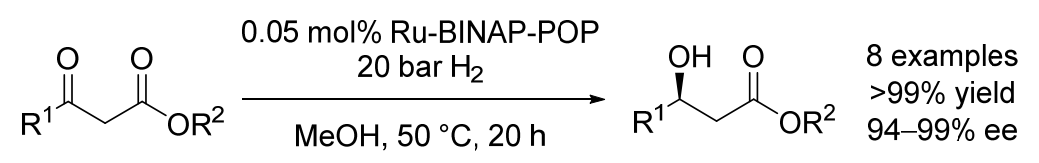

\section{Scheme 24. Asymmetric Hydrogenation of $\beta$-Keto Esters}

In 2015, Liu, Li, and coworkers accessed a ruthenium-BINAP-POP through a different route. ${ }^{29}$ The ligand-containing polymer was synthesized by a palladium-catalyzed Sonogashira coupling between different alkyne-linkers and 4,4'-dibromo-BINAP oxide. Subsequent reduction of the phosphine oxides and metalation with $\left[\mathrm{RuCl}_{2} \text { (benzene) }\right]_{2}$ afforded the ruthenium-BINAP-POP. Also this catalyst provided highly enantioenriched $\beta$-hydroxy esters in quantitative yields. Interestingly, a BINAP-POP, without ruthenium incorporation, was also combined with [ $\mathrm{IrCl}$ $(\mathrm{COD})]_{2}$ for the asymmetric hydrogenation of 2-methyl quinoline (Scheme 25). While the same degree of enantioselectivity was observed for $[\mathrm{IrCl}(\mathrm{COD})]_{2} / \mathrm{BINAP}-\mathrm{POP}$ and a homogeneous $[\operatorname{IrCl}(\mathrm{COD})]_{2} / \mathrm{BINAP}$ system, the porous organic polymer catalyst displayed superior activity ( $99 \%$ conversion vs. $23 \%$ conversion). 


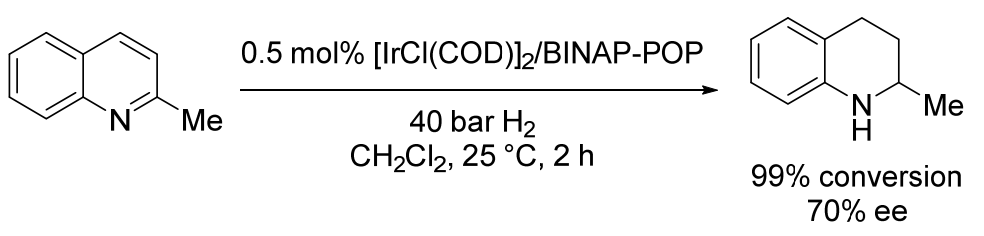

\section{Scheme 25. Asymmetric Hydrogenation of 2-Methyl Quinoline}

Iglesias, Sanchez, and coworkers reported that transfer hydrogenations from iso-propanol to acetophenones are also possible (Scheme 26) ${ }^{73}$ This approach avoids the need for high hydrogen pressures for hydrogenation of the carbonyl moiety. It was demonstrated that the catalyst could be recycled six times providing continuously high yields of the alcohol product.

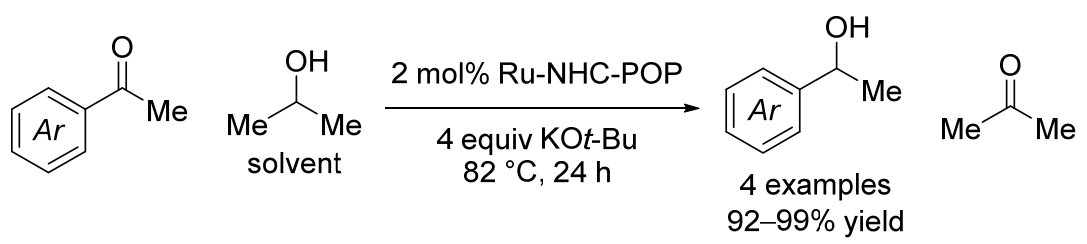

\section{Scheme 26. Transfer Hydrogenation for Reduction of Acetophenones}

Besides reduction of carbonyl groups by addition of hydrogen, hydrosilylation has also been demonstrated. ${ }^{47}$ Hock and coworkers reported the use of an iron-catechol-POP as a highly active catalyst for addition of phenylsilane and diphenylsilane to ketones and aldehydes (Scheme 27). The applied catalyst was a porous organic polymer containing mono-catechol-complexed iron(II) centers. Interestingly, the mono-catechol complex was unattainable by mixing the iron-precursor and 3,6-di-tert-butylbenzene-1,2-diol in a homogeneous solution. It was suggested that it is the 
spacial separation of catechol units in the polymer that allows for the formation of the coordinatively unsaturated iron complexes. The catalyst was highly air sensitive but very active for the hydrosilylation reactions. A filtration experiment revealed no catalytic activity in the filtrate.

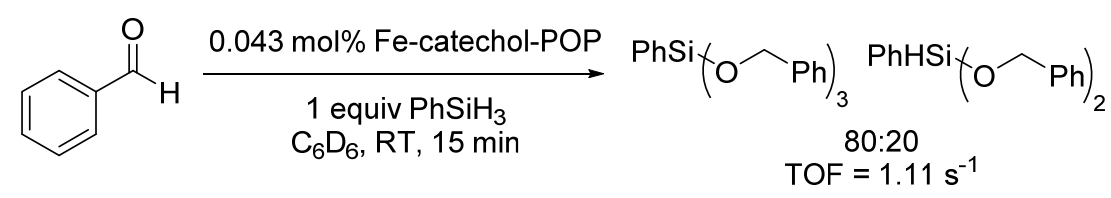

\section{Scheme 27. Hydrosilylation of Carbonyl Groups Catalyzed by an Fe-Catechol-POP}

In addition to reduction of $\mathrm{C}=\mathrm{C}, \mathrm{C}=\mathrm{N}$, and $\mathrm{C}=\mathrm{O}$ bonds, an example of nitro-group reduction in para-nitrophenol with $\mathrm{NaBH}_{4}$ catalyzed by a ruthenium-POP has also been reported. ${ }^{79}$

\subsection{COUPLING REACTIONS}

Coupling reactions are very powerful since they can form a variety of bonds such as carboncarbon, carbon-nitrogen, and carbon-oxygen bonds. ${ }^{112,113}$ These reactions typically connect an aryl or vinyl halide electrophile with an appropriate nucleophile (amines, sulfides, organometallic reagents, etc.). An overview of the reactions discussed in this section is presented in Table 4. A few examples of oxidative coupling between two nucleophiles, in the presence of an oxidant have also been reported and will be discussed in a separate section (Section 3.5.).

Table 4. Overview of Coupling Reactions with Metal-POP Catalysts. 


\begin{tabular}{llll}
\hline Entry & Reaction & Catalyst & Reference \\
\hline 1 & Cyanation of aryl halides & Pd-pyr-POP & 83 \\
2 & Suzuki-Miyaura cross-coupling & Pd-PPh $_{3}$-POP & 96 \\
& - & Pd-salen-POP & 74 \\
& - & Pd-bpy-POP & 79 \\
& - & Pd-IP-POP & 116 \\
3 & Mizoroki-Heck reaction & Pd-salen-POP & 74 \\
4 & Coupling of aryl pivalates and & Ni-dppbz-POP & 42 \\
& benzoxazoles & & \\
5 & Amination of aryl chlorides & Ni-dppbz-POP & 42 \\
6 & Ullmann coupling & Cu-IP-POP & 89 \\
7 & Alkoxycarbonylation of terminal & Pd-PyPPh $2-P O P$ & 92 \\
& alkynes & & \\
\hline
\end{tabular}

In 2017, Zhu, Zhang, Dai, and coworkers reported an efficient palladium-POP-catalyzed cyanation of various aryl halides (iodides, bromides, and chlorides) with $\mathrm{K}_{4}\left[\mathrm{Fe}(\mathrm{CN})_{6}\right]$ as cyanide source (Scheme 28). ${ }^{83}$ The catalyst was made by crosslinking dicarbazolpyridines using FriedelCrafts alkylation with $\mathrm{CH}_{2} \mathrm{Cl}_{2}$ followed by metalation with $\mathrm{Pd}(\mathrm{OAc})_{2}$, which coordinates to the pyridine-nitrogens. It was demonstrated that the catalyst could be used in four consecutive reactions providing continuously high yields. In addition, a hot filtration test also supported the intended heterogeneous nature of catalysis.

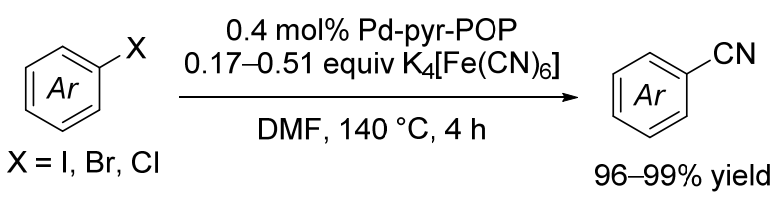

Scheme 28. Cyanation of Aryl Halides using a Palladium-Containing Porous Organic Polymer 
One of the most widely used homogeneous reactions in medicinal chemistry is the SuzukiMiyaura cross-coupling which connects aryl halides and aryl boron species. ${ }^{114}$ In 2013 , Sawamura and coworkers reported the use of a phosphine-containing POP as a heterogeneous ligand for palladium-catalyzed Suzuki-Miyaura coupling. ${ }^{96}$ The heterogeneous ligand was made by radical polymerization of vinyl-functionalized triphenylphosphine and 4-tert-butylstyrene leading to polystyrene-PPh 3 . Interestingly, the rigid spacing of phosphine ligands leads exclusively to mono-phosphine-ligated palladium complexes, which is a key necessity for oxidative addition to aryl chlorides. ${ }^{115}$ Accordingly, a high yield of the desired biaryl product was obtained for the reaction between an unactivated aryl chloride and phenylboronic acid (Scheme 29). The use of POPs made from triphenylphosphines bearing vinyl-moieties on all the aryl groups provided the best yields for the Suzuki-Miyaura cross-coupling. Catalyst recycling was also examined. While the first four recycles of the catalyst provided continuously high yields, after reusing the catalyst seven times, only $24 \%$ yield was obtained. The apparent explanation for the deactivation was the formation of $\operatorname{Pd}(0)$-nanoparticles, which was observed by HRTEM. ICP-AES showed negligible palladium leaching and a hot filtration test revealed no catalytic activity in the liquid phase. Other groups have reported on the Suzuki-Miyaura coupling catalyzed by other metal-POPs. ${ }^{74,79,116}$

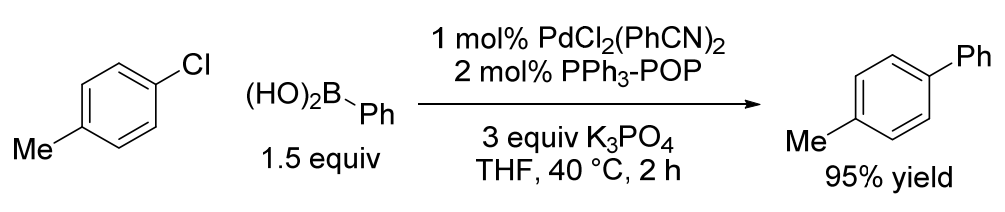

\section{Scheme 29. Suzuki-Miyaura Coupling Catalyzed by a Palladium-POP Complex}


A palladium-POP has also been used to catalyze the widely-used Mizoroki-Heck reaction (Scheme 30). ${ }^{74,117}$ In a convenient synthetic approach, Liu, Mu, and coworkers prepared their catalyst by a Sonogashira coupling between 1,3,5-triethynylbenzene and palladium-complexes bearing bromide-functionalized salen ligands. ${ }^{74}$ The palladium-salen complex catalyzes the incorporation of itself into the polymer, hence, the synthesis requires no separate metalation step. The application of this palladium-POP as catalyst in Suzuki-Miyaura and Mizoroki-Heck reactions was examined. Both aryl iodides and activated aryl bromides could be used as substrates for the reaction with acrylates. In addition, good recyclability of the catalyst was also demonstrated (Scheme 30).

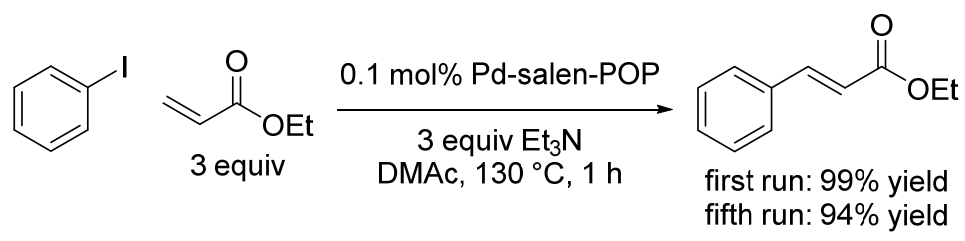

\section{Scheme 30. Mizoroki-Heck Reaction Catalyzed by a Palladium Porous Organic Polymer.}

In 2017, Iwai, Sawamura, and coworkers reported another example of carbon-carbon bond formation, this time through a nickel-catalyzed coupling of aryl pivalates and benzoxazoles (Scheme 31). ${ }^{42}$ The heterogeneous ligand for nickel was made by the same radical polymerization procedure as for their $\mathrm{PPh}_{3}-\mathrm{POP}$ but now using vinyl-functionalized 1,2bis(diphenylphosphino)benzene (dppbz) leading to the polystyrene polymer. The yields were mostly moderate-to-good but in one case $94 \%$ yield was isolated. 


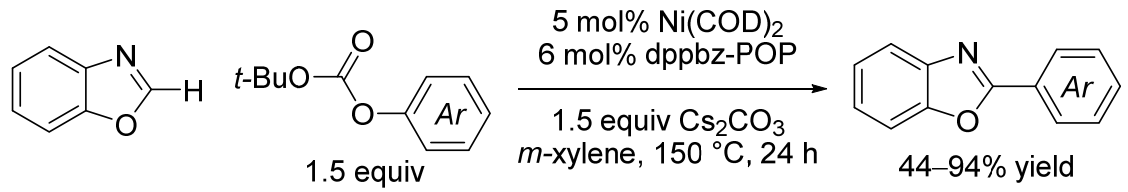

\section{Scheme 31. Nickel-Catalyzed Coupling of Aryl Pivalates and Benzoxazole}

Iwai, Sawamura, and coworkers also demonstrated that their porous organic polymer containing dppbz-ligand sites (dppbz-POP) could be used for aminations of aryl chlorides, which is a another frequently used transformation in medicinal chemistry. ${ }^{42,114}$ By using dppbz-POP in combination with $\mathrm{Ni}(\mathrm{COD}) 2$, high yields of the aniline products were obtained for a range of primary amines as well as both electron rich and electron poor aryl chlorides (Scheme 32a). Furthermore, in one case, it was demonstrated that as little as $0.1 \mathrm{~mol} \%$ nickel and $0.2 \mathrm{~mol} \%$ dppbz-POP is sufficient to provide 93\% yield of the desired aniline (Scheme 32b). The heterogeneous nature of catalysis was supported by a hot filtration test and a mercury poisoning experiment. However, slow leaching of nickel was found to hamper multiple reuses of the Nidppbz-POP catalyst (decrease from $90 \%$ to $73 \%$ yield over four consecutive reactions). An interesting feature of the various methodologies developed by Sawamura and coworkers is the use of in situ formation of metal-ligand complexes - a method which mirrors the one used in homogeneous catalysis. This approach allows for expedited screening of combinations of metal precursors and ligands. Another example of carbon-nitrogen bond formation (Chan-Lam coupling) has been reported; however, the applied catalyst is better described as a crystalline COF rather than an amorphous, porous organic polymer. ${ }^{118}$ 
a) Substrate Scope

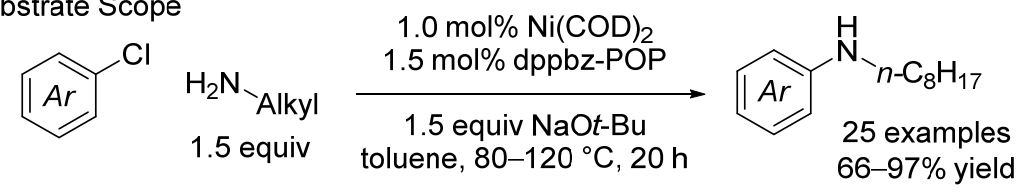

b) Low Catalyst Loading

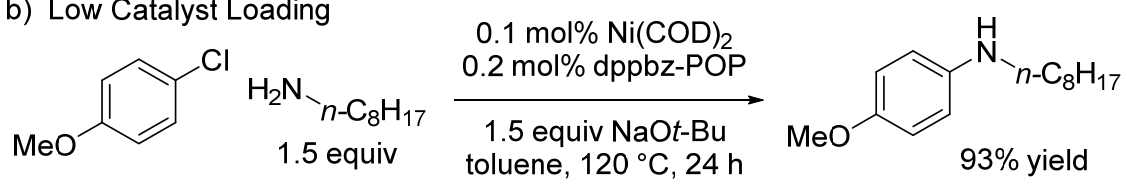

\section{Scheme 32. Nickel-Catalyzed Amination of Aryl Chlorides (a) displays Broad Substrate Scope, and (b) can be performed with Low Catalyst Loading.}

Porous organic polymers containing an active metal center have also found use for the formation of carbon-oxygen bonds. In 2013, Shi, Xiao, and coworkers reported the use of a Cu-POP as catalyst for Ullmann coupling between phenols and aryl halides (Scheme 33) ${ }^{89}$ The catalyst was made by installing iminopyridine (IP) ligand motifs on a porous polydivinylbenzene polymer followed by metalation with $\mathrm{Cu}(\mathrm{OAc})_{2}$. Seven different substrate combinations of various aryl iodides and phenols were examined, all providing good yields of the desired biaryl ether. Aryl chlorides were unreactive, but a reaction with bromobenzene highlighted the compatibility of these electrophiles. For all the substrates examined, the catalyst could be recycled at least four times without significant loss of yield relative to the first run.

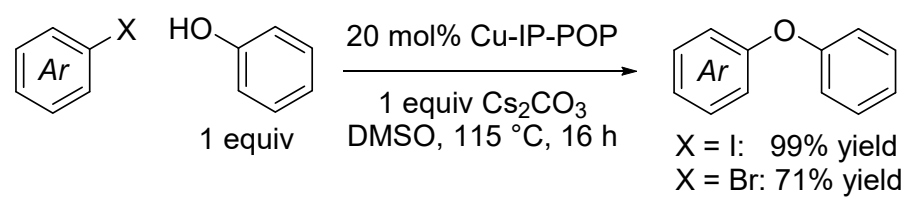




\section{Scheme 33. Cu-IP-POP-Catalyzed Ullmann Coupling for the Formation of Biaryl Ethers (IP $=$ iminopyridine)}

In 2016, Zhu, Ding, and coworkers reported the use of a palladium-POP for alkoxycarbonylation of terminal alkynes with good selectivity for the branched product (Scheme 34). ${ }^{92}$ The catalyst was prepared by radical copolymerization of para-styrene sulfonic acid and a vinylfunctionalized pyridyl-phosphine $\left(\mathrm{PyPPh}_{2}\right)$ followed by metalation with $\mathrm{Pd}(\mathrm{OAc}) 2$. The authors demonstrated that, in the absence of acid additives, the presence of both pyridine and sulfonic acid moieties is crucial for obtaining good activities. A hot filtration experiment supported that the palladium- $\mathrm{PyPPh}_{2}$-POP is operating as a heterogeneous catalyst and ICP-OES also showed very limited palladium leaching. Furthermore, the catalyst could be recycled at least four times with only a minor decrease in activity.

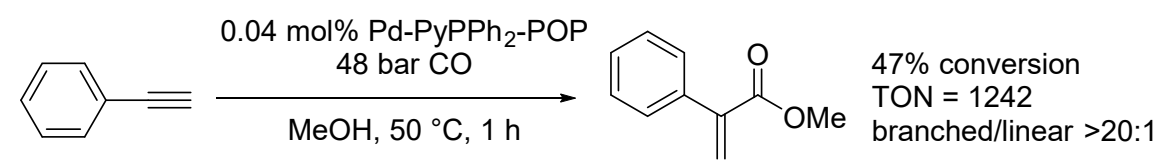

\section{Scheme 34. Alkoxycarbonylation of Terminal Alkynes using a Palladium-PyPPh 2 -POP Catalyst}

\subsection{OXIDATIVE COUPLING REACTIONS}

In addition to coupling reactions between an electrophile and a nucleophile, a few examples of oxidative coupling reactions, i.e. reactions between two nucleophiles, have been reported. 
Although these reactions could be classified as oxidations, we have chosen the classification oxidative coupling reactions since the products often are related to products from coupling reactions. Typically, these reactions involve $\mathrm{C}-\mathrm{H}$ functionalization of one or both coupling partners. At the current state, it has been demonstrated that metal-ligand-POPs can catalyze coupling reactions which functionalize $\mathrm{C}(\mathrm{sp})-\mathrm{H}, \mathrm{C}\left(\mathrm{sp}^{2}\right)-\mathrm{H}$, and $\mathrm{C}\left(\mathrm{sp}^{3}\right)-\mathrm{H}$ bonds (Table 5).

Table 5. Overview of Oxidative Coupling Reactions with Metal-POP Catalysts.

\begin{tabular}{llll}
\hline Entry & Reaction & Catalyst & Reference \\
\hline 1 & Alkyne C-H homocoupling & Cu-Phen-POP & 35 \\
& - & Au-PPh $_{3}$-POP & 108 \\
2 & Aryl C-H homocoupling & Pd-OAc-POP & 119 \\
3 & Aryl C-H acetoxylation & Pd-NHC-POP & 120 \\
4 & Alkyl C-H arylation & Pd-Pyr-POP & 121 \\
\hline
\end{tabular}

In 2013, Meng, Chen, Xiao, and coworkers demonstrated the use of a copper-containing POP for the oxidative coupling of terminal alkynes using $\mathrm{O}_{2}$ as oxidant, i.e. Glaser coupling (Scheme 35). ${ }^{35}$ Through the use of vinyl acrylamide-functionalized phenanthroline building blocks, this ligand was incorporated into a polymer by radical polymerization with 1,4-divinylbenzene. In a subsequent step, $\mathrm{Cu}(\mathrm{OAc})_{2}$ was ligated to the phenanthroline sites. The obtained single-site $\mathrm{Cu}-$ Phen-POP was successfully applied as a catalyst for the oxidative coupling of terminal alkynes and it was demonstrated that the catalyst could be recycled nine times without loss of yield (97\% in $10^{\text {th }}$ run). In addition, ICP showed no copper in the filtrate after a reaction.

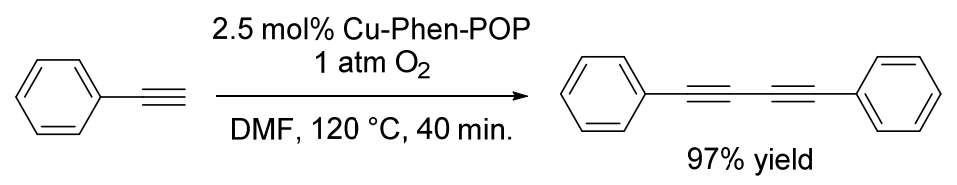




\section{Scheme 35. Glaser Coupling using a Copper-Phen-POP Catalyst}

Later, Ma, Shi, and coworkers reported that the Au-PPh $3-\mathrm{POP}$, which they used for Lewis acid catalysis (Scheme 15 and corresponding text), could also effectively catalyze the oxidative coupling of two terminal alkynes using $\mathrm{PhI}(\mathrm{OAc})_{2}$ as oxidant. ${ }^{108}$ A small decrease in activity was observed during four consecutive reactions with the same catalyst.

Oxidative homocoupling of benzene, toluene, and xylenes catalyzed by a palladium-POP was reported last year by Yan, Wang, and coworkers. ${ }^{119}$ Radical polymerization of maleic anhydride, sodium para-styrene sulfonate, and 1,4-divinylbenzene, followed by hydrolysis, afforded a polymer containing both carboxylic and sulfonic acids. An ensuing ion exchange with $\mathrm{Pd}(\mathrm{OAc})_{2}$ produced the palladium-OAc-POP catalyst. By using $0.036 \mathrm{~mol} \%$ of Pd-OAc-POP, biphenyl was produced in $26 \%$ yield after 4 hours (Scheme 36 ). The reaction was stopped at partial conversion and the selectivity for the biphenyl product over phenol was high. Attempts to reuse the Pd-OAcPOP twice showed a small decrease in activity which was accompanied by a significant loss of palladium content, as detected by ICP of the reused polymer.

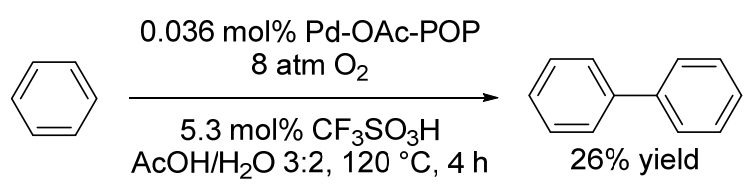

Scheme 36. Oxidative Homocoupling of Benzene using a Pd-OAc-POP 
Another example of palladium-catalyzed oxidative C-H functionalization also appeared in 2017 when Wendt and coworkers reported on the acetoxylation of aromatic compounds. ${ }^{120}$ The catalyst was accessed by radical polymerization of 1,4-divinylbenzene and NHC-palladium complexes containing vinyl moieties on the NHC-ligand. In the presence of the oxidant $\mathrm{PhI}(\mathrm{OAc})_{2}$, biphenyl and other simple unfunctionalized aromatic compounds could be acetoxylated (Scheme 37). A hot filtration experiment indicated heterogeneous nature of catalysis. In addition, similar kinetic profiles were observed for four consecutive runs demonstrating that the catalyst is highly recyclable. Interestingly, the same regioselectivity was observed with palladium-NHC-POP catalysis and with a related homogeneous palladium catalyst which suggests that the two systems have a similar mode of operation.

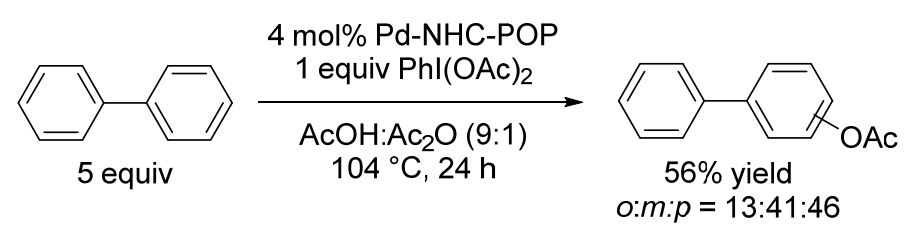

\section{Scheme 37. Aryl C-H Acetoxylation Catalyzed by a Palladium-NHC-POP}

In 2016, a rare example in heterogeneous catalysis of oxidative coupling by activation of a $\mathrm{C}\left(\mathrm{sp}^{3}\right)-\mathrm{H}$ bond was demonstrated by Yu, Jones, and coworkers (Scheme 38$) .{ }^{121} \mathrm{The}$ transformation was catalyzed by palladium(II) bound to a 2-methylpyridine ligand in the porous organic polymer. The developed conditions display good functional group tolerance. Although the first catalyst recycling gave essentially the same result as the fresh catalyst, complete loss of activity was observed when the catalyst was reused a second time. 


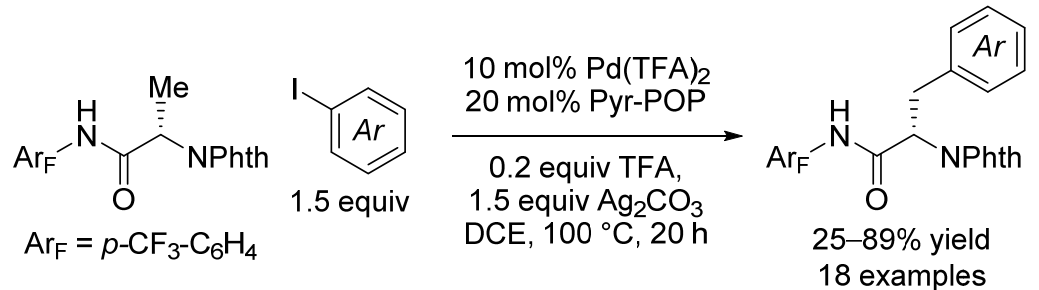

\section{Scheme 38. Oxidative C(sp $\left.{ }^{3}\right)-H$ Arylation Catalyzed by a Palladium-Pyr-POP $($ TFA $=$ trifluoroacetic acid)}

\subsection{PHOTOCATALYSIS}

The ability of a combination of visible light and a photocatalysts to drive known and novel transformations under mild conditions have received considerable interest in recent years. ${ }^{122,123,124}$ Although certain organic molecules, minerals, and first row transition-metal complexes also display photocatalytic properties, at the present, the most widely-used photocatalysts for organic synthesis are based on precious metals, especially ruthenium and iridium. Even though the catalyst loadings are often low, facile recycling and reuse the expensive metal catalysts would be a significant advantage. In this regard, a few reports have appeared on heterogenization of ruthenium- and iridium-based photocatalysts by incorporation into a porous organic polymer and their use in organic synthesis (Table 6).

Table 6. Overview of Photocatalysis Reactions using Metal-POP Catalysts. 


\begin{tabular}{llll}
\hline Entry & Reaction & Catalyst & Reference \\
\hline 1 & Aza-Henry reaction & Ir-ppy-POP & 51,84 \\
& - & Ru-bpy-POP & 31,51 \\
& - & Ru-dipyrrin-POP & 68 \\
2 & Coupling of tetrahydroisoquino- & Ir-ppy-POP & 39 \\
& lines and P-H nucleophiles & & \\
\hline
\end{tabular}

In 2011, Lin and coworkers published the synthesis and use of two POP-photocatalysts. ${ }^{51} \mathrm{~A}$ cobalt-catalyzed cyclotrimerization between a linker bearing four terminal alkynes and bisalkyne-functionalized $\mathrm{Ru}(\mathrm{bpy}){ }_{3} \mathrm{Cl}_{2}$ or bis-alkyne-functionalized $\operatorname{Ir}(\mathrm{ppy})_{2}$ (bpy)Cl afforded the heterogeneous photocatalysts. Although the Ru-bpy-POP was also used for $\alpha$-oxygenation of an imine (one example) and addition of bromomalonates to nucleophilic heterocycles (two examples), most of the study focused on aza-Henry reactions (Scheme 39). Both catalysts increased the rate significantly compared to the background reaction for the aza-Henry reaction between different tetrahydroisoquinolines and nitromethane or nitroethane. The ruthenium catalyst could be recycled at least four times with only minimal decrease in conversion. In addition, a filtration experiment supported the heterogeneous nature of the photocatalyst. In general, the most frequently examined reaction with POP-photocatalysts is the aza-Henry reaction. ${ }^{31,68,84}$

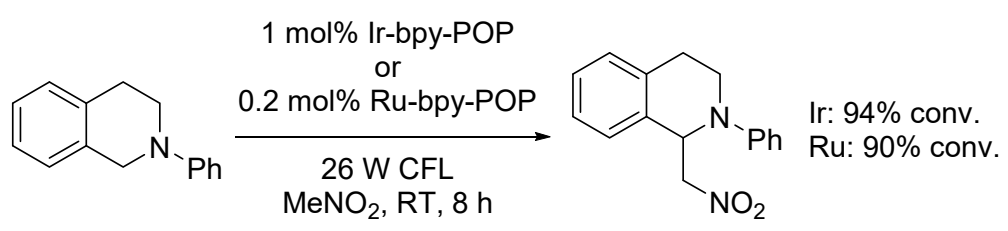

Scheme 39. Photocatalytic Aza-Henry Reaction using Ruthenium- and Iridium-bpy-POPs 
In 2014, Kobayashi and coworker reported a transformation related to the photocatalyzed azaHenry reaction. ${ }^{39}$ Instead of addition of a carbon nucleophile to tetrahydroisoquinolines, different phosphorus-based nucleophiles were utilized (Scheme 40). The catalyst was made by radical polymerization of different acrylates and iridium complexes carrying vinyl moieties on the ligands. High yields were obtained for a number of substrates and it was demonstrated that the catalyst could be recycled four times with only minimal decrease in yield and iridium leaching.

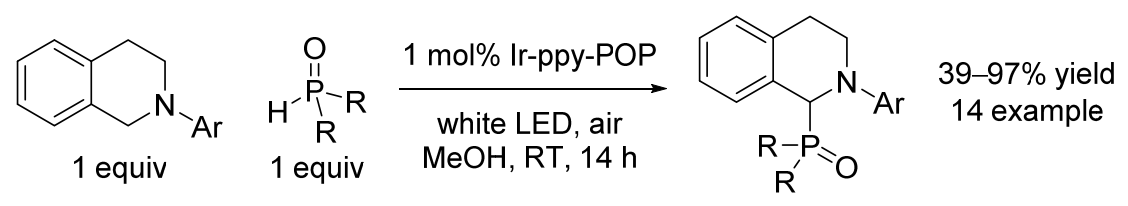

\section{Scheme 40. Photocatalytic Coupling of Tetrahydroisoquinolines and P-H Nucleophiles}

In addition to reactions involving addition of nucleophiles to an oxidized form of tetrahydroisoquinoline, examples of photocatalytic dehalogenation of an $\alpha$-bromo ketone and oxidative imine formation have also been described but only very limited substrate scope was reported. $^{31}$

\subsection{MISCELLANEOUS}

The reactions in this section either fit more than one of the five main categories listed above or they do not fit into the main categories. These transformations include borylation, hydroboration, hydroformylation, ethylene dimerization, and hydrogen-borrowing reactions (Table 7). 
Table 7. Overview of Miscellaneous Reactions using Metal-POP Catalysts.

\begin{tabular}{|c|c|c|c|}
\hline Entry & Reaction & Catalyst & Reference \\
\hline \multirow[t]{2}{*}{1} & $\mathrm{C}\left(\mathrm{sp}^{3}\right)-\mathrm{H}$ borylation & $\mathrm{Ir}-\mathrm{PPh}_{3}-\mathrm{POP}$ & 96 \\
\hline & - & $\mathrm{Ru}-\mathrm{PPh}_{3}-\mathrm{POP}$ & 96 \\
\hline 2 & $\begin{array}{l}\text { Hydroboration of aliphatic } \\
\text { alkenes }\end{array}$ & Cu-dppbz-POP & 42 \\
\hline \multirow[t]{4}{*}{3} & Alkene hydroformylation & Rh-dppe-POP & 95 \\
\hline & - & $\mathrm{Rh}-\mathrm{PPh}_{3}-\mathrm{POP}$ & $30,40,125$ \\
\hline & - & Rh-PPh $/$ Xantphos-POP & 36 \\
\hline & - & Rh-phosphine/phoshite-POP & 32,128 \\
\hline 4 & Ethylene dimerization & Ni-bpy-POP & 129 \\
\hline 5 & Hydrogen-borrowing reaction & Ir-IMes-POP & 73 \\
\hline
\end{tabular}

Sawamura and coworkers reported rare examples of borylation of $\mathrm{C}\left(\mathrm{sp}^{3}\right)-\mathrm{H}$ facilitated by a heterogeneous catalyst. ${ }^{96}$ Using a directing group strategy, they demonstrated that an iridium$\mathrm{PPh}_{3}$-POP catalyst could effectively install a pinacolatoboronic ester group on 2-pentyl-pyridine (Scheme 41a). Furthermore, borylation of $\mathrm{N}$-adjacent $\mathrm{C}\left(\mathrm{sp}^{3}\right)-\mathrm{H}$ using a rhodium- $\mathrm{PPh}_{3}-\mathrm{POP}$ was also included (Scheme 41b).

a)
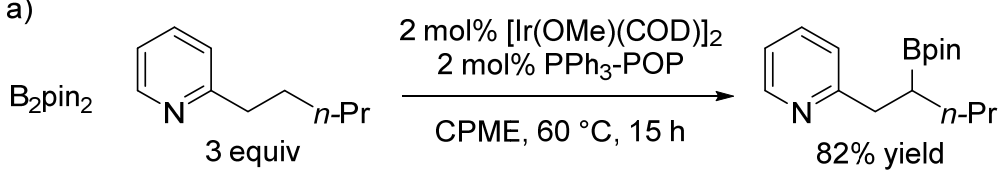

b)<smiles>CN1CCN(C)N(C)C1=O</smiles><smiles>CN1CCCN(Cc2ccccc2)C1=O</smiles>

Scheme 41. Borylation of C(sp $\left.{ }^{3}\right)-H$ Catalyzed by (a) Ir-PPh $-P O P$ and (b) Rh-PPh $-P O P$ 
In 2017, Sawamura and coworkers reported another method for incorporating boronfunctionalities into organic molecules using a metal-containing porous organic polymer catalyst. Metalation of their dppbz-POP (dppbz = 1,2-bis(diphenylphosphino)benzene) with $\mathrm{Cu}(\mathrm{OAc}) 2$ afforded a highly active catalyst for hydroboration of both mono-substituted and 1,1disubstituted alkenes (Scheme 42), thus adding another transformation to this versatile heterogeneous ligand (see amination and cross-coupling reaction in Section 3.4$).{ }^{42}$ Furthermore, it was demonstrated that $\mathrm{CoI}_{2}$ could be used as metal source for hydroboration of $\alpha$-methylstyrene. Interestingly, for the heterogeneous cobalt-based system, 63\% yield was obtained while the analogous homogeneous $\mathrm{CoI}_{2} / \mathrm{dppbz}$ system afforded none of the hydroboration product.

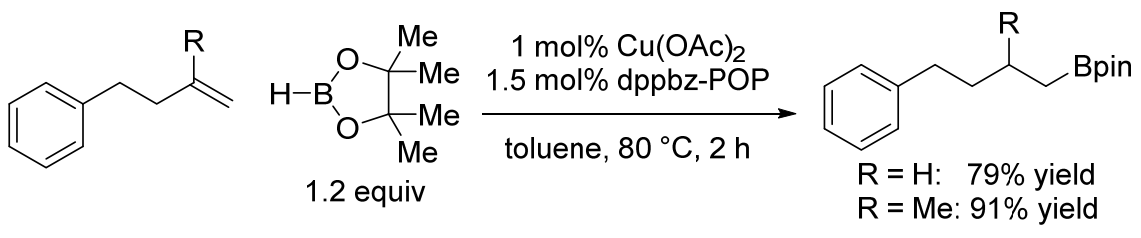

\section{Scheme 42. Hydroboration of Aliphatic Alkenes using a Copper-dppbz-POP Catalyst}

Xiao and coworkers published a thorough investigation of alkene hydroformylation catalyzed by a rhodium-dppe-POP made by radical polymerization of vinyl-functionalized 1,2bis(diphenylphosphino)ethane (dppe) and metalation with $\mathrm{Rh}(\mathrm{CO})_{2}(\mathrm{acac}) .{ }^{95}$ This catalyst, containing a 1:10 metal to bis-phosphine ratio, was able to provide excellent yields and selectivities for the aldehyde products (Scheme 43). The regioselectivity (linear vs. branched) was highly substrate dependent. Among the various parameters investigated was the influence of ligand density in the polymer. It was found that the highest ligand density led to the highest 
activity and selectivity, which was also observed in a later study on the same reaction. ${ }^{125}$ Finally, it was demonstrated that a fresh catalyst batch and a catalyst that had been used in 10 recycles provided essentially identical kinetic profiles. The maintained catalytic activity highlights the excellent recyclability of the Rh-dppe-POP catalyst in the hydroformylation reaction.

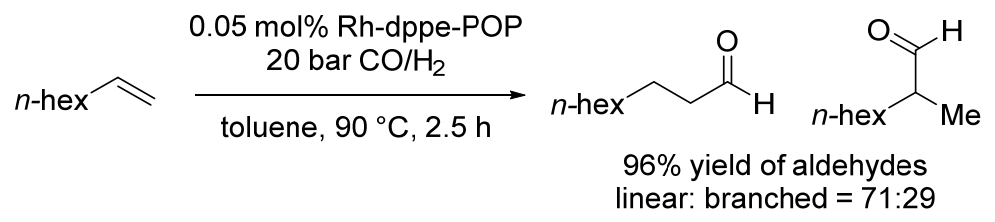

\section{Scheme 43. Hydroformylation of 1-Octene with a Rh-dppe-POP Catalyst}

A few additional reports on the use of rhodium-POPs for hydroformylation of alkenes have also appeared. In 2014, Meng, Ding, Xiao, and coworkers reported a triphenylphosphine-based polymer catalyst and later Yan, Ding, and coworkers utilized a mixed triphenylphosphine/Xantphos polymer. ${ }^{30,36}$ While all the above methodologies rely on phosphine-POPs, Yan, Ding, and coworkers made a mixed phosphine/phosphite polymer which was also used for hydroformylation of various terminal and internal olefins. ${ }^{32}$

Continuous flow production have received considerable attention within recent years as an advantageous production method for the chemical industry. ${ }^{126,127}$ Interestingly, Ding, Liu, and coworkers demonstrated the successful application of a $\mathrm{Rh}-\mathrm{PPh}_{3}-\mathrm{POP}$ for continuous flow hydroformylation of ethylene in a fixed-bed reactor. ${ }^{40}$ During the stability test, a TOF of approximately $4500 \mathrm{~h}^{-1}$ was maintained over 1000 hours on stream with a corresponding $96 \%$ selectivity for propanal. Minimal leaching was detected during the stability test as the rhodium 
content only decreased from $0.125 \mathrm{wt} \%$ in the fresh catalyst to $0.121 \mathrm{wt} \%$ at the end of the test.

Further catalyst development lead to a highly active catalyst for hydroformylation of 1-butene. ${ }^{128}$ It was demonstrated that a rhodium catalyst on a mixed phosphine/phosphite porous organic polymer afforded a TOF of $11,200 \mathrm{~h}^{-1}$ with $94 \%$ selectivity for pentanal and a linear:branched ratio of 62:1 during 24 hours on stream. After 300 hours on stream a small decrease in activity to $5400 \mathrm{~h}^{-1}$ was observed, however, this was not accompanied by any significant metal leaching.

In 2017, Farha, Lee, and coworkers reported that ethylene dimerization could be catalyzed by a nickel-bpy-POP (Scheme 44). ${ }^{129}$ The catalyst was made by a copper-catalyzed click reaction between alkyne-functionalized bipyridine and azide-containing linkers, followed by metalation with $\mathrm{NiCl}_{2}$. The best selectivity for butene was obtained at $0{ }^{\circ} \mathrm{C}$ and 5 bar ethylene pressure. During four consecutive reactions with the same catalyst a ten-fold decrease in activity was observed. The deactivation was caused by significant formation of polyethylene on the catalyst.

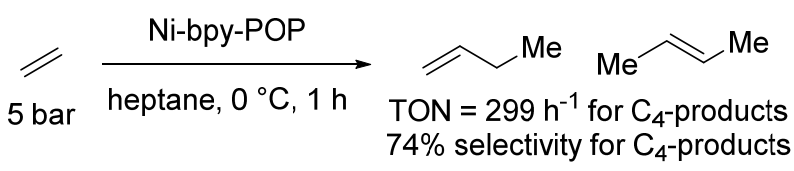

\section{Scheme 44. Ethylene Dimerization Catalyzed by a Ni-bpy-POP}

In 2016, Iglesias, Sanchez, and coworkers reported an example of a hydrogen-borrowing reaction. ${ }^{73}$ The reaction was catalyzed by an iridium-IMes-POP (IMes = 1,3-bis-(2,4,6trimethylphenyl)imidazol-2-ylidene) and proceeds through removal of $\mathrm{H}_{2}$ from benzyl alcohol, condensation with an aniline, and then re-addition of $\mathrm{H}_{2}$ to the formed imine (Scheme 45). 
Overall this is a redox-neutral reaction facilitated by removal and recycling of $\mathrm{H}_{2}$. It was demonstrated that the catalyst could be recycled although a steady decrease in selectivity was observed beyond the fourth recycling. Tests for catalytic activity and for iridium leaching in the filtrate of a filtered reaction mixture indicated that the catalysis was heterogeneous in nature.

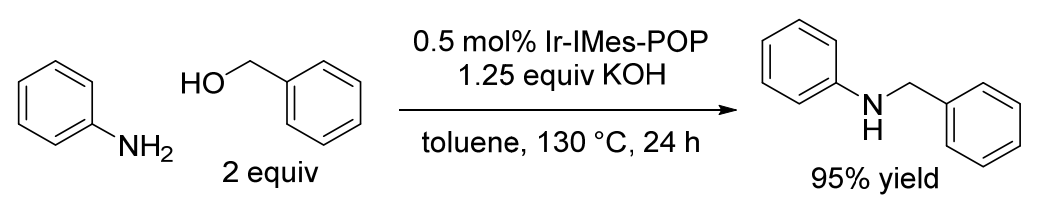

\section{Scheme 45. Hydrogen-Borrowing Reaction Catalyzed by an Iridium-IMes-POP}

\section{OUTLOOK}

Heterogeneous catalysis is typically preferred by the chemical industry due to advantages such as facile removal and recycling of the catalyst material. However, designing heterogeneous catalysts which contain only one type of active site is a great challenge. Unfortunately, the presence of different catalytically active sites can lead to decreased product selectivity. In contrast, organometallic complexes used for homogeneous catalysis contains only one type of active metal center. The incorporation of organometallic catalysts into porous organic polymers combines the advantages of both catalyst classes as it affords heterogeneous catalysts which allows stringent control over the active site analogously to homogeneous catalysis. Accordingly, metal-POP catalysts are expected to be well-suited for industrial applications. While the reactions highlighted in this review clearly demonstrates the large potential of this emerging 
field, there are still several challenges to address in order to move from an academic curiosity to a widely applicable tool for organic synthesis and chemical production.

\begin{abstract}
Although examples of many different reaction types catalyzed by metal-POPs have been described here, sometimes only a single example of a reaction type is reported and, in many cases, very limited substrate scope investigation is performed. Expanded examination of substrate scope and limitations would be very useful information for researchers interested in applying the reported reactions, and thus facilitate more widespread use of these catalyst systems. Furthermore, for some industrially relevant reaction classes, such as asymmetric catalysis and $\mathrm{C}-\mathrm{H}$ functionalizations, there are very few reports. Further investigations into these important reaction types would be highly valuable.
\end{abstract}

In spite of the simple conceptual idea of heterogeneous organometallic catalysts, there are examples of differences in activity and distribution of catalyst species between metal-POPs and the analogous homogeneous systems. For example, incorporation of the ligand into a polymer in some cases prevents the formation of resting states where additional ligands are bound to the metal. In general, a better understanding of the catalytic cycles with metal-POP catalyst as well as the differences and potential advantages compared to the analogous homogeneous systems is warranted. In this regard, it is also important to be able to distinguish formation of discrete metalligand-POP complexes versus much less defined catalysts where the metal ions are randomly distributed at different types of ligand sites on a polymer support. These points could be addressed by experimental reaction mechanism elucidation and thorough characterization of the metal-POP catalysts. 
From an industrial point of view, there are several issues to consider. Significant advantages over homogeneous catalytic systems are necessary to justify building block and polymer synthesis. A straightforward comparison can be made based on TOF and TON for the metal-POP catalysts and the corresponding homogeneous catalyst, when data are available. For large scale production of bulk chemicals, these parameters are often decisive. For pharmaceutical production, other aspects could also be relevant such as the facilitation of toxic metal catalyst removal from active pharmaceutical ingredients.

In terms of bulk chemical production, continuous flow reactors are typically preferred over batch reactors. Due to the immobilized nature of the metal complexes in the metal-POPs, they could be well-suited for such applications. Indeed, as presented in this review, a few successful reports on this topic have appeared, however, reports are still scarce and additional research efforts would be beneficial for the chemical industry. One of the key challenges in this field is the development catalysts for a broad range of reactions which maintain activity and selectivity over extended time on stream.

Deactivation is a significant issue for recycling of heterogeneous catalysts as well as for successful applications in continuous flow production. For the majority of reports in this review, metal leaching seems to be a limited issue; nonetheless, catalyst deactivation is still observed upon extended recycling. Only in a few cases have the changes in catalyst material accompanying the deactivation been thoroughly investigated. Further insight into deactivation pathways is necessary for developing more robust catalysts with extended lifetimes. This point should be addressed by detailed analysis and characterization of deactivated catalysts. In fact, the deactivated catalysts should undergo the same scrutiny as the fresh catalyst, for example 
nanoparticle formation in the used catalyst could be examined by TEM as a cause of deactivation despite minimal metal leaching.

Significant advances have been made in the use of metal-ligand-POP catalysts for synthetic organic chemistry and the current state-of-the-art has moved beyond proof-of-principle. However, as listed above, there are still several challenges to address in order to obtain a better understanding of these catalyst systems (e.g., catalytic cycles and deactivation pathways), improve catalyst stability, as well as examine the suitability of these catalysts for real chemical production. Finally, further investigations which target new reaction types and improve substrate scopes are needed for obtaining a broader and more robust foundation for addressing synthetic challenges in the production of fine and bulk chemicals. We hope the overview of reactions presented here will help identify unexplored territory and guide future research efforts to focus on unsolved issues.

\section{AUTHOR INFORMATION}

\section{Corresponding Authors}

* E-mail for S. Kegnæs: skk@kemi.dtu.dk

* E-mail for S. Kramer: sokr@kemi.dtu.dk

\section{Author Contributions}


The manuscript was written through contributions of all authors. All authors have given approval to the final version of the manuscript.

\section{ACKNOWLEDGMENT}

The authors are grateful for funding from the Independent Research Fund Denmark (Grant no. 6111-00237), from Villum fonden (Grant No. 13158) and from Haldor Topsøe A/S.

\section{REFERENCES}

(1) Corma, A. Heterogeneous Catalysis: Understanding for Designing, and Designing for Applications. Angew. Chem., Int. Ed. 2016, 55, 6112-6113.

(2) Kramer, S.; Hejjo, F.; Rasmussen, K. H.; Kegnæs, S. Silylative Pinacol Coupling Catalyzed by Nitrogen-Doped Carbon-Encapsulated Nickel/Cobalt Nanoparticles: Evidence for a Silyl Radical Pathway. ACS Catal. 2018, 8, 754-759.

(3) Thomas, J. M.; Raja, R.; Lewis, D. W. Single-Site Heterogeneous Catalysts. Angew. Chem., Int. Ed. 2005, 44, 6456-6482.

(4) Coperet, C.; Chabanas, M.; Saint-Arroman, R. P.; Basset, J.-M. Homogeneous and Heterogeneous Catalysis: Bridging the Gap through Surface Organometallic Chemistry. Angew. Chem. Int. Ed. 2003, 42, 156-181.

(5) Rovik, A. K.; Klitgaard, S. K.; Dahl, S.; Christensen, C. H.; Chorkendorff, I. Effect of Alloying on Carbon Formation during Ethane Dehydrogenation. Appl. Catal. A Gen. 2009, 
358, 269-278.

(6) Arnal, P. M.; Comotti, M.; Schüth, F. High-Temperature-Stable Catalysts by Hollow Sphere Encapsulation. Angew. Chem. Int. Ed. 2006, 45, 8224-8227.

(7) Laursen, A. B.; Højholt, K. T.; Lundegaard, L. F.; Simonsen, S. B.; Helveg, S.; Schüth, F.; Paul, M.; Grunwaldt, J. D.; Kegnæs, S.; Christensen, C. H.; Egeblad, K. Substrate SizeSelective Catalysis with Zeolite-Encapsulated Gold Nanoparticles. Angew. Chem., Int. Ed. 2010, 49, 3504-3507.

(8) Joo, S. H.; Park, J. Y.; Tsung, C.; Yamada, Y.; Yang, P. Thermally Stable Pt-Mesoporous Silica Core-Shell Nanocatalysts for High Temperature Reactions. Nat. Mater. 2008, 8, 126131.

(9) Ren, N.; Yang, Y. H.; Shen, J.; Zhang, Y. H.; Xu, H. L.; Gao, Z.; Tang, Y. Novel, Efficient Hollow Zeolitically Microcapsulized Noble Metal Catalysts. J. Catal. 2007, 251, 182-188.

(10) Mielby, J.; Abildstrøm, J. O.; Wang, F.; Kasama, T.; Weidenthaler, C.; Kegnæs, S. Oxidation of Bioethanol Using Zeolite-Encapsulated Gold Nanoparticles. Angew. Chem., Int. Ed. 2014, 53, 12513-12516.

(11) Wang, F.; Mielby, J.; Richter, F. H.; Wang, G.; Prieto, G.; Kasama, T.; Weidenthaler, C.; Bongard, H. J.; Kegnæs, S.; Fürstner, A.; Schüth, F. A Polyphenylene Support for Pd Catalysts with Exceptional Catalytic Activity. Angew. Chem., Int. Ed. 2014, 53, 8645-8648.

(12) Astruc, D.; Lu, F.; Aranzaes, J. R. Nanoparticles as Recyclable Catalysts: The Frontier between Homogeneous and Heterogeneous Catalysis. Angew. Chem., Int. Ed. 2005, 44, $7852-7872$.

(13) Witham, C. A.; Huang, W.; Tsung, C.-K.; Kuhn, J. N.; Somorjai, G. A.; Toste, F. D. Converting Homogeneous to Heterogeneous in Electrophilic Catalysis Using Monodisperse 
Metal Nanoparticles. Nat. Chem. 2009, 2, 36-41.

(14) Sun, Q.; Dai, Z.; Meng, X.; Xiao, F.-S. Porous Polymer Catalysts with Hierarchical Structures. Chem. Soc. Rev. 2015, 44, 6018-6034.

(15) Kaur, P.; Hupp, J. T.; Nguyen, S. T. Porous Organic Polymers in Catalysis: Opportunities and Challenges. ACS Catal. 2011, 1, 819-835.

(16) Zhang, Y.; Riduan, S. N. Functional Porous Organic Polymers for Heterogeneous Catalysis. Chem. Soc. Rev. 2012, 41, 2083-2094.

(17) Dong, K.; Sun, Q.; Meng, X.; Xiao, F.-S. Strategies for the Design of Porous Polymers as Efficient Heterogeneous Catalysts: From Co-Polymerization to Self-Polymerization. Catal. Sci. Technol. 2017, 7, 1028-1039.

(18) Copéret, C.; Comas-Vives, A.; Conley, M. P.; Estes, D. P.; Fedorov, A.; Mougel, V.; Nagae, H.; Núnez-Zarur, F.; Zhizhko, P. A. Surface Organometallic and Coordination Chemistry toward Single-Site Heterogeneous Catalysts: Strategies, Methods, Structures, and Activities. Chem. Rev. 2016, 116, 323-421.

(19) Tan, L.; Tan, B. Hypercrosslinked Porous Polymer Materials: Design, Synthesis, and Applications. Chem. Soc. Rev. 2017, 46, 3322-3356.

(20) Xu, Y.; Jin, S.; Xu, H.; Nagai, A.; Jiang, D. Conjugated Microporous Polymers: Design, Synthesis and Application. Chem. Soc. Rev. 2013, 42, 8012-8031.

(21) Das, S.; Heasman, P.; Ben, T.; Qiu, S. Porous Organic Materials: Strategic Design and Structure-Function Correlation. Chem. Rev. 2017, 117, 1515-1563.

(22) Tan, L.; Tam, B. Hypercrosslinked porous polymer materials: design, synthesis, and applications. Chem. Soc. Rev. 2017, 46, 3322-3356.

(23) Wang, W.; Zhou, M.; Yuan, D. Carbon dioxide capture in amorphous porous organic 
polymers. J. Mater. Chem. A. 2017, 5, 1334-1347.

(24) Unterlass, M. M.; Ando, S.; Tsui, O. K. C. Polymer Characterization and Morphology. Macromol. Chem. Phys. 2018, 219, 1800001.

(25) Lee, I.; Joo, J. B.; Yin, Y.; Zaera, F. A Yolk@shell Nanoarchitecture for Au/ $/ \mathrm{TiO}_{2}$ Catalysts. Angew. Chem., Int. Ed. 2011, 50, 10208-10211.

(26) Gorbanev, Y. Y.; Kegnæs, S.; Hanning, C. W.; Hansen, T. W.; Riisager, A. Acetic Acid Formation by Selective Aerobic Oxidation of Aqueous Ethanol over Heterogeneous Ruthenium Catalysts. ACS Catal. 2012, 2, 604-612.

(27) Xu, Q.; Kharas, K. C.; Croley, B. J.; Datye, A. K. The Sintering of Supported Pd Automotive Catalysts. ChemCatChem 2011, 3, 1004-1014.

(28) Abildstrøm, J. O.; Kegnæs, M.; Hytoft, G.; Mielby, J.; Kegnæs, S. Synthesis of Mesoporous Zeolite Catalysts by in Situ Formation of Carbon Template over Nickel Nanoparticles. Microporous Mesoporous Mater. 2016, 225, 232-237.

(29) Wang, X.; Lu, S.; Li, J.; Liu, Y.; Li, C. Conjugated Microporous Polymers with Chiral BINAP Ligand Built-in as Efficient Catalysts for Asymmetric Hydrogenation. Catal. Sci. Technol. 2015, 5, 2585-2589.

(30) Sun, Q.; Jiang, M.; Shen, Z.; Jin, Y.; Pan, S.; Wang, L.; Meng, X.; Chen, W.; Ding, Y.; Li, J.; Xiao, F.-S. Porous Organic Ligands (POLs) for Synthesizing Highly Efficient Heterogeneous Catalysts. Chem. Commun. 2014, 50, 11844-11847.

(31) Wang, J.-L.; Wang, C.; DeKrafft, K. E.; Lin, W. Cross-Linked Polymers with Exceptionally High Ru(bipy) $3^{2+}$ Loadings for Efficient Heterogeneous Photocatalysis. ACS Catal. 2012, 2, 417-424.

(32) Li, C.; Xiong, K.; Yan, L.; Jiang, M.; Song, X.; Wang, T.; Chen, X.; Zhan, Z.; Ding, Y. 
Designing Highly Efficient Rh/CPOL-bp\&PPh ${ }_{3}$ Heterogenous Catalysts for Hydroformylation of Internal and Terminal Olefins. Catal. Sci. Technol. 2016, 6, 21432149.

(33) Sun, Q.; Zhu, L. F.; Sun, Z. H.; Meng, X. J.; Xiao, F. S. Porous Polymer Supported Palladium Catalyst for Cross Coupling Reactions with High Activity and Recyclability. Science China Chemistry 2012, 55, 2095-2103.

(34) Wang, T.; Lyu, Y.; Xiong, K.; Wang, W.; Zhang, H.; Zhan, Z.; Jiang, Z.; Ding, Y. Chiral BINAP-Based Hierarchical Porous Polymers as Platforms for Efficient Heterogeneous Asymmetric Catalysis. Cuihua Xuebao/Chinese J. Catal. 2017, 38, 890-898.

(35) Sun, Q.; Lv, Z.; Du, Y.; Wu, Q.; Wang, L.; Zhu, L.; Meng, X.; Chen, W.; Xiao, F. S. Recyclable Porous Polymer-Supported Copper Catalysts for Glaser and Huisgen 1,3-Diolar Cycloaddition Reactions. Chem. Asian J. 2013, 8, 2822-2827.

Li, C.; Sun, K.; Wang, W.; Yan, L.; Sun, X.; Wang, Y.; Xiong, K.; Zhan, Z.; Jiang, Z.; Ding, Y. Xantphos Doped Rh/POPs-PPh3catalyst for Highly Selective Long-Chain Olefins Hydroformylation: Chemical and DFT Insights into Rh Location and the Roles of Xantphos and $\mathrm{PPh}_{3}$. J. Catal. 2017, 353, 123-132.

(37) Dai, Z.; Sun, Q.; Chen, F.; Pan, S.; Wang, L.; Meng, X.; Li, J.; Xiao, F. S. Enhancement of Catalytic Activity in Epoxide Hydration by Increasing the Concentration of Cobalt(III)/Salen in Porous Polymer Catalysts. ChemCatChem 2016, 8, 812-817.

Dai, Z.; Sun, Q.; Liu, X.; Bian, C.; Wu, Q.; Pan, S.; Wang, L.; Meng, X.; Deng, F.; Xiao, F. S. Metalated Porous Porphyrin Polymers as Efficient Heterogeneous Catalysts for Cycloaddition of Epoxides with $\mathrm{CO}_{2}$ under Ambient Conditions. J. Catal. 2016, 338, 202209. 
(39) Yoo, W.-J.; Kobayashi, S. Efficient Visible Light-Mediated Cross-Dehydrogenative Coupling Reactions of Tertiary Amines Catalyzed by a Polymer-Immobilized IridiumBased Photocatalyst. Green Chem. 2014, 16, 2438-2442.

(40) Jiang, M.; Yan, L.; Ding, Y.; Sun, Q.; Liu, J.; Zhu, H.; Lin, R.; Xiao, F.; Jiang, Z.; Liu, J. Ultrastable 3V-PPh 3 Polymers Supported Single Rh Sites for Fixed-Bed Hydroformylation of Olefins. J. Mol. Catal. A Chem. 2015, 404-405, 211-217.

(41) Dai, Z.; Sun, Q.; Liu, X.; Guo, L.; Li, J.; Pan, S.; Bian, C.; Wang, L.; Hu, X.; Meng, X.; Zhao, L; Deng, F.; Xiao, F.-S. A Hierarchical Bipyridine-Constructed Framework for Highly Efficient Carbon Dioxide Capture and Catalytic Conversion. ChemSusChem 2017, 10, 1186-1192.

(42) Iwai, T.; Harada, T.; Shimada, H.; Asano, K.; Sawamura, M. A Polystyrene-Cross-Linking Bisphosphine: Controlled Metal Monochelation and Ligand-Enabled First-Row Transition Metal Catalysis. ACS Catal. 2017, 7, 1681-1692.

(43) Weston, M. H.; Farha, O. K.; Hauser, B. G.; Hupp, J. T.; Nguyen, S. T. Synthesis and Metalation of Catechol-Functionalized Porous Organic Polymers. Chem. Mater. 2012, 24, $1292-1296$.

(44) Tanabe, K. K.; Siladke, N. A.; Broderick, E. M.; Kobayashi, T.; Goldston, J. F.; Weston, M. H.; Farha, O. K.; Hupp, J. T.; Pruski, M.; Mader, E. A.; Johnson, M. J. A.; Nguyen, S. T. Stabilizing Unstable Species through Single-Site Isolation: A Catalytically Active $\mathrm{Ta}^{\mathrm{V}}$ Trialkyl in a Porous Organic Polymer. Chem. Sci. 2013, 4, 2483-2489.

(45) Totten, R. K.; Weston, M. H.; Park, J. K.; Farha, O. K.; Hupp, J. T.; Nguyen, S. T. Catalytic Solvolytic and Hydrolytic Degradation of Toxic Methyl Paraoxon with La(catecholate)Functionalized Porous Organic Polymers. ACS Catal. 2013, 3, 1454-1459. 
(46) Camacho-Bunquin, J.; Siladke, N. A.; Zhang, G.; Niklas, J.; Poluektov, O. G.; Nguyen, S. T.; Miller, J. T.; Hock, A. S. Synthesis and Catalytic Hydrogenation Reactivity of a Chromium Catecholate Porous Organic Polymer. Organometallics 2015, 34, 947-952.

(47) Kraft, S. J.; Sánchez, R. H.; Hock, A. S. A Remarkably Active Iron Catecholate Catalyst Immobilized in a Porous Organic Polymer. ACS Catal. 2013, 3, 826-830.

(48) Tanabe, K. K.; Ferrandon, M. S.; Siladke, N. A.; Kraft, S. J.; Zhang, G.; Niklas, J.; Poluektov, O. G.; Lopykinski, S. J.; Bunel, E. E.; Krause, T. R.; Miller, J. T.; Hock, A. S.; Nguyen, S. T. Discovery of Highly Selective Alkyne Semihydrogenation Catalysts Based on First-Row Transition-Metallated Porous Organic Polymers. Angew. Chem., Int. Ed. 2014, 53, 12055-12058.

(49) Camacho-Bunquin, J.; Ferrandon, M.; Das, U.; Dogan, F.; Liu, C.; Larsen, C.; Platero-Prats, A. E.; Curtiss, L. A.; Hock, A. S.; Miller, J. T.; Nguyen, S. T.; Marshall, C. L.; Delferro, M.; Stair, P. C. Supported Aluminum Catalysts for Olefin Hydrogenation. ACS Catal. 2017, 7, 689-694.

(50) Ma, L.; Wanderley, M. M.; Lin, W. Highly Porous Cross-Linked Polymers for Catalytic Asymmetric Diethylzinc Addition to Aldehydes. ACS Catal. 2011, 1, 691-697.

(51) Xie, Z.; Wang, C.; DeKrafft, K. E.; Lin, W. Highly Stable and Porous Cross-Linked Polymers for Efficient Photocatalysis. J. Am. Chem. Soc. 2011, 133, 2056-2059.

(52) Gunasekar, G. H.; Park, K.; Ganesan, V.; Lee, K.; Kim, N. K.; Jung, K. D.; Yoon, S. A Covalent Triazine Framework, Functionalized with Ir/N-Heterocyclic Carbene Sites, for the Efficient Hydrogenation of $\mathrm{CO}_{2}$ to Formate. Chem. Mater. 2017, 29, 6740-6748.

(53) Kuhn, P.; Antonietti, M.; Thomas, A. Porous Covalent Triazine-Based Frameworks Prepared by Ionothermal Synthesis. Angew. Chem. Int. Ed. 2008, 47, 3450-3453. 
(54) Gomes, R.; Bhanja, P.; Bhaumik, A. A triazine-based covalent organic polymer for efficient $\mathrm{CO}_{2}$ adsorption. Chem. Commun. 2015, 51, 10050-10053.

(55) Ren, S.; Bojdys, M. J.; Dawson, R.; Laybourn, A.; Khimyak, Y. Z.; Adams, D. J.; Cooper, A. I. Porous, Fluoroscent, Covalent Triazine-Based Frameworks Via Room-Temperature and Microwave-Assisted Synthesis. Adv. Mater. 2012, 24, 2357-2361.

(56) Yu, H.; Shen, C.; Tian, M.; Qu, J.; Wang. Z. Microporous cyanate Resins: Synthesis, Porous Structure, and Correlations with Gas and Vapor Adsorptions. Macromolecules, 2012, 45, $5140-5150$

(57) Modak, A.; Pramanik, M.; Inagaki, S.; Bhaumik, A. A triazine functionalized porous organic polymer: excellent $\mathrm{CO}_{2}$ storage material and support for designing Pd nanocatalyst for $\mathrm{C}-\mathrm{C}$ cross-coupling reactions. J. Mater. Chem. A. 2014, 2, 11642-11650.

(58) Modak, A.; Mondal, J.; Sasidharan, M.; Bhaumik A. Triazine functionalized ordered mesoporous polymer: a novel solid support for $\mathrm{Pd}-$ mediated $\mathrm{C}-\mathrm{C}$ cross-coupling reactions in water. Green Chem. 2011, 13, 1317-1331.

(59) Stegbauer, L.; Schwinghammer, K.; Lotsch, B. V. A hydrozone-based covalent organic framework for photocatalytic hydrogen production. Chem. Sci. 2014, 5, 2789-2793.

(60) Ren, S.; Dawson, R.; Laybourn, A.; Jiang, J.; Khimyak, Y.; Adams, D. J.; Cooper, A. I. Functional conjugated microporous polymers: from 1,3,5-benzene to 1,3,5-triazine. Polym. Chem. 2012, 3, 928-934.

(61) Dey, S.; Bhunia, A.; Esquivel, D.; Janiak, C. Covalent triazine-based frameworks (CTFs) from triptycene and fluorene motifs for $\mathrm{CO}_{2}$ adsorption. J. Mater. Chem. A. 2016, 4, 62596263.

(62) Puthiaraj, P.; Cho, S.-M.; Lee, Y.-R; Ahn, W.-S. Microporous covalent triazine polymers: 
efficient Friedel-Crafts synthesis and adsorption/storage of $\mathrm{CO}_{2}$ and $\mathrm{CH}_{4}$. J. Mater. Chem. A. 2015, 3, 6792-6797.

(63) Puthiaraj, P.; Lee, Y.-R.; Zhang, S.; Ahn, W.-S. Triazine-Based Covalent Organic Polymers: Design, Synthesis and Applications in Heterogeneous Catalysis. J. Mater. Chem. A 2016, 4, 16288-16311.

(64) Puthiaraj, P.; Pitchumani, K. Triazine-Based Mesoporous Covalent Imine Polymers as Solid Supports for Copper-Mediated Chan-Lam Cross-Coupling N-Arylation Reactions. Chem. Eur. J., 2014, 20, 8761-8770.

(65) Liao, Y.; Cheng, Z.; Zuo, W.; Thomas, A.; Faul, C. F. J. Nitrogen-Rich Conjugated Microporous Polymers: Facile Synthesis, Efficient Gas Storage, and Heterogeneous Catalysis. ACS Appl. Mater. Interfaces 2017, 9, 38390-38400.

(66) Broicher, C.; Foit, S. R.; Rose, M.; Hausoul, P. J. C.; Palkovits, R. A Bipyridine-Based Conjugated Microporous Polymer for the Ir-Catalyzed Dehydrogenation of Formic Acid. ACS Catal. 2017, 7, 8413-8419.

(67) Wang, W.; Zheng, A.; Zhao, P.; Xia, C.; Li, F. Au-NHC@porous Organic Polymers: Synthetic Control and Its Catalytic Application in Alkyne Hydration Reactions. ACS Catal. 2014, 4, 321-327.

(68) Liras, M.; Pintado-Sierra, M.; Iglesias, M.; Sánchez, F. A Deprotection Strategy of a BODIPY Conjugated Porous Polymer to Obtain a Heterogeneous (Dipyrrin)(bipyridine)ruthenium ${ }^{\mathrm{II}}$ Visible Light Photocatalyst. J. Mater. Chem. A 2016, 4, $17274-17278$.

(69) Lee, J.; Farha, O. K.; Roberts, J.; Scheidt, K. A.; Nguyen, S. T.; Hupp, J. T. Metal-organic Framework Materials as Catalysts. Chem. Soc. Rev. 2009, 38, 1450-1459. 
(70) Liu, T. T.; Lin, Z. J.; Shi, P. C.; Ma, T.; Huang, Y. B.; Cao, R. A Metallosalen-Based Porous Organic Polymer for Olefin Epoxidation. ChemCatChem 2015, 7, 2340-2345.

(71) An, W. K.; Han, M. Y.; Wang, C. A.; Yu, S. M.; Zhang, Y.; Bai, S.; Wang, W. Insights into the Asymmetric Heterogeneous Catalysis in Porous Organic Polymers: Constructing A TADDOL-Embedded Chiral Catalyst for Studying the Structure-Activity Relationship. Chem. - A Eur. J. 2014, 20, 11019-11028.

(72) Haikal, R. R.; Wang, X.; Hassan, Y. S.; Parida, M. R.; Murali, B.; Mohammed, O. F.; Pellechia, P. J.; Fontecave, M.; Alkordi, M. H. Porous-Hybrid Polymers as Platforms for Heterogeneous Photochemical Catalysis. ACS Appl. Mater. Interfaces 2016, 8, 1999420002.

(73) Rangel-Rangel, E.; Verde-Sesto, E.; Rasero-Almansa, A. M.; Iglesias, M.; Sánchez, F. Porous Aromatic Frameworks (PAFs) as Efficient Supports for N-Heterocyclic Carbene Catalysts. Catal. Sci. Technol. 2016, 6, 6037-6045.

(74) Li, H.; Xu, B.; Liu, X.; A, S. ; He, C.; Xia, H.; Mu, Y. A Metallosalen-Based Microporous Organic Polymer as a Heterogeneous Carbon-carbon Coupling Catalyst. J. Mater. Chem. A 2013, 1, 14108-14114.

(75) Wang, Z. J.; Deng, G. J.; Li, Y.; He, Y. M.; Tang, W. J.; Fan, Q. H. Enantioselective Hydrogenation of Quinolines Catalyzed by $\operatorname{Ir(BINAP)-Cored~Dendrimers:~Dramatic~}$ Enhancement of Catalytic Activity. Org. Lett. 2007, 9, 1243-1246.

(76) Wang, S.; Song, K.; Zhang, C.; Shu, Y.; Li, T.; Tan, B. A Novel Metalporphyrin-Based Microporous Organic Polymer with High $\mathrm{CO}_{2}$ Uptake and Efficient Chemical Conversion of $\mathrm{CO}_{2}$ under Ambient Conditions. J. Mater. Chem. A 2017, 5, 1509-1515.

(77) Chen, Y.; Luo, R.; Xu, Q.; Zhang, W.; Zhou, X.; Ji, H. State-of-the-Art Aluminum 
Porphyrin-Based Heterogeneous Catalysts for the Chemical Fixation of $\mathrm{CO}_{2}$ into Cyclic Carbonates at Ambient Conditions. ChemCatChem 2017, 9, 767-773.

(78) Dou, Z.; Xu, L.; Zhi, Y.; Zhang, Y.; Xia, H.; Mu, Y.; Liu, X. Metalloporphyrin-Based Hypercrosslinked Polymers Catalyze Hetero-Diels-Alder Reactions of Unactivated Aldehydes with Simple Dienes: A Fascinating Strategy for the Construction of Heterogeneous Catalysts. Chem. - A Eur. J. 2016, 22, 9919-9922.

(79) Xu, Y.; Wang, T.; He, Z.; Zhou, M.; Yu, W.; Shi, B.; Huang, K. Organic Ligands Incorporated Hypercrosslinked Microporous Organic Nanotube Frameworks for Accelerating Mass Transfer in Efficient Heterogeneous Catalysis. Appl. Catal. A Gen. 2017, $541,112-119$.

(80) Ding, Z.-D.; Zhu, W.; Li, T.; Shen, R.; Li, Y.; Li, Z.; Ren, X.; Gu, Z.-G. A Metalloporphyrin-Based Porous Organic Polymer as an Efficient Catalyst for the Catalytic Oxidation of Olefins and Arylalkanes. Dalt. Trans. 2017, 46, 11372-11379.

(81) Shultz, A. M.; Farha, O. K.; Hupp, J. T.; Nguyen, S. T. Synthesis of Catalytically Active Porous Organic Polymers from Metalloporphyrin Building Blocks. Chem. Sci. 2011, 2, 686.

(82) Modak, A.; Mondal, J.; Bhaumik, A. Porphyrin based porous organic polymers as bifunctional catalysts for selective oxidation and Knoevenagel condensations reactions. Appl. Catal., A: Gen. 2013, 459, 41-51.

(83) Ding, S.; Tian, C.; Zhu, X.; Abney, C. W.; Tian, Z.; Chen, B.; Li, M.; Jiang, D. E.; Zhang, N.; Dai, S. Pd-Metalated Conjugated Nanoporous Polycarbazoles for Additive-Free Cyanation of Aryl Halides: Boosting Catalytic Efficiency through Spatial Modulation. ChemSusChem 2017, 10, 2348-2351.

(84) Pan, L.; Xu, M.-Y.; Feng, L.-J.; Chen, Q.; He, Y.-J.; Han, B.-H. Conjugated Microporous 
Polycarbazole Containing tris(2-Phenylpyridine)iridium ${ }^{\mathrm{III}}$ Complexes: Phosphorescence, Porosity, and Heterogeneous Organic Photocatalysis. Polym. Chem. 2016, 7, 2299-2307.

(85) Oveisi, A. R.; Zhang, K.; Khorramabadi-Zad, A.; Farha, O. K.; Hupp, J. T. Stable and Catalytically Active Iron Porphyrin-Based Porous Organic Polymer: Activity as Both a Redox and Lewis Acid Catalyst. Sci. Rep. 2015, 5, 1-8.

(86) Mackintosh, H. J.; Budd, P. M.; McKeown, N. B. Catalysis by Microporous Phthalocyanine and Porphyrin Network Polymers. J. Mater. Chem. 2008, 18, 573-578.

(87) Zhang, K.; Farha, O. K.; Hupp, J. T.; Nguyen, S. T. Complete Double Epoxidation of Divinylbenzene Using Mn(porphyrin)-Based Porous Organic Polymers. ACS Catal. 2015, 5, 4859-4866.

(88) Meng, S.; Zou, X.; Liu, C.; Ma, H.; Zhao, N.; Ren, H.; Jia, M.; Liu, J.; Zhu, G. Synthesis and Catalytic Properties of New Metalloporphyrin-Based Porous Organic Framework Materials with Single and Accessible Sites. ChemCatChem 2016, 8, 2393-2400.

(89) Wang, L.; Zhang, J.; Sun, J.; Zhu, L.; Zhang, H.; Liu, F.; Zheng, D.; Meng, X.; Shi, X.; Xiao, F. S. Copper-Incorporated Porous Polydivinylbenzene as Efficient and Recyclable Heterogeneous Catalyst in Ullmann Biaryl Ether Coupling. ChemCatChem 2013, 5, 16061613.

(90) Becker, J. J.; Gagné, M. R. Exploiting the Synergy between Coordination Chemistry and Molecular Imprinting in the Quest for New Catalysts. Acc. Chem. Res. 2004, 37, 798-804.

(91) Hodge, P. Polymer-Supported Organic Reactions: What Takes Place in the Beads? Chem. Soc. Rev. 1997, 26, 417-424.

(92) Chen, X.; Zhu, H.; Wang, W.; Du, H.; Wang, T.; Yan, L.; Hu, X.; Ding, Y. Multifunctional Single-Site Catalysts for Alkoxycarbonylation of Terminal Alkynes. ChemSusChem 2016, 
9, 2451-2459.

(93) Li, C.; Wang, W.; Yan, L.; Wang, Y.; Jiang, M.; Ding, Y. Phosphonium Salt and ZnX2$\mathrm{PPh}_{3}$ Integrated Hierarchical POPs: Tailorable Synthesis and Highly Efficient Cooperative Catalysis in $\mathrm{CO}_{2}$ Utilization. J. Mater. Chem. A 2016, 4, 16017-16027.

(94) Wang, W.; Li, C.; Yan, L.; Wang, Y.; Jiang, M.; Ding, Y. Ionic Liquid/Zn-PPh3 Integrated Porous Organic Polymers Featuring Multifunctional Sites: Highly Active Heterogeneous Catalyst for Cooperative Conversion of $\mathrm{CO}_{2}$ to Cyclic Carbonates. ACS Catal. 2016, 6, 6091-6100.

(95) Sun, Q.; Dai, Z.; Liu, X.; Sheng, N.; Deng, F.; Meng, X.; Xiao, F. S. Highly Efficient Heterogeneous Hydroformylation over Rh-Metalated Porous Organic Polymers: Synergistic Effect of High Ligand Concentration and Flexible Framework. J. Am. Chem. Soc. 2015, 137, 5204-5209.

(96) Iwai, T.; Harada, T.; Hara, K.; Sawamura, M. Threefold Cross-Linked PolystyreneTriphenylphosphane Hybrids: Mono-P-Ligating Behavior and Catalytic Applications for Aryl Chloride Cross-Coupling and $\mathrm{C}\left(\mathrm{sp}^{3}\right)-\mathrm{H}$ Borylation. Angew. Chem., Int. Ed. 2013, 52, $12322-12326$.

(97) Weber, J.; Antonietti, M.; Thomas, A. Microporous Networks of High-Performance Polymers: Elastic Deformations and Gas Sorption Properties. Macromolecules 2008, 41, $2880-2885$.

(98) Wang, J.; Yang, J. G. W.; Yi, G.; Zhang, Y. Phosphonium Salt Incorporated Hypercrosslinked Porous Polymers for $\mathrm{CO}_{2}$ Capture and Conversion. Chem. Commun. 2015, 51, 15708-15711.

(99) Wang, W.; Wang, Y.; Li, C.; Yan, L.; Jiang, M.; Ding. Y. State-of-the-art Multifunctional 
Heterogeneous POP Catalyst for Cooperative Transformation of $\mathrm{CO}_{2}$ to Cyclic Carbonates. ACS Sustainable Chem. Eng. 2017, 5, 4523-4528.

(100) Rostovtsev, V. V.; Green, L. G.; Fokin, V. V.; Sharpless, K. B. A Stepwise Huisgen Cycloaddition Process Catalyzed by Copper (I): Regioselective Ligation of Azides and Terminal Alkynes. Angew. Chem. Int. Ed. 2002, 41, 2596-2599.

(101) Tornøe, C. W.; Christensen, C.; Meldal, M. Peptidotriazoles on Solid Phase: [1,2,3]Triazoles by Regiospecific copper(I)-Catalyzed 1,3-Dipolar Cycloadditions of Terminal Alkynes to Azides. J. Org. Chem. 2002, 67, 3057-3064.

(102) Fürstner, A.; Davies, P. W. Catalytic Carbophilic Activation: Catalysis by Platinum and Gold $\pi$ Acids. Angew. Chem., Int. Ed. 2007, 46, 3410-3449.

(103) Shapiro, N. D.; Toste, F. D. A Reactivity-Driven Approach to the Discovery and Development of Gold-Catalyzed Organic Reactions. Synlett 2010, 675-691.

(104) Corma, A.; Leyva-Pérez, A.; Sabater, M. J. Gold-Catalyzed Carbon-Heteroatom BondForming Reactions. Chem. Rev. 2011, 111, 1657-1712.

(105) Hashmi, A. S. K. Gold-Catalyzed Organic Reactions. Top. Organomet. Chem. 2013, 44, 143-164.

(106) Kramer, S. Recent Advances in Gold-Catalyzed Intermolecular Aryl C-H Functionalization. Chem. - A Eur. J. 2016, 22, 15584-15598.

(107) Zheng, Z.; Wang, Z.; Wang, Y.; Zhang, L. Au-Catalysed Oxidative Cyclisation. Chem. Soc. Rev. 2016, 45, 4448-4458.

(108) Cai, R.; Ye, X.; Sun, Q.; He, Q.; He, Y.; Ma, S.; Shi, X. Anchoring Triazole-Gold(I) Complex into Porous Organic Polymer to Boost the Stability and Reactivity of Gold(I) Catalyst. ACS Catal. 2017, 7, 1087-1092. 
(109) Kraft, S. J.; Zhang, G.; Childers, D.; Dogan, F.; Miller, J. T.; Nguyen, S. T.; Hock, A. S. Rhodium Catechol Containing Porous Organic Polymers: Defined Catalysis for Single-Site and Supported Nanoparticulate Materials. Organometallics 2014, 33, 2517-2522.

(110) Jiang, J. X.; Wang, C.; Laybourn, A.; Hasell, T.; Clowes, R.; Khimyak, Y. Z.; Xiao, J.; Higgins, S. J.; Adams, D. J.; Cooper, A. I. Metal-Organic Conjugated Microporous Polymers. Angew. Chem., Int. Ed. 2011, 50, 1072-1075.

(111) Sun, Q.; Meng, X.; Liu, X.; Zhang, X.; Yang, Y.; Yang, Q.; Xiao, F.-S. Mesoporous CrossLinked Polymer Copolymerized with Chiral BINAP Ligand Coordinated to a Ruthenium Species as an Efficient Heterogeneous Catalyst for Asymmetric Hydrogenation. Chem. Commun. 2012, 48, 10505-10507.

(112) Johansson Seechurn, C. C. C.; Kitching, M. O.; Colacot, T. J.; Snieckus, V. PalladiumCatalyzed Cross-Coupling: A Historical Contextual Perspective to the 2010 Nobel Prize. Angew. Chem., Int. Ed. 2012, 51, 5062-5085.

(113) Metal-Catalyzed Cross-Coupling Reactions and More; de Meijere, A., Bräse, S., Oestreich, M., Eds.; Wiley-VCH: Weinheim, 2014.

(114) Brown, D. G.; Boström, J. Analysis of Past and Present Synthetic Methodologies on Medicinal Chemistry: Where Have All the New Reactions Gone? J. Med. Chem. 2016, 59, 4443-4458.

(115) Fu, G. C. The Development of Versatile Methods for Palladium-Catalyzed Coupling Reactions of Aryl Electrophiles through the Use of $\mathrm{P}(\mathrm{t}-\mathrm{Bu})_{3}$ and $\mathrm{PC} \mathrm{y}_{3}$ as Ligands. Acc. Chem. Res. 2008, 41, 1555-1564.

(116) Jing, L.; Sun, J.; Sun, F.; Chen, P.; Zhu, G. Porous aromatic framework with mesopores as a platform for a super-efficient heterogeneous Pd-based organometallic catalysis. Chem. 
Sci. 2018, 9, 3523-3530.

(117) Beletskaya, I. P.; Cheprakov, A. V. Heck Reaction as a Sharpening Stone of Palladium Catalysis. Chem. Rev. 2000, 100, 3009-3066.

(118) Puthiaraj, P.; Pitchumani, K. Triazine-Based Mesoporous Covalent Imine Polymers as Solid Supports for Copper-Mediated Chan-Lam Cross-Coupling N-Arylation Reactions. Chem. A Eur. J. 2014, 20, 8761-8770.

(119) Liu, Y.; Zhou, Y.; Li, J.; Wang, Q.; Qin, Q.; Zhang, W.; Asakura, H.; Yan, N.; Wang, J. Direct Aerobic Oxidative Homocoupling of Benzene to Biphenyl over Functional Porous Organic Polymer Supported Atomically Dispersed Palladium Catalyst. Appl. Catal. B Environ. 2017, 209, 679-688.

(120) Majeed, M. H.; Shayesteh, P.; Wallenberg, L. R.; Persson, A. R.; Johansson, N.; Ye, L.; Schnadt, J.; Wendt, O. F. Polymer-Supported Palladium(II) Carbene Complexes: Catalytic Activity, Recyclability, and Selectivity in $\mathrm{C}-\mathrm{H}$ Acetoxylation of Arenes. Chem. - A Eur. J. 2017, 23, 8457-8465.

(121) Lee, L. C.; He, J.; Yu, J. Q.; Jones, C. W. Functionalized Polymer-Supported Pyridine Ligands for Palladium-Catalyzed C( $\left.\mathrm{sp}^{3}\right)$-H Arylation. ACS Catal. 2016, 6, 5245-5250.

(122) Prier, C. K.; Rankic, D. A.; MacMillan, D. W. C. Visible Light Photoredox Catalysis with Transition Metal Complexes: Applications in Organic Synthesis. Chem. Rev. 2013, 113, $5322-5363$.

(123) Schultz, D. M.; Yoon, T. P. Solar Synthesis: Prospects in Visible Light Photocatalysis. Science 2014, 343, 1239176.

(124) Brimioulle, R.; Lenhart, D.; Maturi, M. M.; Bach, T. Enantioselective Catalysis of Photochemical Reactions. Angew. Chem., Int. Ed. 2015, 54, 3872-3890. 
(125) Sun, Q.; Dai, Z.; Meng, X.; Xiao, F. S. Enhancement of Hydroformylation Performance via Increasing the Phosphine Ligand Concentration in Porous Organic Polymer Catalysts. Catal. Today 2017, 298, 40-45.

(126) Hartman, R. L.; McMullen, J. P.; Jensen, K. F. Deciding Whether To Go with the Flow: Evaluating the Merits of Flow Reactors for Synthesis. Angew. Chem. Int. Ed. 2011, 50, $7502-7519$

(127) Webb, D.; Jamison, T. F. Continuous flow multi-step organic synthesis. Chem. Sci. 2010, $1,675-680$.

(128) Wang, Y.; Yan, L.; Li, C.; Jiang, M.; Wang, W.; Ding, Y. Highly efficient porous organic copolymer supported Rh catalysts for heterogeneous hydroformylation of butenes. Appl. Catal., A, Gen. 2018, 551, 98-105

(129) Kim, M. J.; Ahn, S.; Yi, J.; Hupp, J. T.; Notestein, J. M.; Farha, O. K.; Lee, S. J. Ni ${ }^{\mathrm{II}}$ Complex on a Bispyridine-Based Porous Organic Polymer as a Heterogeneous Catalyst for Ethylene Oligomerization. Catal. Sci. Technol. 2017, 7, 4351-4354.

\section{TOC-Graphic}

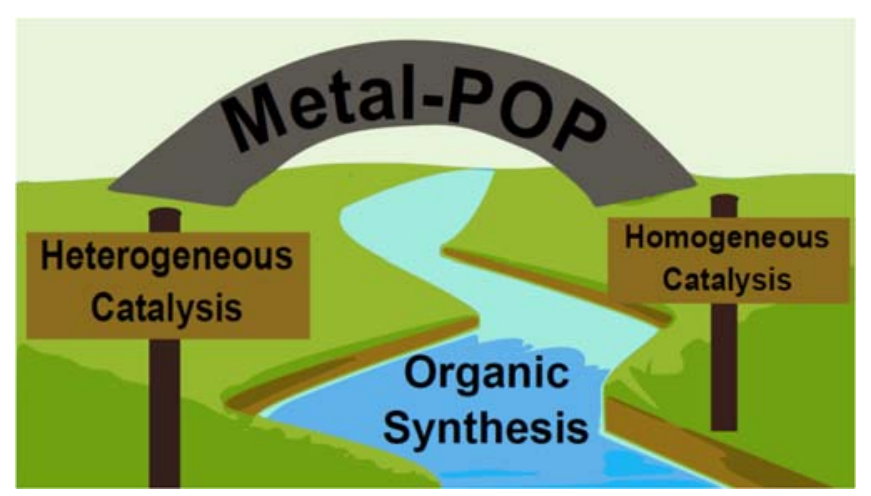




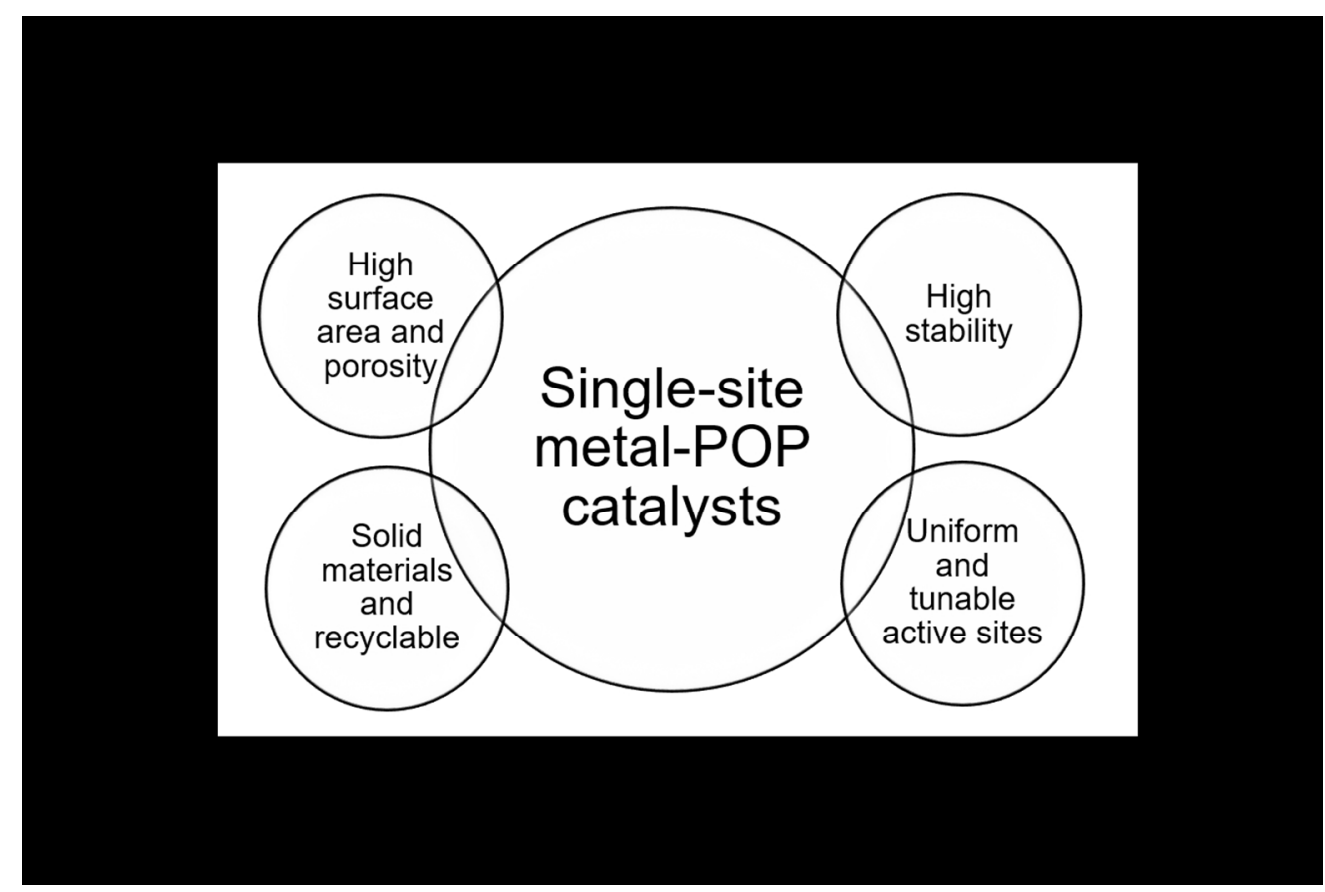

Figure 1. Important properties of porous organic polymers (POPs) containing active mononuclear metal centers for catalysis.

$225 \times 150 \mathrm{~mm}(150 \times 150 \mathrm{DPI})$ 


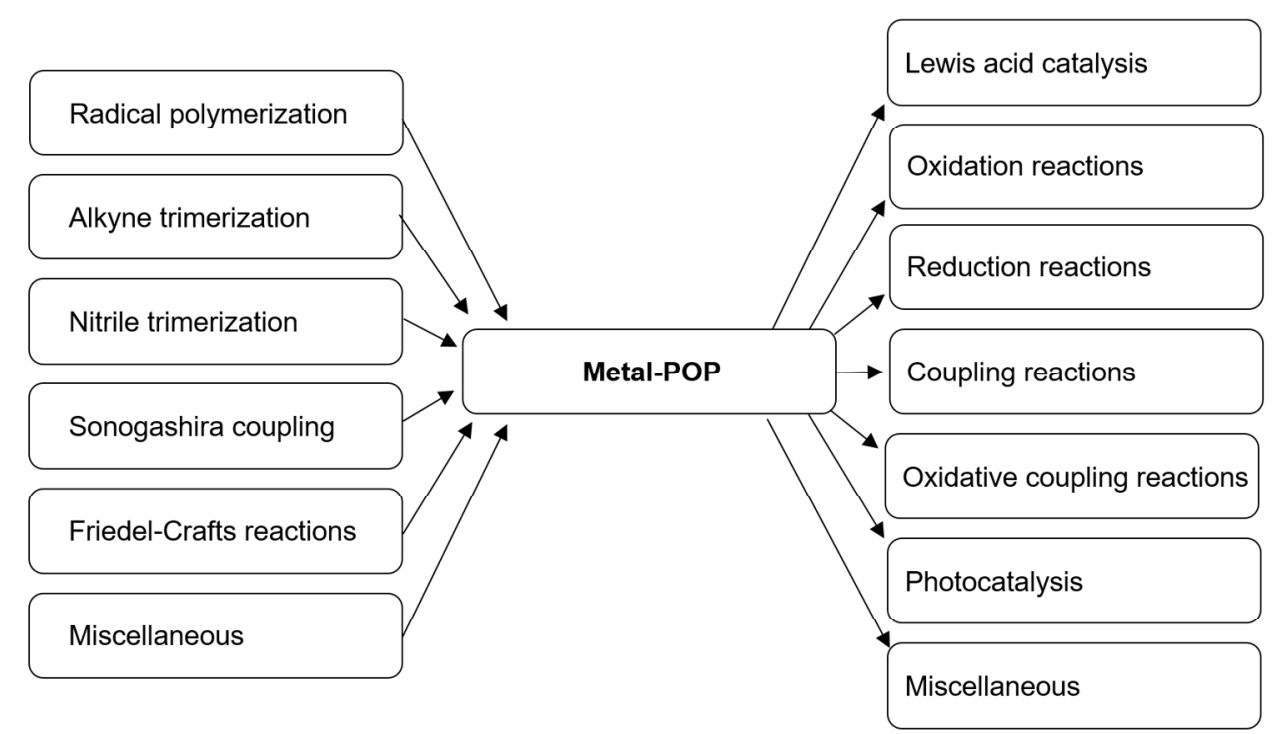

Figure 2. Overview of synthesis of metal-containing porous organic polymers (POPs) and their application in catalysis.

$298 \times 169 \mathrm{~mm}(150 \times 150 \mathrm{DPI})$ 


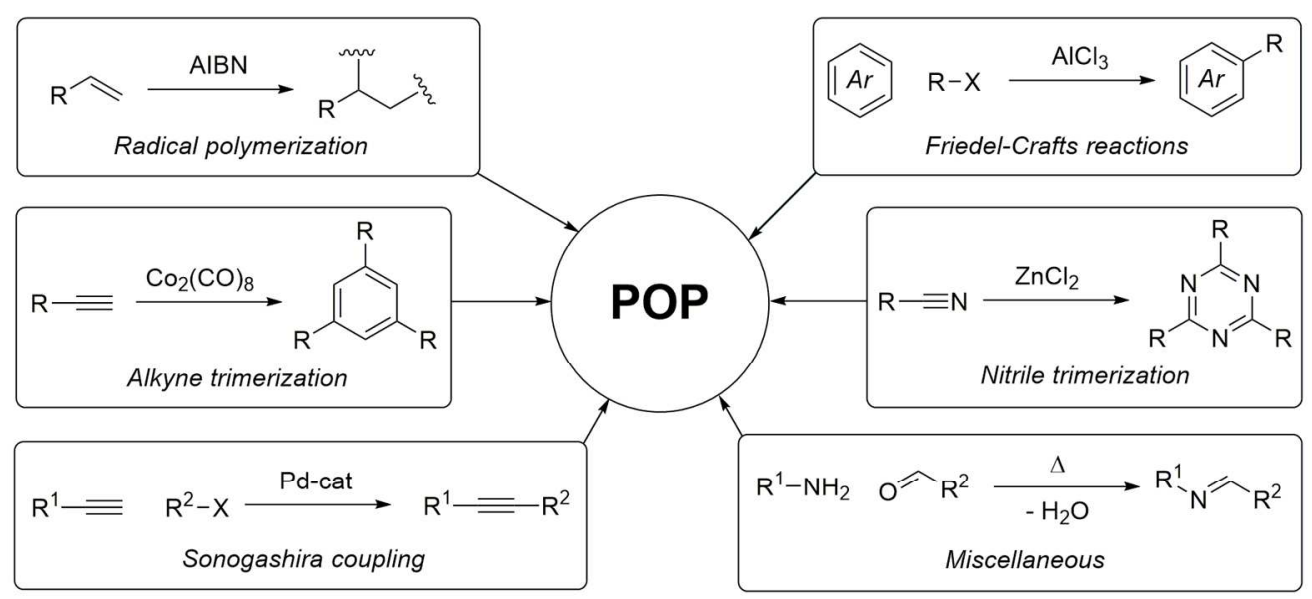

Figure 3. The different types of polymerization techniques presented in this review. Each technique is represented by a general example.

$154 \times 69 \mathrm{~mm}(300 \times 300 \mathrm{DPI})$ 

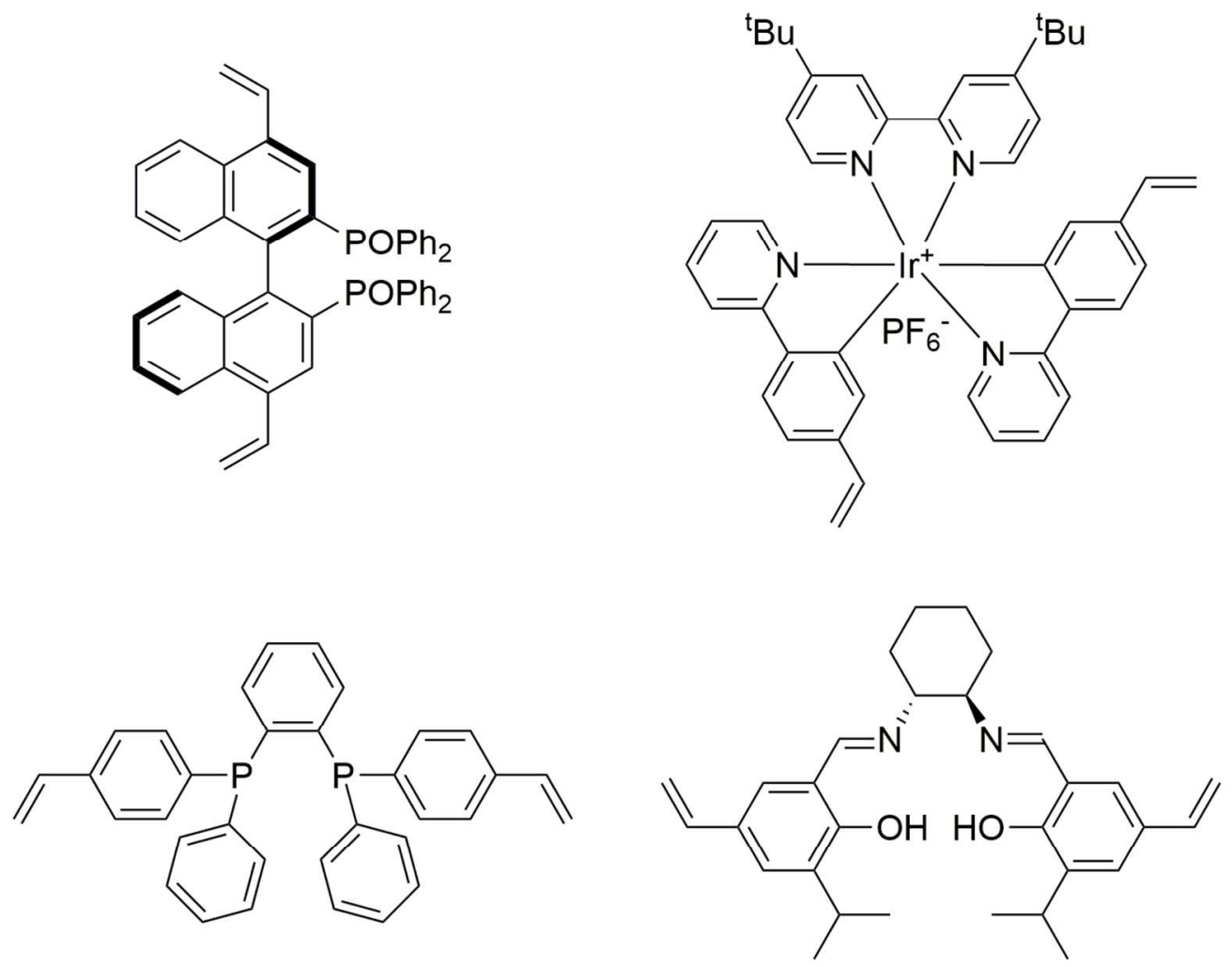

Figure 4. Examples of building blocks used for radical polymerization.

$122 \times 97 \mathrm{~mm}(300 \times 300$ DPI $)$ 
1

2

3

4

5

6

7

8

10

11

12

13

14

15

16

17

18

19

20

21

22

23

24

25

26

27

28

29

30

31

32

33

34

35

36

37

38

39

40

41

42

43

44

45

46

47

48

49

50

51

52

53

54

55

56

57

58

59

60

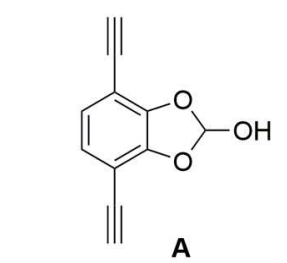

A

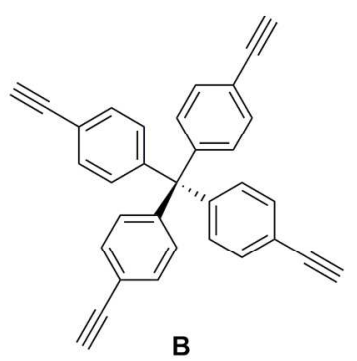

$\mathrm{Co}_{2}(\mathrm{CO})_{8}$

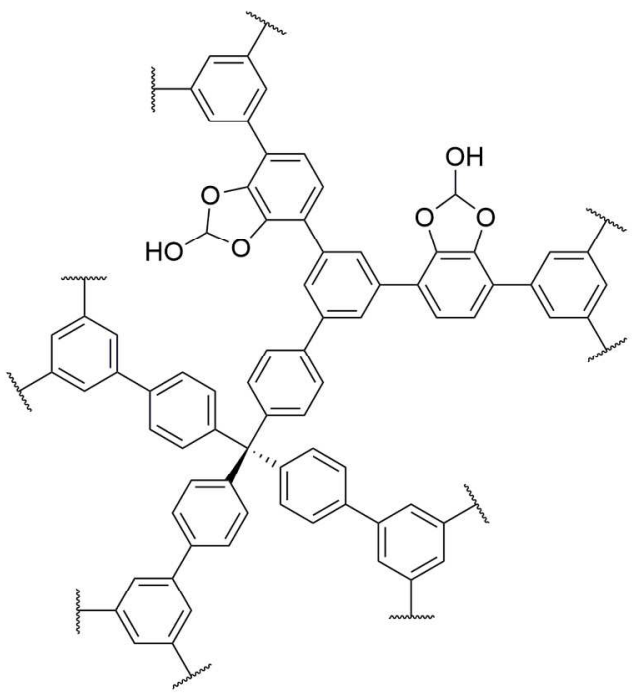

Scheme 1. Synthesis of a Catechol-POP through Alkyne Trimerization by Nguyen and Coworkers. ${ }^{43}$ $175 \times 94 \mathrm{~mm}(300 \times 300$ DPI $)$ 
<smiles>O=P(O)(O)c1cc(Br)c2ccccc2c1-c1c(P(=O)(O)O)cc(Br)c2ccccc12</smiles>

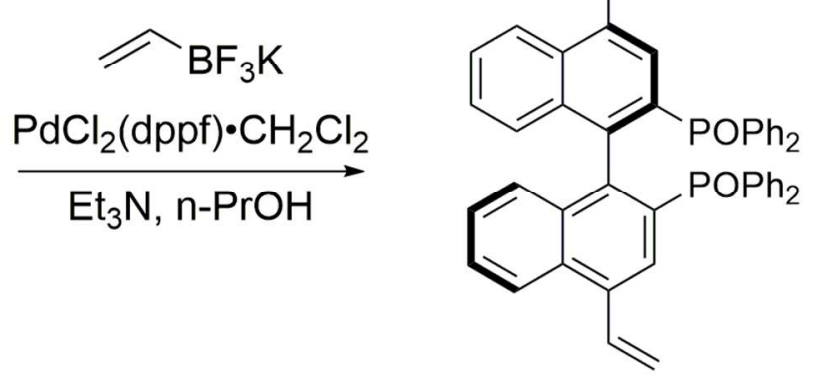<smiles>CCOc1cc(Br)c2cc(Br)ccc2c1-c1c(OCC)cc(Br)c2cc(Br)ccc12</smiles><smiles>N#C[As][Mg]</smiles>

$\mathrm{Pd}\left(\mathrm{PPh}_{3}\right)_{4}, \mathrm{Cul}, \mathrm{THF}$ $\mathrm{Et}_{3} \mathrm{~N}, 80^{\circ} \mathrm{C}$<smiles>C#Cc1ccc2c(-c3c(OCC)cc(C#C)c4cc(C#C)ccc34)c(OCC)cc(C#C)c2c1</smiles>

Scheme 2. Comparison of Monomer Synthesis for Radical Polymerization and Alkyne Trimerization for two BINAP-derivatives ( $\mathrm{dppf}=1,1^{\prime}$-bisphenylphosphino)ferrocene).

$112 \times 88 \mathrm{~mm}$ ( $300 \times 300 \mathrm{DPI})$ 

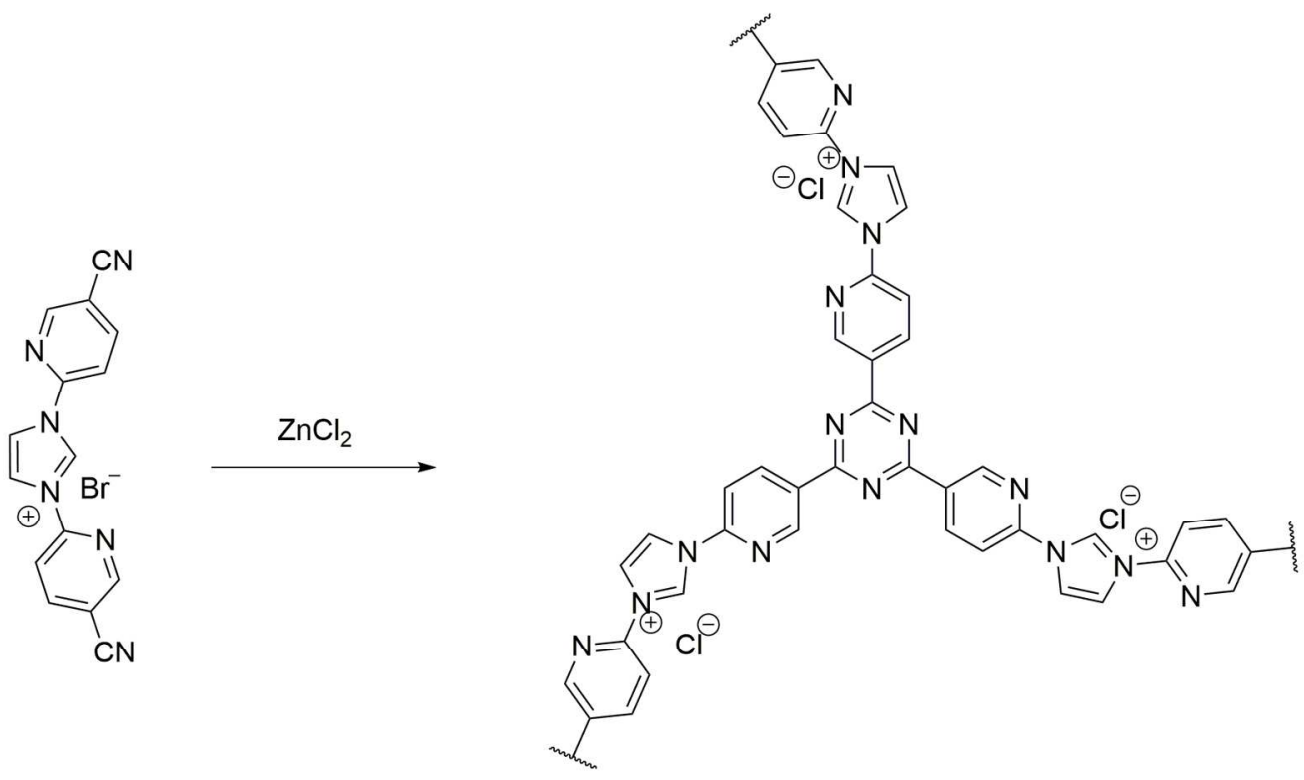

Scheme 3. Polymerization by Trimerization of Nitrile Groups Promoted by $\mathrm{ZnCl}_{2} .{ }^{52}$ $155 \times 92 \mathrm{~mm}(300 \times 300 \mathrm{DPI})$ 


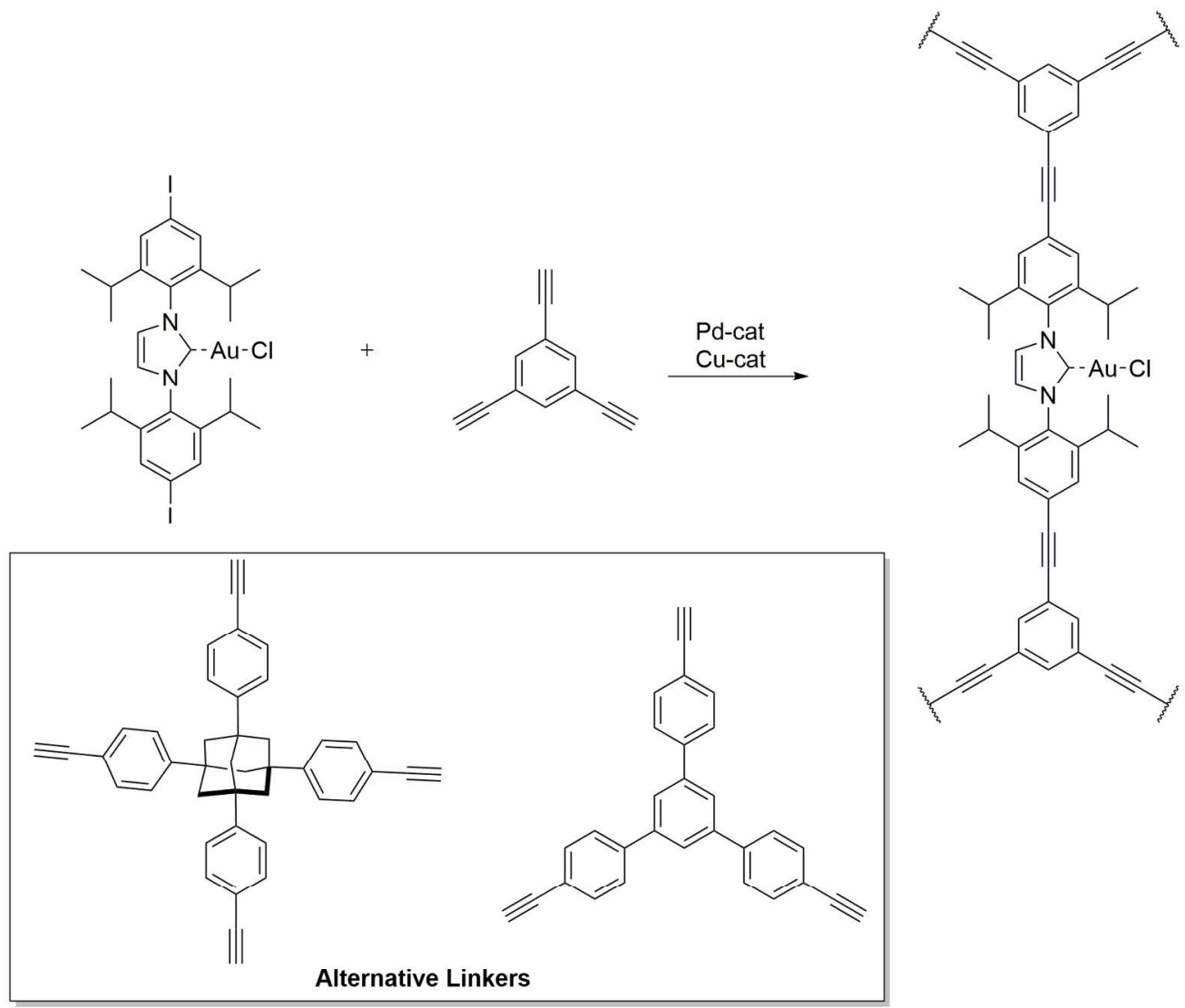

Scheme 4. Synthesis of Au-IPr-POPs through Sonogashira Coupling by Li et al. ${ }^{67}$ $174 \times 148 \mathrm{~mm}(300 \times 300$ DPI $)$ 


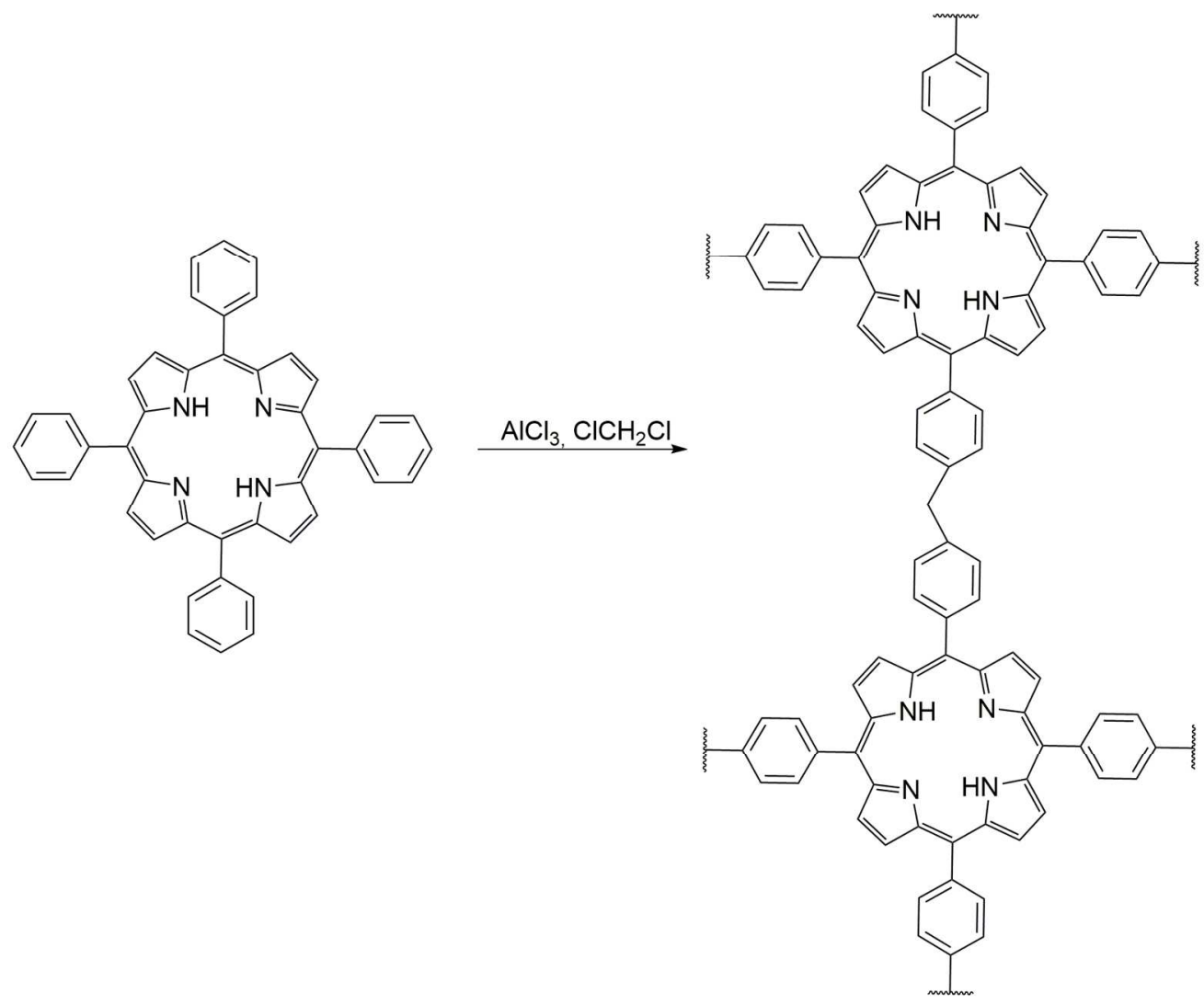

Scheme 5. Synthesis of a Porphyrin-POP by Friedel-Crafts Alkylation Reported by Li, Tan, and Coworkers. ${ }^{76}$ $161 \times 133 \mathrm{~mm}(300 \times 300 \mathrm{DPI})$ 

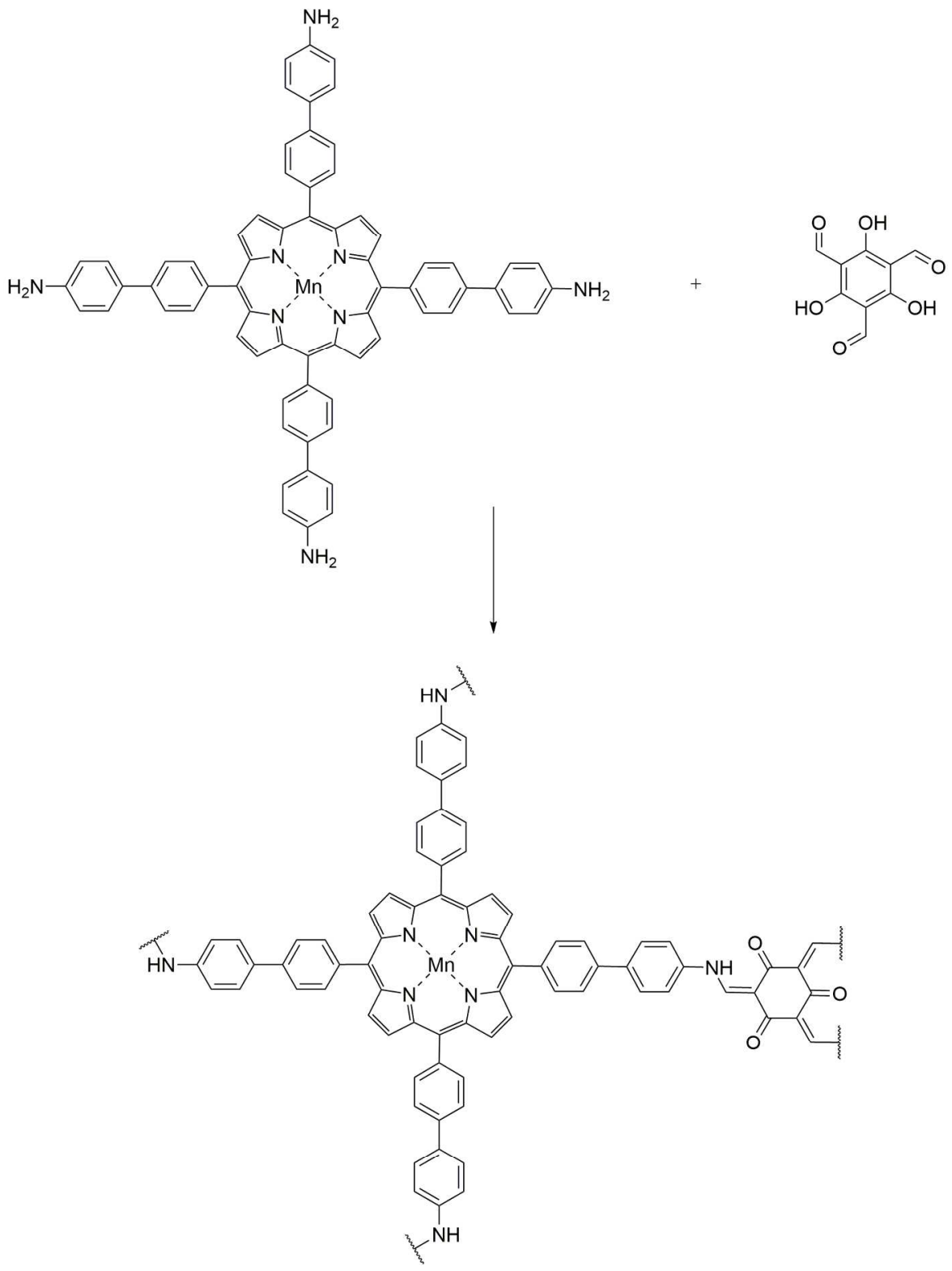

Scheme 6. Synthesis of a Mn-Porphyrin-POP by Ketoenamine Condensation. ${ }^{80}$ $168 \times 225 \mathrm{~mm}(300 \times 300$ DPI $)$ 
Figure 5. Two different metalation strategies utilized for the syntheses of metal-POPs.

$$
268 \times 57 \mathrm{~mm}(150 \times 150 \mathrm{DPI})
$$



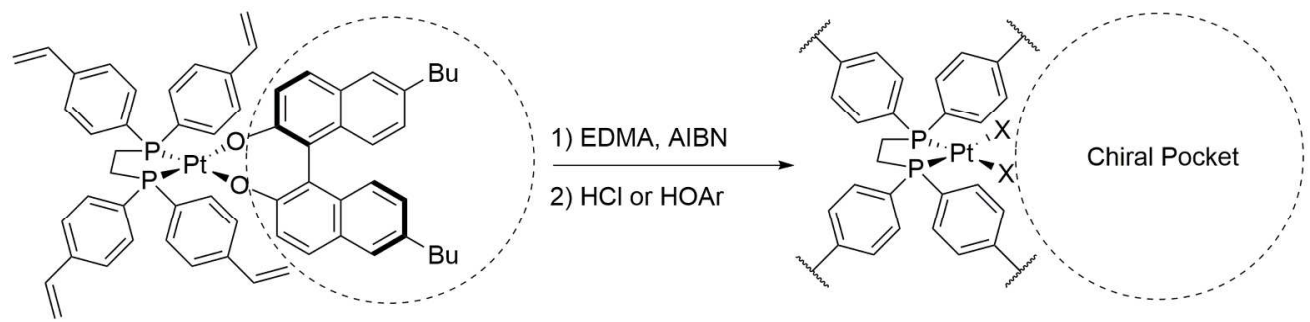

Scheme 7. Synthesis of Chiral Pocket by Metal Templating Reported by Gagné et al.(EDMA = ethylenedimethacrylate) ${ }^{90}$

$179 \times 44 \mathrm{~mm}(300 \times 300 \mathrm{DPI})$ 


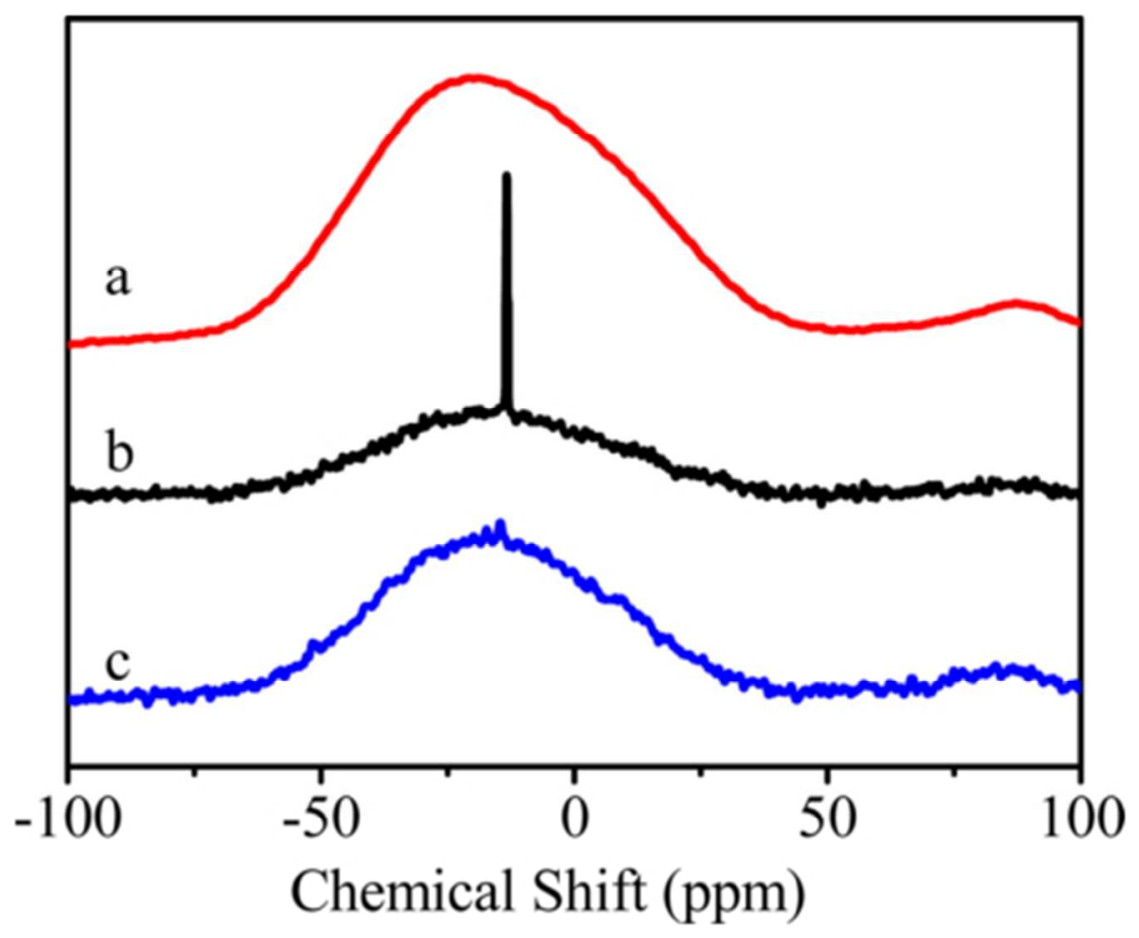

Figure 6. Static solid-state ${ }^{31} \mathrm{P}$ NMR of (a) the dried dppe-based polymer, (b) the dppe-based polymer in the presence of toluene, and (c) an non-porous dppe-based polymer in the presence of toluene. The sharp signal for the swollen polymer indicates homogeneous environment for the ligand in the swollen polymer. Adapted from Xiao and coworkers. ${ }^{95}$

$150 \times 110 \mathrm{~mm}(96 \times 96 \mathrm{DPI})$ 

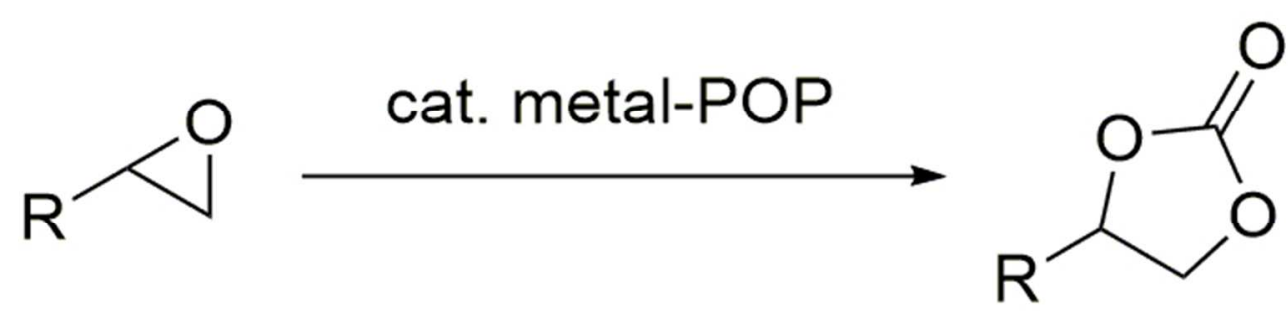

\section{metal center: $\mathrm{Zn}, \mathrm{Al}, \mathrm{Cu}, \mathrm{Co}, \mathrm{Mg}$}

Scheme 8. Formation of Cyclic Carbonates from $\mathrm{CO}_{2}$ and Epoxides

$58 \times 20 \mathrm{~mm}(300 \times 300 \mathrm{DPI})$ 

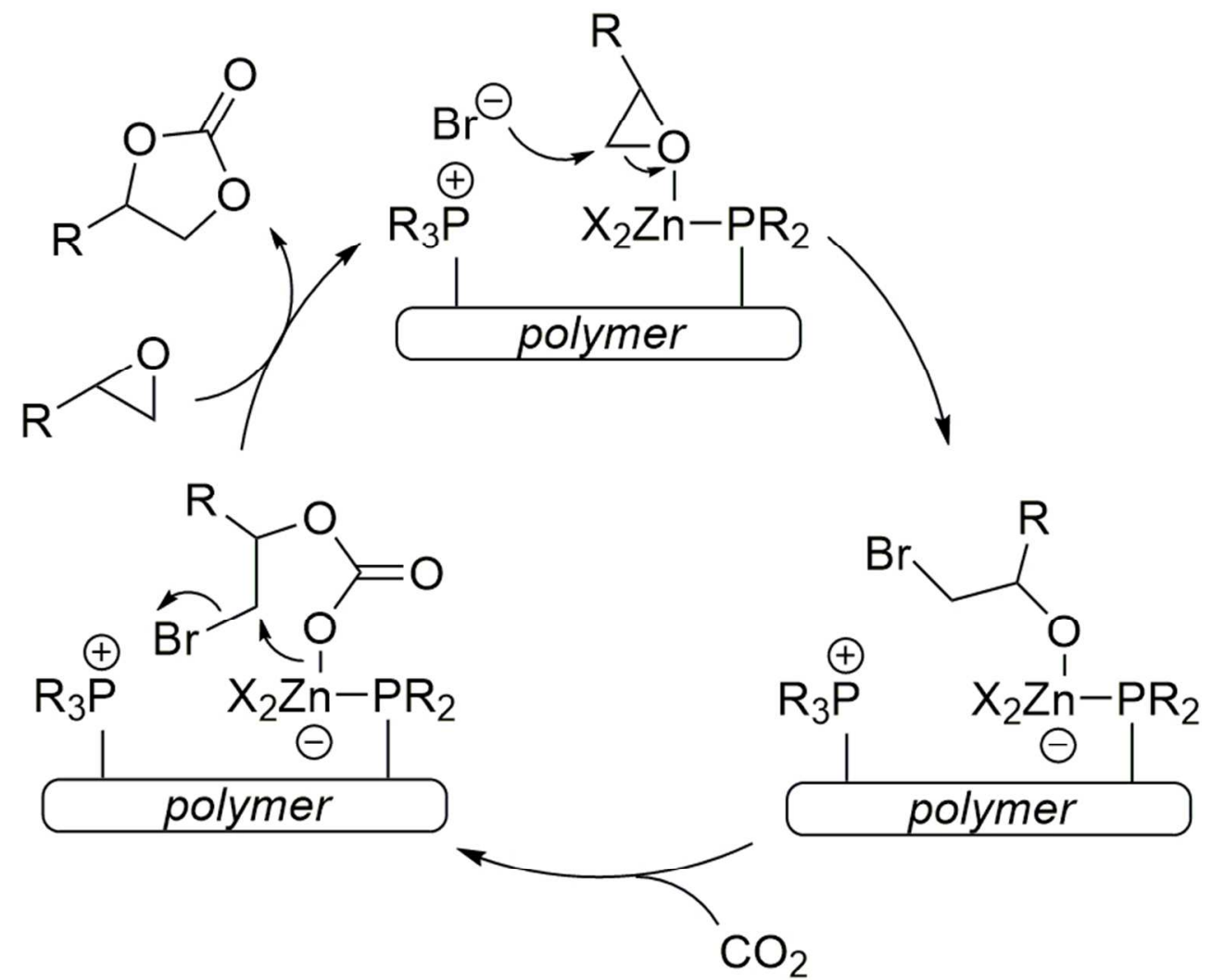

Scheme 9. Proposed Cooperative Mechanism for Cyclic Carbonate Formation using POPs Containing Bifunctional Sites.

$77 \times 63 \mathrm{~mm}(300 \times 300 \mathrm{DPI})$ 


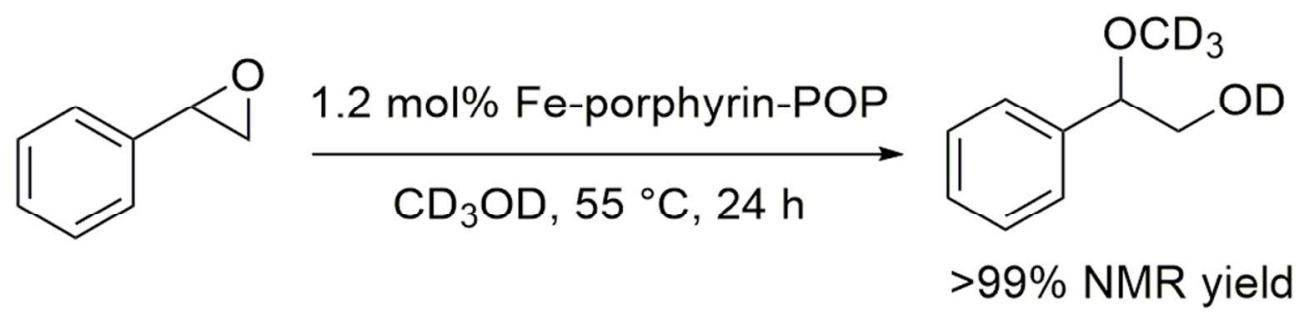

Scheme 10. Nucleophilic Addition to Epoxide Catalyzed by an Iron-Porphyrin-POP.

$84 \times 21 \mathrm{~mm}(300 \times 300$ DPI $)$ 
a) Lin et al.

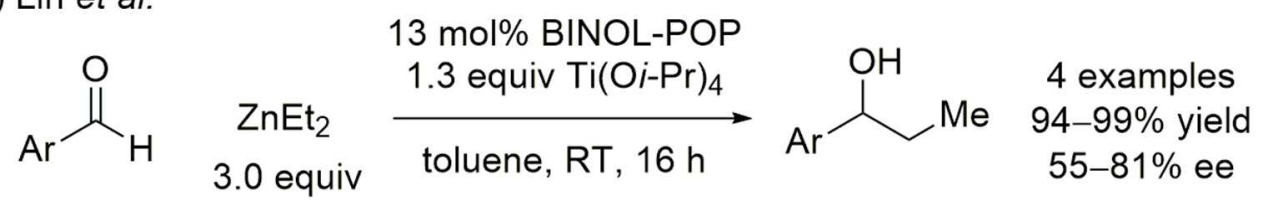

b) Wang et al.

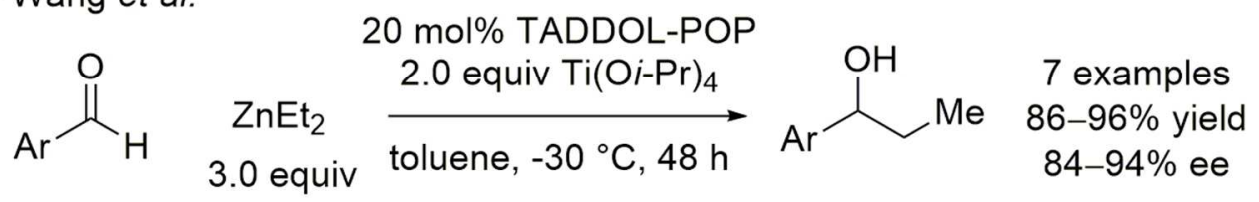

Scheme 11. Titanium-Catalyzed Asymmetric Addition of $\mathrm{ZnEt}_{2}$ to Aldehydes using (a) a BINOL-POP Ligand and (b) a TADDOL-POP Ligand

$105 \times 42 \mathrm{~mm}(300 \times 300$ DPI $)$ 
Scheme 12. Hetero-Diels-Alder Reaction Catalyzed by Heterogeneous Iron-Porphyrin-POP and AgBF 4 . $109 \times 23 \mathrm{~mm}(300 \times 300 \mathrm{DPI})$ 


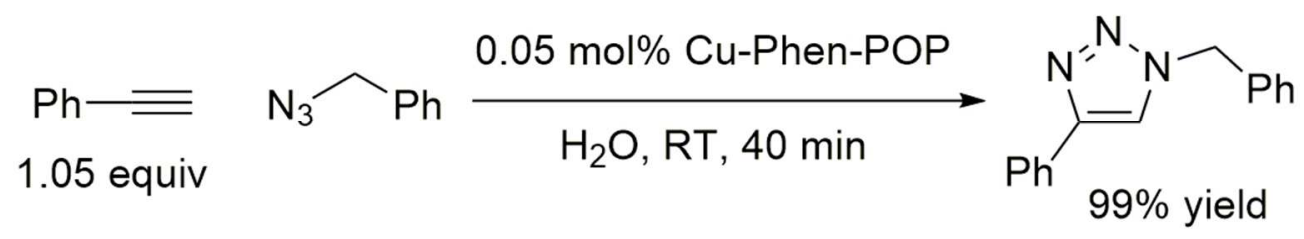

Scheme 13. Formal 1,3-Dipolar Cycloaddition Catalyzed by a Cu-Phen-POP. $93 \times 17 \mathrm{~mm}(300 \times 300 \mathrm{DPI})$ 


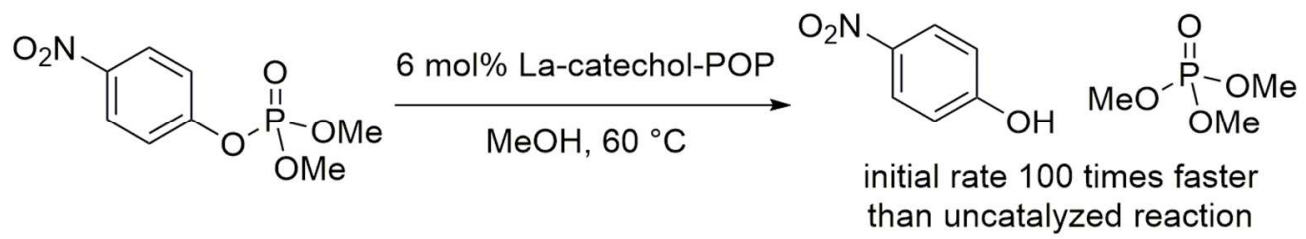

Scheme 14. Methanolysis of an Organophosphate Catalyzed by a Lanthanum-Catechol-POP. $115 \times 21 \mathrm{~mm}(300 \times 300 \mathrm{DPI})$ 
a) Li et al.

Scheme 15. Selected Reactions Catalyzed by Gold-Containing Porous Organic Polymers: (a) Alkyne Hydration by Li et al. and (b) Meyer-Schuster Rearrangement and Enyne Rearrangement by Shi et al.

$115 \times 66 \mathrm{~mm}(300 \times 300$ DPI $)$ 


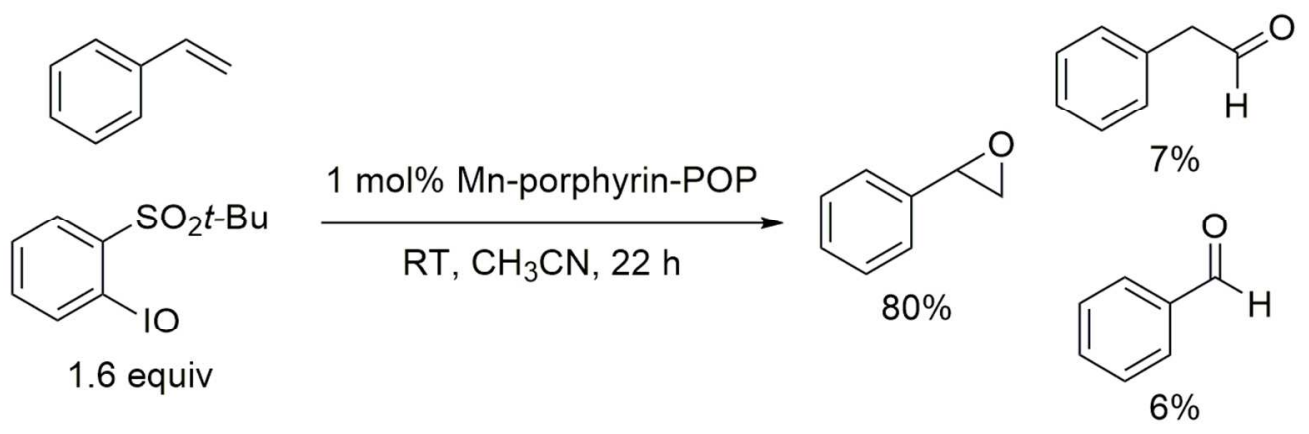

Scheme 16. Epoxidation of Styrene Catalyzed by a Mn-porphyrin-POP.

$107 \times 36 \mathrm{~mm}(300 \times 300$ DPI $)$ 


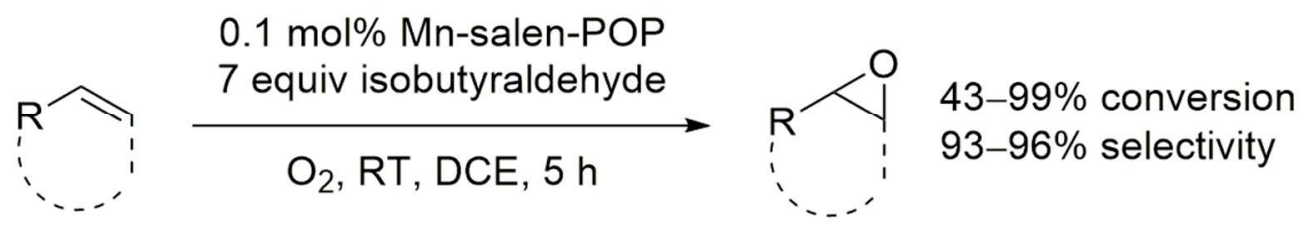

Scheme 17. Aliphatic Alkene Epoxidation Catalyzed by a Mn-Salen-POP.

$96 \times 16 \mathrm{~mm}(300 \times 300 \mathrm{DPI})$ 


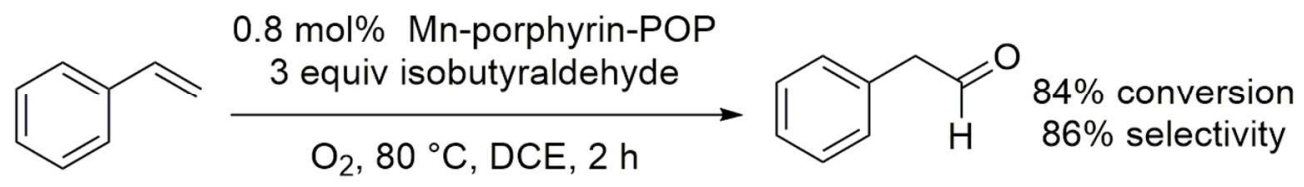

Scheme 18. Catalytic Oxidation of Styrene to Phenylacetaldehyde.

$105 \times 15 \mathrm{~mm}(300 \times 300$ DPI $)$ 
Scheme 19. Oxidation of Primary and Secondary Alcohols Catalyzed by an Iron-Porphyrin-POP $103 \times 20 \mathrm{~mm}(300 \times 300 \mathrm{DPI})$ 


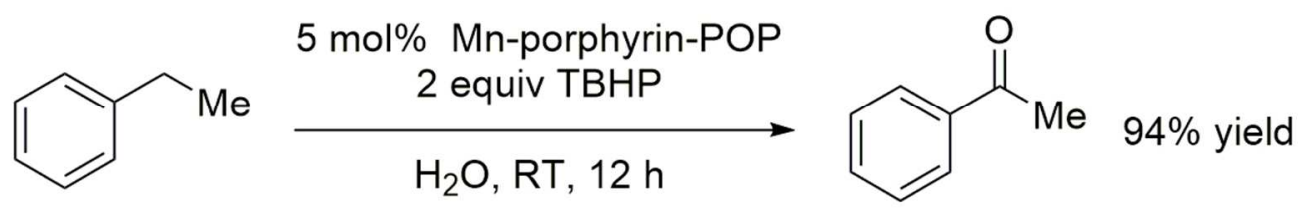

Scheme 20. Acetophenone Synthesis from Ethylbenzene Catalyzed by a Manganese-Porphyrin-POP $98 \times 15 \mathrm{~mm}(300 \times 300 \mathrm{DPI})$ 
Scheme 21. Oxidation/Condensation Sequence Catalyzed by a Ruthenium-IMes-POP (IMes $=1,3$-bis-(2,4,6trimethylphenyl)imidazol-2-ylidene). $118 \times 21 \mathrm{~mm}(300 \times 300$ DPI $)$ 
a)

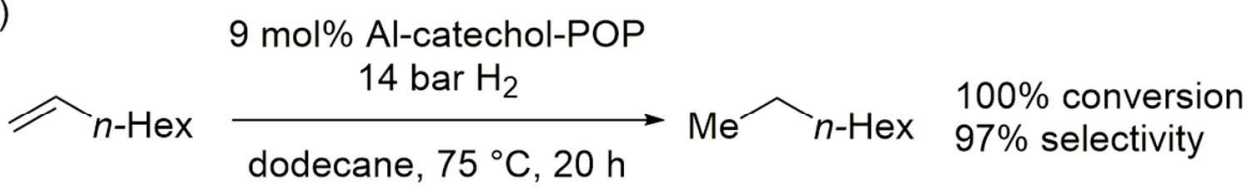

b)

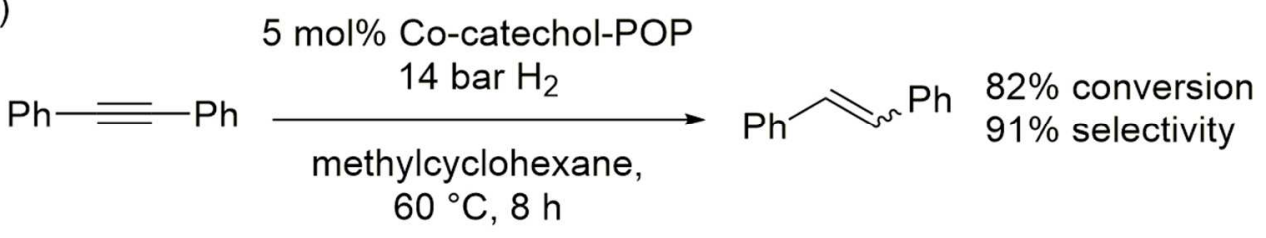

c)

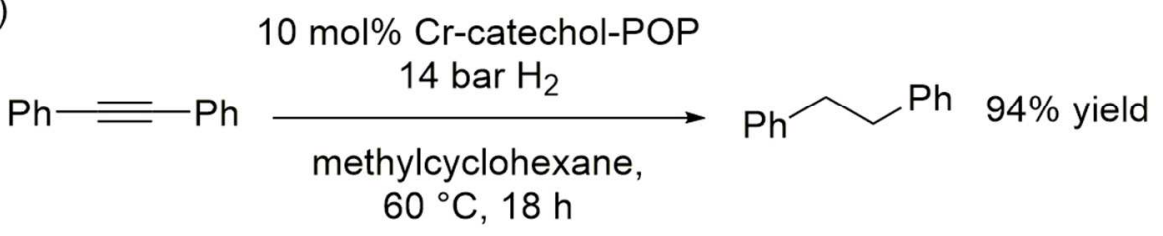

Scheme 22. Alkene and Alkyne Hydrogenation Catalyzed by Metal-Catechol-POPs. (a) Aluminum Catalyst, (b) Cobalt Catalyst, and (c) Chromium Catalyst.

$102 \times 62 \mathrm{~mm}(300 \times 300 \mathrm{DPI})$ 


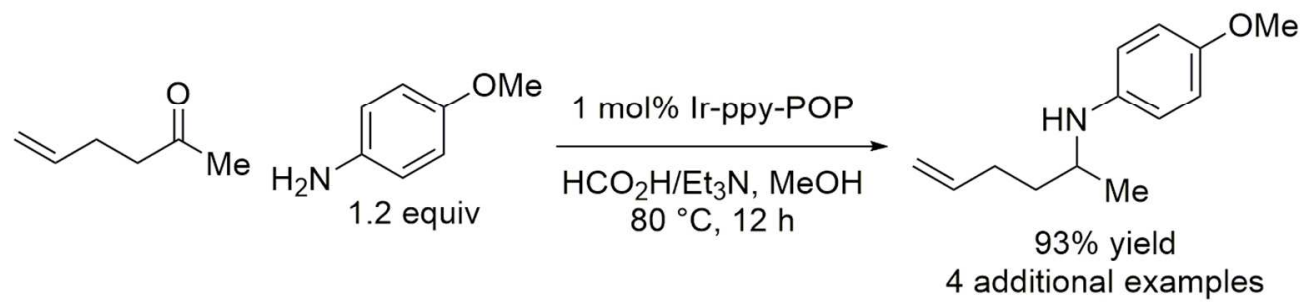

Scheme 23. Reductive Amination Catalyzed by an Iridium-ppy-POP $118 \times 28 \mathrm{~mm}(300 \times 300$ DPI $)$ 


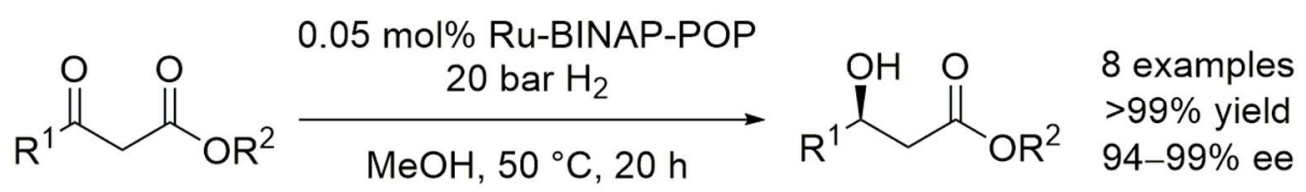

Scheme 24. Asymmetric Hydrogenation of $\beta$-Keto Esters.

$102 \times 15 \mathrm{~mm}(300 \times 300 \mathrm{DPI})$ 
<smiles>CC1CCc2ccccc2N1</smiles>
99\% conversion $70 \%$ ee

Scheme 25. Asymmetric Hydrogenation of 2-Methyl Quinoline.

$98 \times 22 \mathrm{~mm}(300 \times 300$ DPI $)$ 


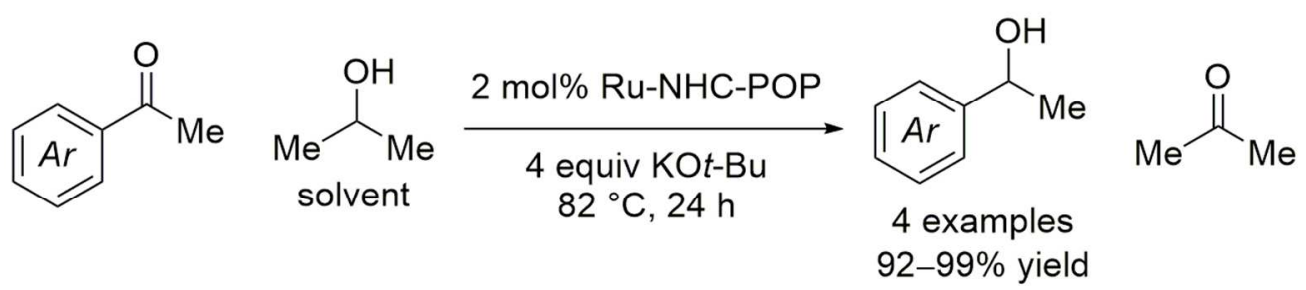

Scheme 26. Transfer Hydrogenation for Reduction of Acetophenones.

$109 \times 24 \mathrm{~mm}(300 \times 300$ DPI $)$ 


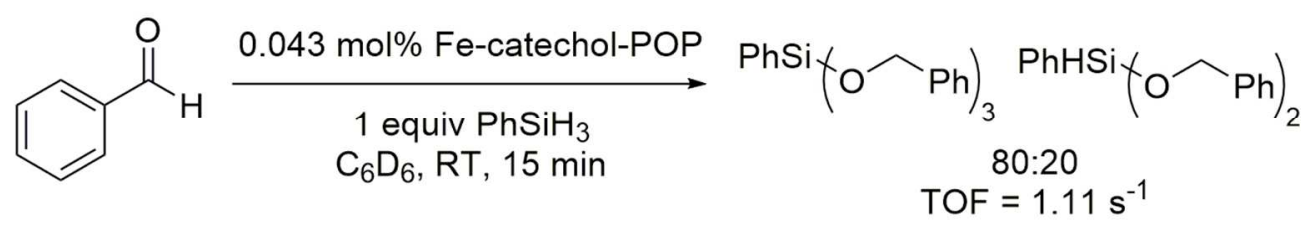

Scheme 27. Hydrosilylation of Carbonyl Groups Catalyzed by an Fe-Catechol-POP.

$111 \times 19 \mathrm{~mm}(300 \times 300$ DPI $)$ 


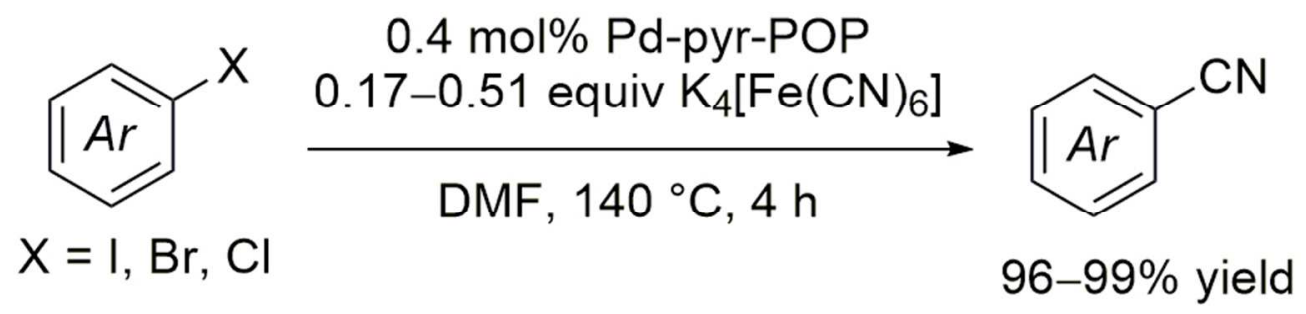

Scheme 28. Cyanation of Aryl Halides using a Palladium-Containing Porous Organic Polymer.

$79 \times 19 \mathrm{~mm}(300 \times 300 \mathrm{DPI})$ 


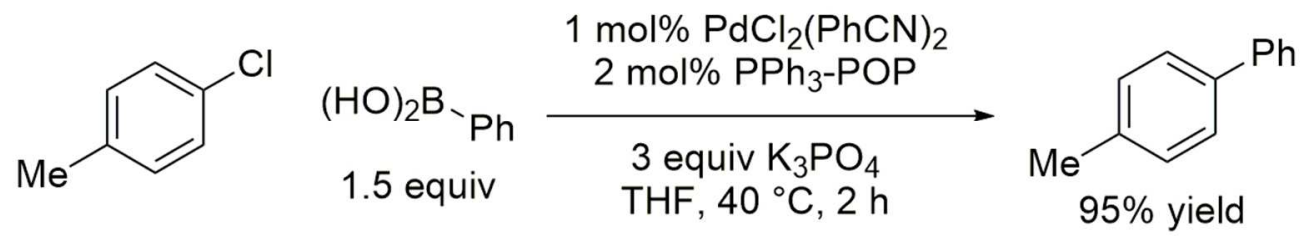

Scheme 29. Suzuki-Miyaura Coupling Catalyzed by a Palladium-POP Complex.

$101 \times 18 \mathrm{~mm}(300 \times 300$ DPI $)$ 
Scheme 30. Mizoroki-Heck Reaction Catalyzed by a Palladium Porous Organic Polymer.

$97 \times 24 \mathrm{~mm}(300 \times 300$ DPI $)$ 


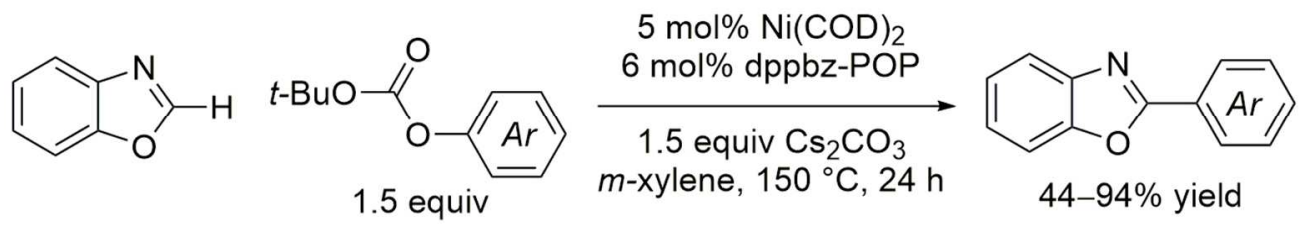

Scheme 31. Nickel-Catalyzed Coupling of Aryl Pivalates and Benzoxazole.

$114 \times 20 \mathrm{~mm}(300 \times 300$ DPI $)$ 
a) Substrate Scope

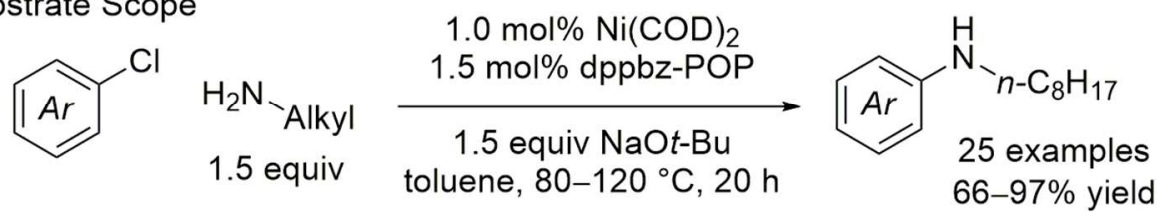

b) Low Catalyst Loading

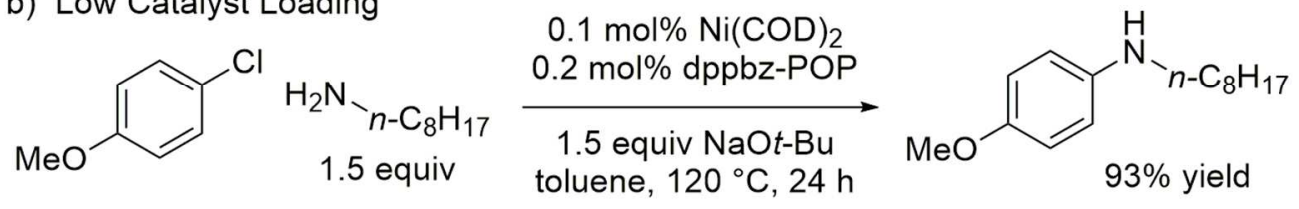

Scheme 32. Nickel-Catalyzed Amination of Aryl Chlorides (a) displays Broad Substrate Scope, and (b) can be
performed with Low Catalyst Loading. $114 \times 44 \mathrm{~mm}(300 \times 300$ DPI $)$ 


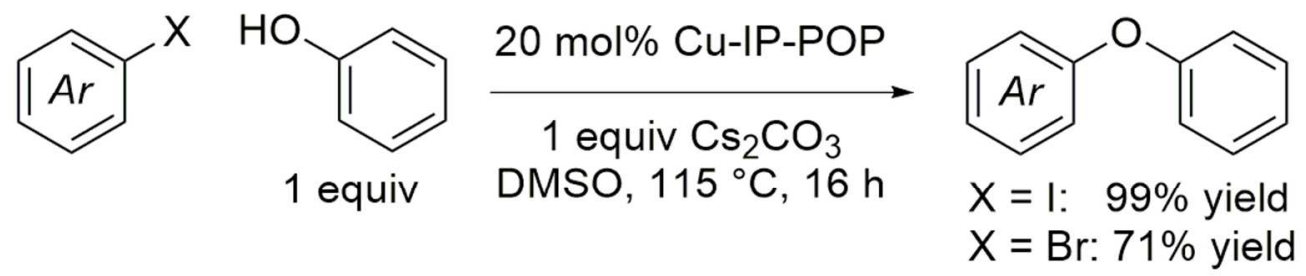

Scheme 33. Cu-IP-POP-Catalyzed Ullmann Coupling for the Formation of Biaryl Ethers (IP = iminopyridine)

$91 \times 20 \mathrm{~mm}(300 \times 300$ DPI $)$ 


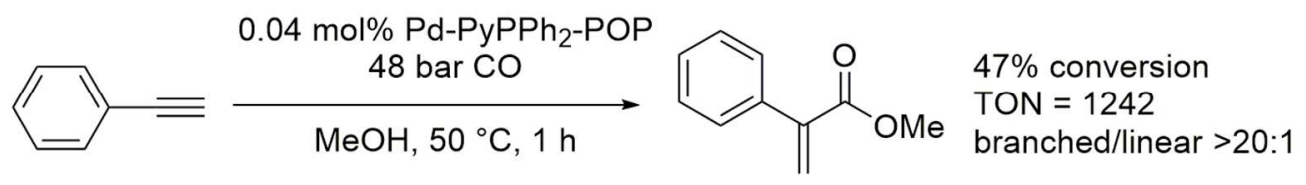

Scheme 34. Alkoxycarbonylation of Terminal Alkynes using a Palladium-PyPPh $2-P O P$ Catalyst $117 \times 16 \mathrm{~mm}(300 \times 300 \mathrm{DPI})$ 


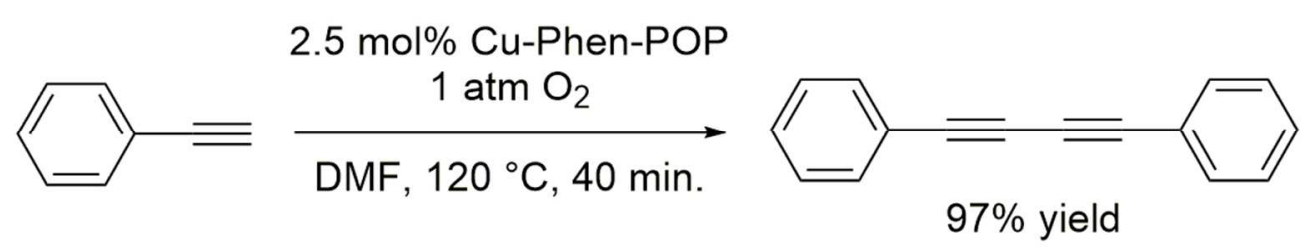

Scheme 35. Glaser Coupling using a Copper-Phen-POP Catalyst.

$96 \times 17 \mathrm{~mm}(300 \times 300$ DPI $)$ 


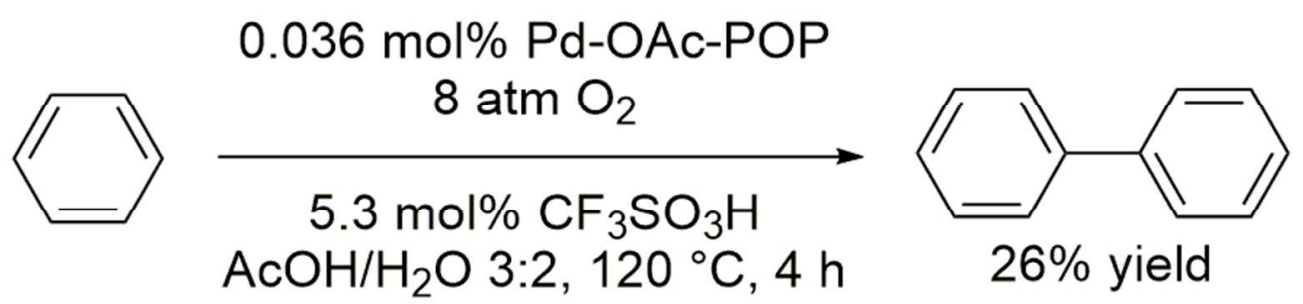

Scheme 36. Oxidative Homocoupling of Benzene using a Pd-OAc-POP.

$75 \times 18 \mathrm{~mm}(300 \times 300$ DPI $)$ 


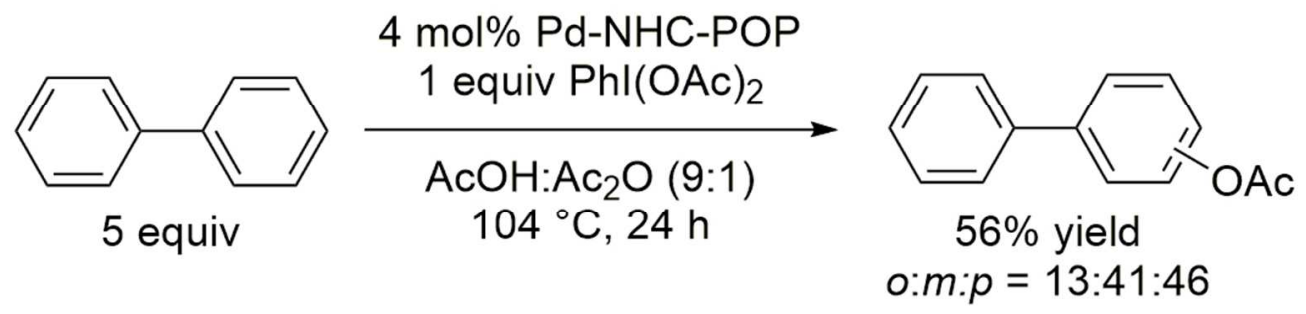

Scheme 37. Aryl C-H Acetoxylation Catalyzed by a Palladium-NHC-POP.

$90 \times 22 \mathrm{~mm}(300 \times 300 \mathrm{DPI})$ 
Scheme 38. Oxidative C(sp3)-H Arylation Catalyzed by a Palladium-Pyr-POP (TFA = trifluoroacetic acid). $103 \times 30 \mathrm{~mm}(300 \times 300 \mathrm{DPI})$ 


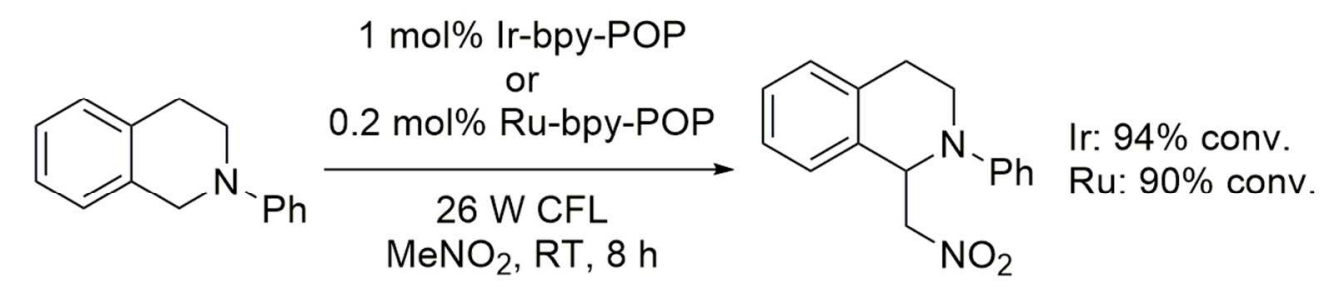

Scheme 39. Photocatalytic Aza-Henry Reaction using Ruthenium- and Iridium-bpy-POPs.

$102 \times 22 \mathrm{~mm}(300 \times 300 \mathrm{DPI})$ 


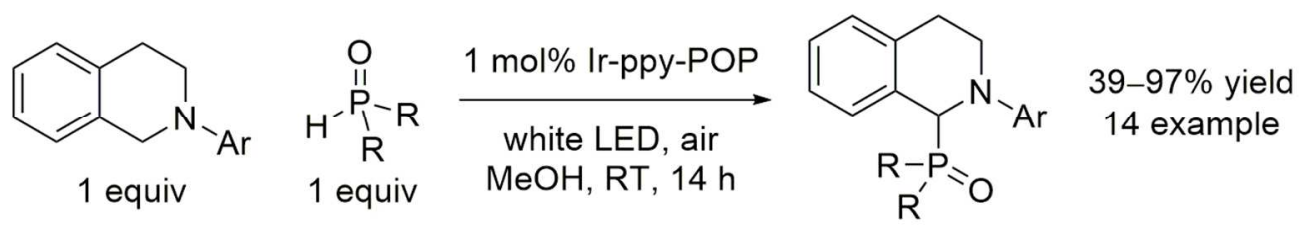

Scheme 40. Photocatalytic Coupling of Tetrahydroisoquinolines and P-H Nucleophiles.

$113 \times 19 \mathrm{~mm}(300 \times 300 \mathrm{DPI})$ 
a)

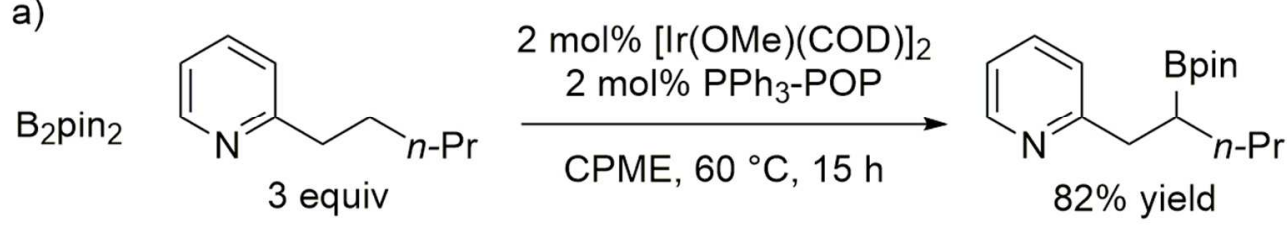

b)<smiles>CN1CCCN(C)C1=O</smiles>

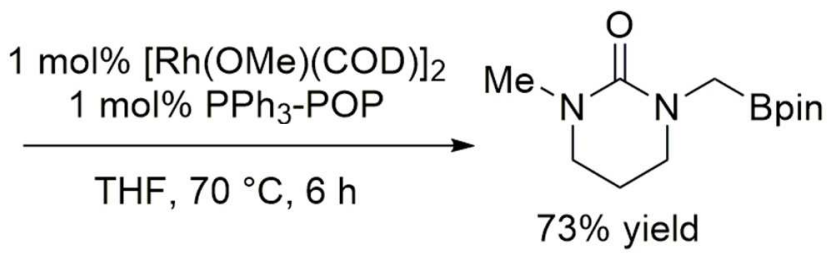

Scheme 41. Borylation of $\mathrm{C}\left(\mathrm{sp}^{3}\right)-\mathrm{H}$ Catalyzed by (a) $\mathrm{Ir}-\mathrm{PPh}_{3}-\mathrm{POP}$ and (b) $\mathrm{Rh}-\mathrm{PPh}_{3}-\mathrm{POP}$. $103 \times 43 \mathrm{~mm}(300 \times 300 \mathrm{DPI})$ 

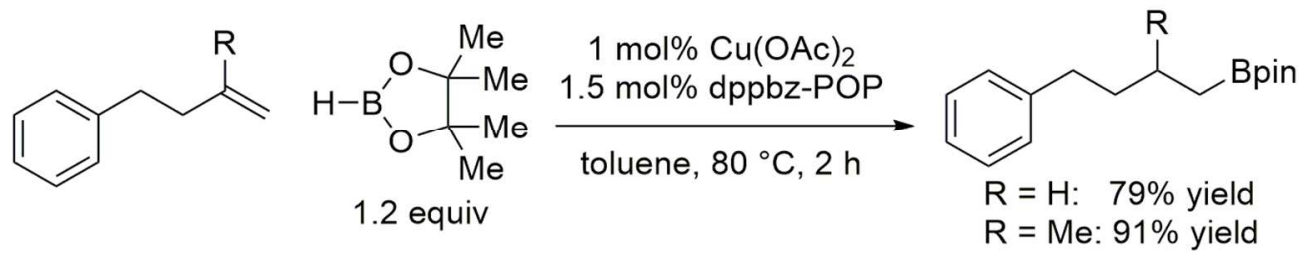

Scheme 42. Hydroboration of Aliphatic Alkenes using a Copper-dppbz-POP Catalyst. $115 \times 23 \mathrm{~mm}(300 \times 300 \mathrm{DPI})$ 


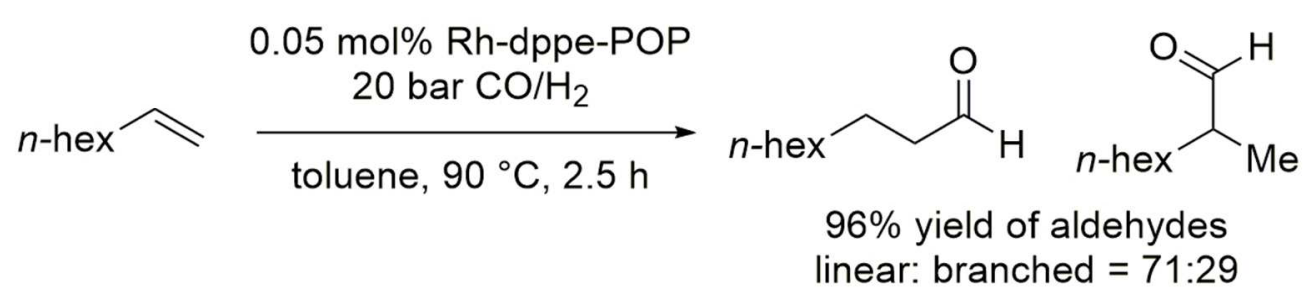

Scheme 43. Hydroformylation of 1-Octene with a Rh-dppe-POP Catalyst.

$99 \times 22 \mathrm{~mm}(300 \times 300$ DPI $)$ 


\section{$\Longrightarrow \stackrel{\mathrm{Ni-bpy-POP}}{\longrightarrow \mathrm{Me}} \mathrm{Me}^{\curvearrowright} \mathrm{Me}$ 5 bar heptane, $0{ }^{\circ} \mathrm{C}, 1 \mathrm{~h} \quad$ TON $=299 \mathrm{~h}^{-1}$ for $\mathrm{C}_{4}$-products $74 \%$ selectivity for $\mathrm{C}_{4}$-products}

Scheme 44. Ethylene Dimerization Catalyzed by a Ni-bpy-POP.

$80 \times 16 \mathrm{~mm}(300 \times 300$ DPI $)$ 


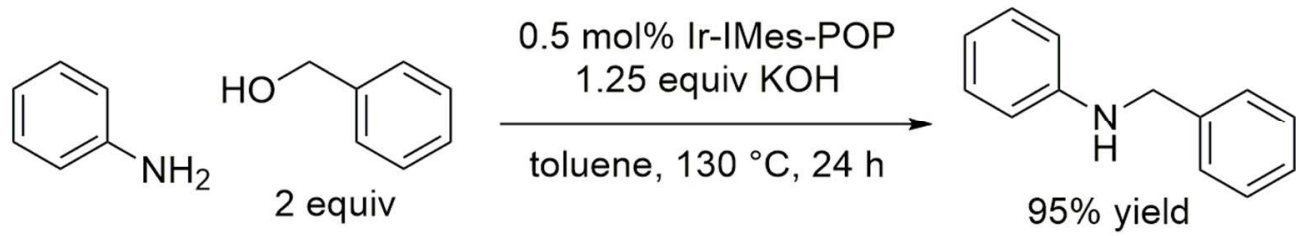

Scheme 45. Hydrogen-Borrowing Reaction Catalyzed by an Iridium-IMes-POP.

$103 \times 19 \mathrm{~mm}(300 \times 300 \mathrm{DPI})$ 


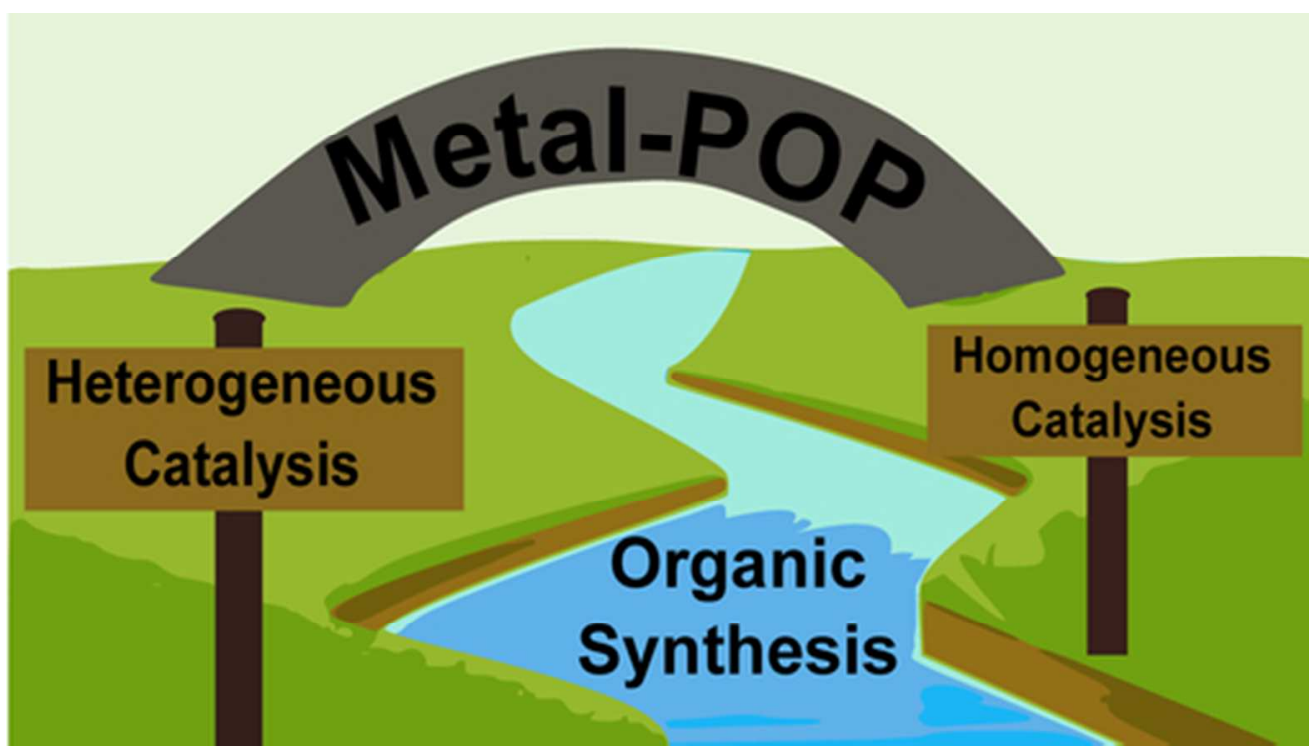

$21 \times 12 \mathrm{~mm}(600 \times 600 \mathrm{DPI})$ 